UNIVERSIDADE DE SÃO PAULO

INSTITUTO DE GEOCIÊNCIAS

\title{
RECONSTITUIÇÃO PALEOCLIMÁTICA DOS ÚLTIMOS 5500 ANOS NOS ANDES ORIENTAIS DA COLÔMBIA
}

\author{
Verónica Marcela Ramirez Ruiz \\ Orientador: Prof. Dr. Francisco William da Cruz Júnior \\ DISSERTAÇÃO DE MESTRADO \\ Programa de Pós-Graduação em Geoquímica e Geotectônica
}

São Paulo

2014 


\title{
UNIVERSIDADE DE SÃO PAULO \\ INSTITUTO DE GEOCIÊNCIAS
}

\section{RECONSTITUIÇÃO PALEOCLIMÁTICA DOS ÚLTIMOS 5500 ANOS NOS ANDES ORIENTAIS DA COLÔMBIA}

\author{
Verónica Marcela Ramirez Ruiz
}

Dissertação de mestrado apresentada junto ao Instituto de Geociências da Universidade de São Paulo na Área de Geoquímica dos Processos Exógenos para a obtenção do título de Mestre em Geociências

São Paulo

2014 
Autorizo a reprodução e divulgação total ou parcial deste trabalho, por qualquer meio convencional ou eletrônico, para fins de estudo e pesquisa, desde que citada a fonte

Ficha catalográfica preparada pelo Serviço de Biblioteca e Documentação do Instituto de Geociências da Universidade de São Paulo.

Ramirez Ruiz, Verónica Marcela

Reconstituição Paleoclimática dos últimos 5500 anos nos Andes

Orientais Da Colômbia / Verónica Marcela Ramirez Ruiz. - São Paulo, 2014.

101 p.: Il + 1 anexo

Dissertação (Mestrado): IGc/USP

Orient.: Cruz Júnior, Francisco William da

1. Colômbia: Paleoclimamatologia 2. Colômbia: Espeleotemas 3. Colômbia:

Holoceno 4. Colômbia: Sedimentologia 5. Geoquímica I. Título 
“Los días del futuro están delante de nosotros como una hilera de velas encendidas -velas doradas, cálidas, y vivas. Quedan atrás los días ya pasados, una triste línea de velas apagadas; las más cercanas aún despiden humo, velas frías, derretidas, y dobladas. No quiero verlas; sus formas me apenan, y me apena recordar su luz primera. Miro adelante mis velas encendidas. No quiero volverme, para no verlas y temblar, cuán rápido la línea oscura crece, cuán rápido aumentan las velas apagadas. " Constantino Cavafis. 


\section{AGRADECIMENTOS}

O desenvolvimento da presente dissertação conto com o apoio na realização das análises Laboratório de Isótopos Estáveis do Instituto de Geociências da Universidade de São Paulo (LIE- IgcUSP), Laboratório de Geocronologia do Instituto de Geociências da Universidade de Brasília (UnB) e o Laboratorio de Geocronologia da Universidade de Minneapolis nos Estados Unidos de América. Igualmente o apoio institucional do Instituto de Geociências da Universidade de São Paulo, a Asociacion Colombiana de Geologos y Geofisicos del Petroleo e a Corporación Geológica ARES, por meio das bolsas para pesquisa ARESCorrigan.

Agradeço a colaboração recebida pelos orientadores Chico Bill e Juan Carlos Silva, pela ajuda no encaminhamento das análises dos dados e a discussão; igualmente aos colegas e amigos do Laboratório de Sistemas Carsticos, Eline, Nicolas (Panico), Valdir, Jean Sebastian, Christian e Maria Gracias, por enriquecer as discussões, ajudar em momentos de dúvida e dar a calma em momentos de exaltação; além um forte agradecimento para Guillaume Bertrand pela ajuda e disposição para as discussões referentes aos isótopos.

Os amigos conhecidos e as amizades fortalecidas, especialmente a Yohana Villafañez, que deram força e boas energias para continuar.

E por último, mas sendo eles as pessoas mais importantes na minha vida, agradeço a minha família, meu pai pelo força e amor ao estudo que me ensinou, meus irmãos e irmã pela companhia e bons momentos cheios de alegria; minhas tias, tios e avós pela atenção, força, pela boa energia com que sempre estão a meu lado. Com todo o amor que tenho agradeço Sergio pelo amor, a companhia, a ajuda, por ser o melhor amigo, por estar a meu lado apesar da distância.

Com a saudade que se pode ter pelas pessoas que se amam mas agora não estão mais conosco, dedico todo meu esforço e minhas alegrias a minha Mae, pelo amor que foi o que me fez crescer e ser a mulher que hoje sou. 


\section{RESUMO}

RAMIREZ, V. M. Reconstituição Paleoclimática Dos Últimos 5500 Anos Nos Andes Orientais Da Colômbia. 2014. 100.f. Dissertação (mestrado) - Instituto de Geociências, Universidade de São Paulo, São Paulo

Registros geocronológicos e isotópicos de $\delta^{18} \mathrm{O}$ e $\delta^{13} \mathrm{C}$ obtidos em alta resolução em estalagmites da caverna Caracos, município colombiano El Peñon, permitiram reconstituir a paleopluviosidade dos últimos 5500 anos nos Andes Orientais da Colômbia. Esses registros permitiram discutir as variações climáticas ocorridas em escala decadal durante o Holoceno Médio e Inferior e caracterizar a influência dos padrões atmosféricos e da temperatura da superfície do mar nos oceanos Atlântico e Pacífico. O estudo paleoclimático realizado na Colômbia foi apoiado na calibração prévia realizada na caverna Caracos que indicou uma correlação positiva entre a assinatura isotópica da água da chuva e do gotejamento das estalagmites CAR1, CAR2 e CAR3, como também, que a deposição isotópica destas ocorreu em equilíbrio. A partir dessa observação, foi interpretado que a variação dos valores de $\delta^{18} \mathrm{O}$ dos espeleotemas da caverna Caracos ocorreu em função do condicionante isotópico amount effect (efeito quantidade) e da fonte de umidade. O registro isotópico de El Peñon mostrou que a variação da chuva, entre 3500-2500 anos BP e durante o Anomalia Climática Medieval e a Pequena Idade do Gelo, nos Andes Orientais da Colômbia esteve relacionada com as Oscilações do Attântico e Pacífico, como também ao posicionamento meridional da Zona de Convergência Intertropical. Tais mudanças na paleoprecipitação, além de serem observadas na Colômbia, também estão registradas em outros locais como em Cariaco, na Venezuela, em Pumacocha e no México. Além disso, observou-se através de análises estatísticas das séries temporais dos registrosisotópicos de El Peñon, que as mudanças da paleopluviosidade observadas na Colômbia nos últimos 1500 ocorreram com uma peridiodicidade de $\sim 65,30$ e 5 anos, relacionadas respectivamente com a Oscilação Multidecenal do Attântico (OMA), com a Oscilação Decadal do Pacífico (ODP) e com os eventos El Niño Southern Oscilation.

Os ciclos que mostram as análises estatísticas tem variações ao longo do registro, mostrando enfraquecimento/ fortalecimento em períodos como a ACM, LIA e CWP.

Essa relação está de acordo com o fator "amount effect", que atua na variação das razões isotópicas do oxigênio da chuva na região tal como foi identificado em estudos da série histórica de monitoramento das estações IAEA-GNIP, mostrando que nas áreas tropicais é o principal componente no fracionamento isotópico de oxigênio.

Palavras-chave: Colômbia,Paleoclimatologia,Paleopluviosidade, Espeleotemas, Holoceno, ZCIT, Isótopos, Quaternário 


\begin{abstract}
RAMIREZ, V. M. Paleoclimate Reconstruction for the Last 5500 years from Eastern Andes in Colombia. 2014. 100.f. Dissertação (mestrado) - Instituto de Geociências, Universidade de São Paulo, São Paulo
\end{abstract}

From records of $\delta 180$ and $13 \mathrm{C}$ and growth rates of speleothems precisely dated by U-Th method was possible to reconstruct the paleo rainfall the last 5500 years in the region of the Eastern Andes in Colombia. Records high-resolution ( 1 year for the past 1500 years) propitiated characterize the influence of weather patterns and sea surface temperature (SST) currently observed in the Atlantic and Pacific oceans in the region paleo rainfall.

Through the rainfall data collected in the study area for a year, a comparison of rainfall data of Bogota and the $\mathrm{d} 18 \mathrm{O}$ record of stalagmites CAR1, CAR2 and CAR3, was possible to relate the variations of $\delta 180$ of speleothems with variation in rainfall; this showed that more negative isotopic values in the registry are representative of greater precipitation and vice versa, in addition to a component of variation due to moisture source. This relationship is consistent with the factor "amount effect", which acts on the variation of the oxygen isotope ratios of rain in the region as was identified in studies of the historical series of monitoring stations IAEA-GNIP, showing that in tropical areas is major component in the oxygen isotopic fractionation.

The isotope record of El Penon showed a relationship with the variations in the Atlantic and Pacific oscillations, as observed in other records of South America. Were also recorded changes in the location of the ITCZ that influences rainfall in the area, as are the periods between 3500-2500 years BP, ACM and LIA, changes are also recorded in other places like Cariacos, Pumacocha and Mexico.

Through statistical analyzes in the time series obtained from the paleoclimate record of stalagmites of the last 1500 years, periodicity of $\sim 65$ years was correlated with the detected Multidecenal Atlantic Oscillation (OMA) in the entire record of El Penon, and periodicities between $\sim 30$ years associated with the Pacific Decadal Oscillation (PDO) and between $\sim 5$ with respect to ENSO events. The cycles show statistical analyzes have variations throughout the record, showing weakening / strengthening in periods such as ACM, LIA and CWP.

Key words: Colombia,Paleoclimate, Paleorainfall, Speleothems, Holoceno, ITCZ, Isotopes, Quaternary 


\section{LISTA DE ABREVIATURAS}

$\delta 180$ - Razão dos isótopos de Oxigênio

$\delta 13 C$ - Razão dos isótopos de Carbono

ACM - Anomalia Climática Medieval

AD - Anos Domini

AMO - Atlantic Multidecal Oscillation

AMOC - Atlantic Meridional Overturning Circulation

AN - América no Norte

ANA - Agência Nacional de Águas

A.P. - Antes do Presente

ASAN - Anticiclones Subtropicais do Atlântico Norte

ASAS - Anticiclones Subtropicais do Atlântico Sul

CAR - Estalagmites caverna Caracos

CTD - Carbono total dissolvido

CRMA - Circulação de Revolvimento Meridional Atlântica

DJF - Dezembro, Janeiro e Fevereiro

EN - El Niño

ENOS - El Niño Oscilação Sul

ENSO - El Niño Southern Oscillation

GCM's - general circulation models

GMWL- Global Meteoric Water Line

HS - Hemisfério Sul

HN - Hemisfério Norte

IAEA-GNIP - International Agency Energy Agency - Global Network of Isotopes in

Precipitation

ICP-MS - Inductively coupled plasma mass spectrometry

IGc/USP - Instituto de Geociências da USP

JJA - Junho, Julho e Agosto 
LMWL - Local Meteoric Water Line

LIE-CPGEO - Laboratório de Isótopos Estáveis, Centro de Pesquisas Geocronológicas

LIs - Linhas de Instabilidade

LN - El Niño

MAM - Março, Abril e Maio

MAS - Monção Sul Americana

NO-SE - Noroeste para Sudeste

OAN - Oscilação do Atlântico Norte

ODP - Oscilação Decadal do Pacífico

OMA - Oscilação Multidecadal do Atlântico

PDO - Pacific Decadal Oscillation

PNM - Pressão no nivel do mar

PIG - Pequena Idade do Gelo

$\mathrm{r}^{2}$ - Coeficiente de correlação

SON - Setembro, outubro e novembro

SALLJ - South American Low Level Jet

SMSA - Sistema de Monção Sul Americana

[Ti] - Concentração de Titânio

THC - Thermohaline Circulation

TSM - Temperatura da Superfície Marinha

U/Th - Urânio-Tório

ZCA - Zona de Confluência dos Alísios

ZCAS - Zona de Convergência do Atlântico Sul

ZCIT - Zona de Convergência Intertropical 


\section{TABLA DE CONTENIDO}

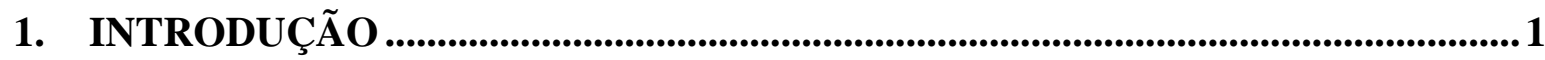

1.1 Objetivos da Pesquisa..................................................................................................................... 4

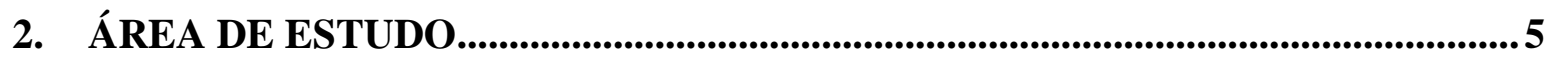

2.1 Localização e Caracterização Geológica .................................................................................... 5

2.2 Climatologia Atual........................................................................................................... 9

3. ISÓTOPOS ESTÁVEIS E A INFORMAÇÃO PALEOAMBIENTAL .....................20

3.1 Formação de Cavernas..................................................................................................................... 20

3.2 Isótopos de Oxigênio no ciclo Hidrológico........................................................................... 23

3.3 Linha Meteórica de Água (MWL)..............................................................................................26

3.4 Fatores que Afetam a Composição Isotópica da Água de Gotejamento..............................27

3.5 Fracionamento de $\square^{18} \mathrm{O}$ no Solo................................................................................................... 28

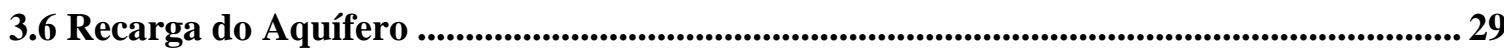

4. MATERIAIS Y MÉTODOS...........................................................................................31

4.1 Coleta de Estalagmites .......................................................................................................... 31

4.2 Preparação de amostras para análise paleoclimáticas e amostras de datação radiométrica ................................................................................................................................ 31

4.3 Datação Geocronológica pelo método U/Th ..................................................................... 32

4.4 Analises da Água Chuva ......................................................................................................... 37

4.5 Método de tratamento de séries temporais...................................................................................... 38

4.6 Transformada de Fourier ................................................................................................................ 39

4.7 REDFIT ………….................................................................................................................. 40

4.8 Analises de Coerência ............................................................................................................................. 40

4.9 Análise de Ondoletas ..................................................................................................................... 41

5. RESULTADOS …........................................................................................................................43

5.1 Resultados Geocronológicos e Taxas de Crescimento ............................................................. 43

5.2 Monitoramento de Chuva na Área .................................................................................................. 49

5.3 Linha Meteórica Local ....................................................................................................................54

5.4 Registro Isotópico de $\delta 180$ y $\delta 13 \mathrm{C}$...........................................................................................56

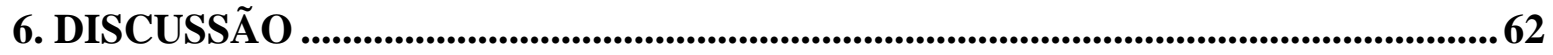

6.1 Alteração no deslocamento da ZCIT durante o Holoceno Superior.................................... 62

8. BIBLIOGRAFIA .....................................................................................................................8 


\section{FIGURAS}

Figura 2.1 Localizações da área de estudo no norte de Sul américa, na Cordilheira Oriental na Colômbia. A área de estudo encontra-se localizada na zona de influência das correntes de ar que proveem do Oceano Atlântico, Pacifico e o Mar Caribe.

Figura2.2. Paisagem cárstica na área de estudo, observação de dolinas no setor próximo a caverna Caracos; área de percurso até a entrada da caverna no município de El Peñon.

Figura 2.3 Dolinas na área de superficial do recorrido para a Caverna Caracos; também se observam taludes abruptos nas rochas carbonáticas. 7

Figura 2.4. Geologia da área de estudo com a localização das cavernas visitadas no setor sudoeste do departamento de Santander. Na área observam-se estruturas com direção preferencial NE-SW, tais como falhas e dobramentos. Mapa adaptado de Gómez et al., (2008). . .8

Figuras 2.5 e 2.6 Dispersões dos dados de $\delta^{18} \mathrm{O}$ com a quantidade de chuva em Bogotá, mostrando uma relação entre a quantidade de chuva e a variação isotópica das águas; no entanto alguns meses apresentam uma maior dispersão relacionada com o câmbio na fonte de umidade. A variação entre a quantidade de chuva e $\delta^{18} \mathrm{O}$ mostra igualmente uma relação entre a quantidade de chuva e o fracionamento isotópico do Oxigênio, sendo uma relação mais forte durante a primeira temporada de chuva do ano e mais fraca na segunda. .18

Figura 2.7 Mapas de fontes de umidade que tem influenciam na área da Colômbia na atualidade (Poveda et al, 2014). Proveniência das fontes de umidade e rios aéreos.

Figura 3.1 Regimes da dissolução e de precipitação do sistema cárstico. Modificado de Fairchild et al, 2006 .

Figura 3.2 Relações de características de crescimento para a localização das séries de tempo; as estalagmites normalmente são estudadas em chapas polidas perpendicular à direção do seu crescimento máxima, mas secções transversais de estalactites também têm sido utilizadas. Modificado de Fairchild et al, 2006.

Figura 3.3 Variações de $\delta^{18} \mathrm{O} \mathrm{D}$ pela fracção residual de vapor e a temperatura $\left({ }^{\circ} \mathrm{C}\right)$, no processo conhecido como Destilação Rayleigh; neste processo observa-se maior fracionamento do oxigênio pelo esfriamento progressivo e a chuva, além de ter relação com o descenso na temperatura.

Figura 3.4 Linha Meteórica de Água Global que relaciona os dados de $\delta \mathrm{O}^{18} \mathrm{e} \delta \mathrm{D}$, feita com dados da Base de dados global da GNIP; contígua a Linha Meteórica de Água Global se tem a curva de variação dos valores de $\delta \mathrm{O}^{18}$ e $\delta \mathrm{D}$ nos processos de evaporação. .27

Figura 5.1 Intervalos de deposição das estalagmites coletadas na região de El Peñon (Santander, Colômbia) que apresentaram idades holocênicas, com o nome dos espeleotemas no eixo vertical. Os pontos destacados são referentes a posição das idades U-Th.

Figura 5.2. Taxas de crescimento das estalagmitesCAR1, CAR2 e CAR3: a) Taxas de crescimento de CAR1 com variações entre $0,2 \mathrm{~mm} /$ ano até $0,42 \mathrm{~mm} / \mathrm{ano}$, apresenta um hiato entre 761 e 251 anos BP.; b) A estalagmite CAR 2 tem uma deposição continua entre 602 até 246 anos BP, a taxa de crescimento aproximada é de $0,2 \mathrm{~mm} /$ ano.; c). A deposição da estalagmite CAR3 é continua entre 5244 até 1227 anos $0,034 \mathrm{~mm} /$ ano no 
setor mais antigo, seguido por taxas de $0,103 \mathrm{e} 0,052 \mathrm{~mm} / \mathrm{ano}$, e 0,07 ; d) variação da taxa de crescimento ao longo dos últimos 5 mil anos para o conjunto de estalagmites estudadas.

Figura 5.3 - Comparação entra as taxas de crescimento em (mm/ano) com o sinal isotópico de $\delta^{18} \mathrm{O}$ das estalagmites CAR1 (a), CAR2 (b) e CAR3 (c). Note a inversão da escala da taxa de crescimento........

Figura 5.4 - Comparação entra as taxas de crescimento em (mm/ano) com o sinal isotópico de $\delta^{13} \mathrm{C}$ das estalagmites CAR1 (a), CAR2 (b) e CAR3 (c). Note a inversão da escala da taxa de crescimento... . .48

Figura 5.5 - Comparação entre os resultados isotópicos de $\delta^{18} \mathrm{O}$ e $\delta^{13} \mathrm{C}$ das estalagmites CAR1 (a), CAR2 (b) e CAR3 (c).

Figura 5.6 Variações da quantidade de chuva mensal em Bogotá (Colômbia) comparada com as mudanças no registro de $\delta^{18} \mathrm{O}$ na água de chuva no mesmo período. Observa-se uma relação entre a quantidade de chuva e o fracionamento isotópico do Oxigênio, no entanto no segundo período de chuvas na área (Setembro até Novembro) a relação da quantidade de chuva e fracionamento isotópico do Oxigênio varia sendo mais fraca possivelmente pela influência na mudança de fonte de umidade .51

Figura 5.7 Covariância do acumulado de quantidade de chuva mensal e o fracionamento isotópico de Oxigênio para cada mês, mostrando relacionamento entre ambas variáveis; porém alguns meses apresentam um desvio da reta pela relação com a mudança de fonte.

Figura 5.8 Variaçãoes da quantidade de chuva mensal em El Peñon (Colômbia) comparada com as mudanças no registro de $\delta^{18} \mathrm{O}$ na água de chuva no mesmo período. Observa-se uma relação entre a quantidade de chuva e o fracionamento isotópico do Oxigênio, no entanto no segundo período de chuvas na área (Setembro até Novembro) a relação da quantidade de chuva e fracionamento isotópico do Oxigênio varia sendo mais fraca possivelmente pela influência na mudança de fonte de umidade, justamente no período de influência das fontes provenientes do Pacifico pelo Chorro de Choco... . .53

Figura 5.9 Covariância do acumulado de quantidade de chuva mensal e o fracionamento isotópico de Oxigênio para cada mês em El Peñon (Colômbia), tendo um relacionamento entre ambas variáveis; porém alguns meses apresentam um desvio da reta pela relação com a mudança de fonte. . .53

Figura 5.10 Relações na variação do $\delta 18 \mathrm{O}$ e a temperatura em El Peñon (Colômbia), mostrando uma falta de influência no fracionamento isotópico e os câmbios na temperatura; a localização da área de estudo no tropico faz que a variação sazonal da temperatura seja menor de $3^{\circ} \mathrm{C}$. . .54

Figura 5.11 Linhas de Água Meteórica Local dos dados analisados de El Peñon (Colômbia), com a LWML pode-se identificar condições de fracionamento a que foi submetida às águas da chuva além de associar com processos na fonte de umidade pelo excesso de deutério .56

Figura 5.12 Correlações dos valores de $\delta^{18} \mathrm{O}$ e $\delta^{13} \mathrm{C}$ nas estalagmites CAR1(azul), CAR2 (amarelo) e CAR3 (vermelho), mostra relação entre as variações às amostras em cada uma das estalagmites, mas tem diferenças entre os valores gerais de CAR1, CAR2 e CAR3. .58

Figura 5.13 Curvas isotópicas de variações de $\delta^{13} \mathrm{C}$ e $\delta^{18} \mathrm{O}$ nas estalagmites CAR1, CAR2 e CAR3 entre 5500 anos B.P até o presente. .59

Figura 6.1 Registro das variações de $\delta^{18} \mathrm{O}$ na área de El Peñon (Santander, Colômbia) durante os últimos 5300 anos. Os valores mais baixos de $\delta^{18} \mathrm{O}$ estão associados ao aumento de chuvas, principalmente durante o 
verão boreal. O traço pontilhado representa o valor médio de todo registro, em torno de $-9,0 \%$, a partir do qual se identifica períodos mais secos e úmidos.

.64

Figura 6.2 Curvas comparativas dos registros de Cariaco na Venezuela (Haug et al, 2001), El Peñon na Colômbia e variações icebergs no Hemisfério Norte a partir do índice \%HGS (Bond et al, 2001). Observamse variações no Holoceno Médio (5500 anos BP) marcada por sincronias nas variações entre 3500-2500 anos BP e durante a Pequena Idade do Gelo, períodos caracterizados por aumento de HSG, ou seja, esfriamento do Atlântico Norte.

Figura 6.3 Comparação do registro de $\delta 180$ de El Peñon dos últimos 800 anos, variações de TSM do Oceano Atlântico (Black et al, 2007) e os registros de Ti \% da Bacia de Cariaco.

Figura 6.4 Comparação do registro isotópico de El Peñon (Colômbia) com as variações dos modos climáticos multidecadais do Atlântico (AMO) e decadais do Pacífico PDO (Mann et al, 2009), durante os últimos 1500 anos. .72

Figura 6.5 Comparação do registro isotópico de El Peñon (Colômbia) com as variações dos modos climáticos multidecadais do Atlântico (AMO e decadais do Pacífico PDO (Mann et al, 2009) durante o LIA. Atentar para o deslocamento temporal da curva de AMO em 25 anos. 73

Figura 6.6 Gráficos da análise de ondoletas realizado no registro de $\delta^{18} \mathrm{O}$ de El Peñon, Colômbia, do software PAST (Hammer et al., 2001). No eixo x, está a idade em anos abrangendo todo o intervalo temporal do registro, no eixo y estão os valores das periodicidades em escala logarítmica e a o índice de cor é indicativo da intensidade dos eventos periódicos, as cores mais quentes (vermelho) determinam os eventos de maior intensidade e as cores mais frias (azul) os de menores. .74

Figura 6.7 Comparações entre os registros de El Peñon (Colombia), Peninsula de Yucatan (Medina-Elizalde et al, 2010), El Gancho (Stansell et al, 2012), Cariaco (Haug et al, 2001), Pumacocha (Bird et al, 2011) e El Junco (Conroy et al, 2008), para os últimos 1500 anos apresentando as variações acontecidas principalmente durante a ACM e LIA..................................................................

Figura 6.8. Comparación entre los registros de El Peñon (Colombia), Cariaco (Haug et al, 2001), El Junco (Conroy et al, 2008), Pumacocha (Bird et al, 2011) y las islas Palmyra (Cobb et al, 2003), para los últimos 390 años haciendo énfasis principalmente en la variaciones durante el CWP y los eventos ENSO registrados en el Pacifico. .79

\section{TABELAS}

Tabela 2.1. Medias de chuva nas municipalidades próximas na área de entrada do jato de choco na Colômbia durante 30 anos, as quais vão de 4950a $12541 \mathrm{~mm}$. O jato de Choco entra na Colômbia aos $5^{\circ} \mathrm{N}$, pelo sitio de Mistrato. Tabela de Poveda \& Mesa, 2000.

Tabela 2.2. Comparação das velocidades dos jatos que tem influência sobre Colômbia nos diferentes trimestres. Poveda et al, 2006. .12

Tabela 4.1 Valores dos padrões de comparação dos dados da água de chuva no processo da analises no espectrômetro tipo PICARRO no Laboratório de Geocronologia da Universidade de Brasília (UnB). Os padrões de comparação apresentam amplos registros de valores de $\square \mathrm{O}^{18} \mathrm{e} \square \mathrm{D}$, para um maior ajuste estatístico. 



\section{INTRODUÇÃO}

Espeleotemas são depósitos minerais secundários formados quase que, predominantemente, pela precipitação de carbonato de cálcio $\left(\mathrm{CaCO}_{3}\right)$ dentro de cavernas. Nesse processo, a água meteórica reage com o gás carbônico $\left(\mathrm{CO}_{2}\right)$ existente no solo quando infiltrada formando ácido carbônico $\left(\mathrm{H}_{2} \mathrm{CO}_{3}\right)$ que dissolve a rocha carbonática encaixante transportando uma solução saturada em carbonato. Tal solução, por sua vez, percola na zona vadosa do aquífero cárstico até encontrar a atmosfera da caverna que devido à diferença entre a pressão parcial do $\mathrm{CO}_{2}\left(\mathrm{P}_{\mathrm{CO} 2}\right)$ da água de gotejamento com a atmosfera da caverna induz a precipitação do $\mathrm{CaCO}_{3}$ por meio da desgaseificação da solução saturada. Desde sua infiltração no epicarste até o gotejamento no espeleotema tipo estalactite, o contínuo processo de hidratação do $\mathrm{CO}_{2}$ e formação do $\mathrm{HCO}_{3}{ }^{-}$imprime ao oxigênio do carbonato de cálcio a assinatura isotópica da água da chuva. Em regiões tropicais e subtropicais as interpretações baseadas em razões isotópicas de oxigênio $\left(\delta^{18} \mathrm{O}\right)$ em espeleotemas são fortemente direcionadas à variação na quantidade de precipitação, devido à forte relação entre a composição isotópica da chuva e pluviométrica (McDermott, 2004; Fairchild et al., 2006; Saylor et al, 2009).Igualmente variação no registro isotópico pode também expressar uma relação entre a precipitação e mudanças na fontes de umidade, o qual é importante para áreas onde há mudanças de fontes em ciclos anuais como na Colômbia que tem influência do Pacifico e Atlântico nas chuvas e umidade (Poveda et al, 2006; Saylor et al, 2009).

Os registros isotópicos obtidos em espeleotemas figuram dentre os arquivos paleoclimáticos mais promissores para compreender o clima do Pleistoceno Tardio e Holoceno por serem obtidos em alta resolução (e. g. Linge et al., 2001; Dykoski et al., 2005; Tan et al., 2006). Reconstituições de paleoprecipitação realizadas com base em nos

valores de $\delta^{18} \mathrm{O}$ em espeleotemas permitiram relacionar o regime hidrológico das zonas tropicais a eventos climáticos de escala global (Cruz et al., 2005; Wang et al., 2006; Cruz et al., 2006; Cruz et al., 2007; Wang et al., 2007; Cruz et al. 2009; Wang et al., 2008; Bird et al, 2011). 
Estudos anteriores mostram uma relação entre as variações na Temperatura Superficial do Mar (TSM) no Atlântico Norte, variações na Temperatura no Hemisfério Norte e as Forçantes Solares, durante os últimos 1500 anos (Bird et al, 2011). O esfriamento no Hemisfério Norte (HN) dirige o deslocamento á sul da ZCIT, também tem sido documentada em modelos e estudos paleoclimáticos como o realizado por Bird (2011) com registro da lagoa Pumacocha no Peru; esta relação de esfriamento no $\mathrm{HN}$ e deslocamento ao sul da ZCIT é devida ao ajuste da circulação na célula de Hadley o que equilibra a necessidade de transportar para o norte de calor (Bird et al, 2011).

As variações da TSM no HN e Forçantes Solares mostram uma relação entre as temperaturas quentes da TSM no Atlântico Norte e as temperaturas do HN durante a ACM, igualmente tem uma relação com a Irradiancia Solar durante o mesmo tempo onde mostra uma mudança semelhante mas com picos mais fortes. Durante a LIA esta relação entre as variações nas temperaturas do Atlântico Norte, o Hemisfério Norte e as forçantes Solares mostram deslocamentos em fase; para este período mostra-se uma redução na TSM no Atlântico Norte que tem relação com uma diminuição nas temperaturas do NH, a Irradiança Solar apresenta mudanças iguais mas com amplitudes maiores (Bird et al, 2011).

Os registros do Pacifico durante os últimos 1000 anos mostram também movimentos relativos, tanto para o sul como ao norte; estas variações som base nas mudanças acontecidas na "língua Fria do Pacifico" que se localiza entre o Pacifico Central e o Pacifico Equatorial Leste. Na atualidade não tem teorias aceitadas as quais expliquem as variações na posição da ZCIT especificamente sobre o Pacifico, mas o deslocamento ao sul tem relação com a diminuição do gradiente da TSM Transversal Equatorial no Pacifico, seja pelo aquecimento da "Língua fria Equatorial Leste" como acontece nas condições tipo El Niño, o por o esfriamento das regiões extratropicais no HN (Sachs et al, 2009). El acercamiento de la ZCIT al Equador durante el LIA en el área del Pacifico, ha sido vinculado por varios estudios con eventos del HN en el sector Atlántico por la influencia que los vientos del nordeste hacen sobre la secciones del Pacifico Oriental (Timmerman, 2007; Sachs et al, 2011).

Registro do deslocamento da ZCIT no Pacifico e no Atlântico, mostram mudanças na posição para o sul em ambos locais durante a LIA; no Atlântico o deslocamento á sul da ZCIT apresenta uma relação com os modelos que mostram o esfriamento aproximadamente 
de $1^{\circ} \mathrm{C}$ no HN na LIA, além de variações no registro da TSM no Atlântico Norte. Registros no Pacifico da Ilhas e Washington, amostram que no Pacifico durante a LIA também apresento um deslocamento ao sul da posição atual da ZCIT á $5^{\circ} \mathrm{N}$. A ligação do deslocamento da ZCIT com eventos tipo ENSO, Conroy (2008) relaciona com variações nos valores de precipitação no Junco, localizado nas Ilhas Galápagos no Oceano Pacífico, mostrando fortalecimento dos eventos tipo El Niño durante a ACM e enfraquecimento durante o LIA (Conroy et al, 2008).

A mudança de posição da ZCIT no leste do Pacífico durante os últimos 1500 anos tem sido estudada registros na Ilha Palmyra (Cobb et al, 2003), Ilha de Galápagos (Conroy et al, 2008) e Lagoa Washington (Sachs et al, 2009); outros registros, como a lagoa El Gancho na Nicarágua (Stansell et al, 2012), mostra a influência da ZCIT em sua atual localização no norte do Pacífico oriental. Para o início da ACM a posição da ZCIT fica ao sul da posição atual, mostrando os períodos de seca em Galápagos, no final da ACM a ZCIT mostra uma excursão ao sul de $5^{\circ} \mathrm{N}$ aumentando assim a quantidade de chuva nas ilhas.

Na América Central os registros da Nicarágua e no México, onde ele se sente a influência das correntes provenientes do Atlântico e Pacífico, bem como o deslocamento da ZCIT, tem registro de variações significativas para ACM, LIA e CWP. Durante a ACM os registros da América Central mostram uma tendência geral para condições mais úmidas, estas mudanças na precipitação na área se relacionam com as variações observadas na Colômbia, no entanto nossa área de estudo apresenta uma menor intensidade nas mudanças em comparação com o México e Nicaragua.

Na Colômbia têm sido realizadas pesquisas focadas no registro e análises de variações climáticas que ocorreram durante o Holoceno, baseados principalmente na análise de núcleos de lagos na Cordilheira Oriental, a Cordilheira Ocidental e as Planícies Orientais. Os estudos paleoclimáticos mostraram variações na umidade por ciclos de longa duração, baseando na análise sobre os registros de pólen, diatomáceas e registro de sedimentos. Dessa forma, eles conseguiram reconstruir condições de umidade, vegetação e atmosfera, que podem ser associados com ciclos climáticos com durações centenal e milenar (Berrio et al, 2000; 2002; Plaza et al., 1988; Vélez et al, 2001; 2005; 2006). 


\subsection{Objetivos da Pesquisa}

- Realizar levantamento paleoclimático e paleoambiental, com base em perfis isotópicos de

- $\mathrm{O}^{18}$ e $\mathrm{C}^{13}$ em estalagmites depositadas em cavernas da região do Santander (Colômbia) durante o Holoceno.

- Identificar e caracterizar o comportamento climatológico da região durante eventos climáticos de escala global.

- Determinar a influência de padrões de oscilações atmosféricas e oceânicas presentes no Atlântico e Pacífico na variabilidade da paleopluviosidade da região.

- Discutir os mecanismos responsáveis por mudanças da intensidade e

posicionamento geográfico dos sistemas climáticos que afetaram a paleopluviosidade da região leste da Colômbia. 


\section{2. ÁREA DE ESTUDO}

\subsection{Localizacão e Caracterizacão Geológica}

A área de estudo está localizada no município colombiano El Peñon, setor sudoeste do departamento de Santander, nas encostas ocidentais da Cordilheira andina Oriental (figura 2.1), as quais fazem parte do vale do rio Magdalena. A Caverna Caracos está nas coordenadas $6.0820 \mathrm{~N} / 73.8286 \mathrm{~W}$ (datum Bogotá), a $10 \mathrm{~km}$ da sede municipal e a uma altitude média de $2500 \mathrm{~m}$ acima do nível do mar (a.n.m).

Os sistemas de cavernas que estão localizados no citado setor foram desenvolvidos em rochas cretáceas da Formação Rosablanca a qual apresenta: várias camadas de calcário e dolomitas, intercalados com calcário marrom; uma camada intermediária margoso, com shales intercalados com calcário; e um nível de areia (Royero et al, 2004; Zamarreño, 1963; Bedoya e Nomesqui, 2013). Nas diferentes camadas da Formação Rosablanca também há a ocorrência de fósseis tais como bivalves, gastrópodes e equinodermos (Bedoya e Nomesqui, 2013).

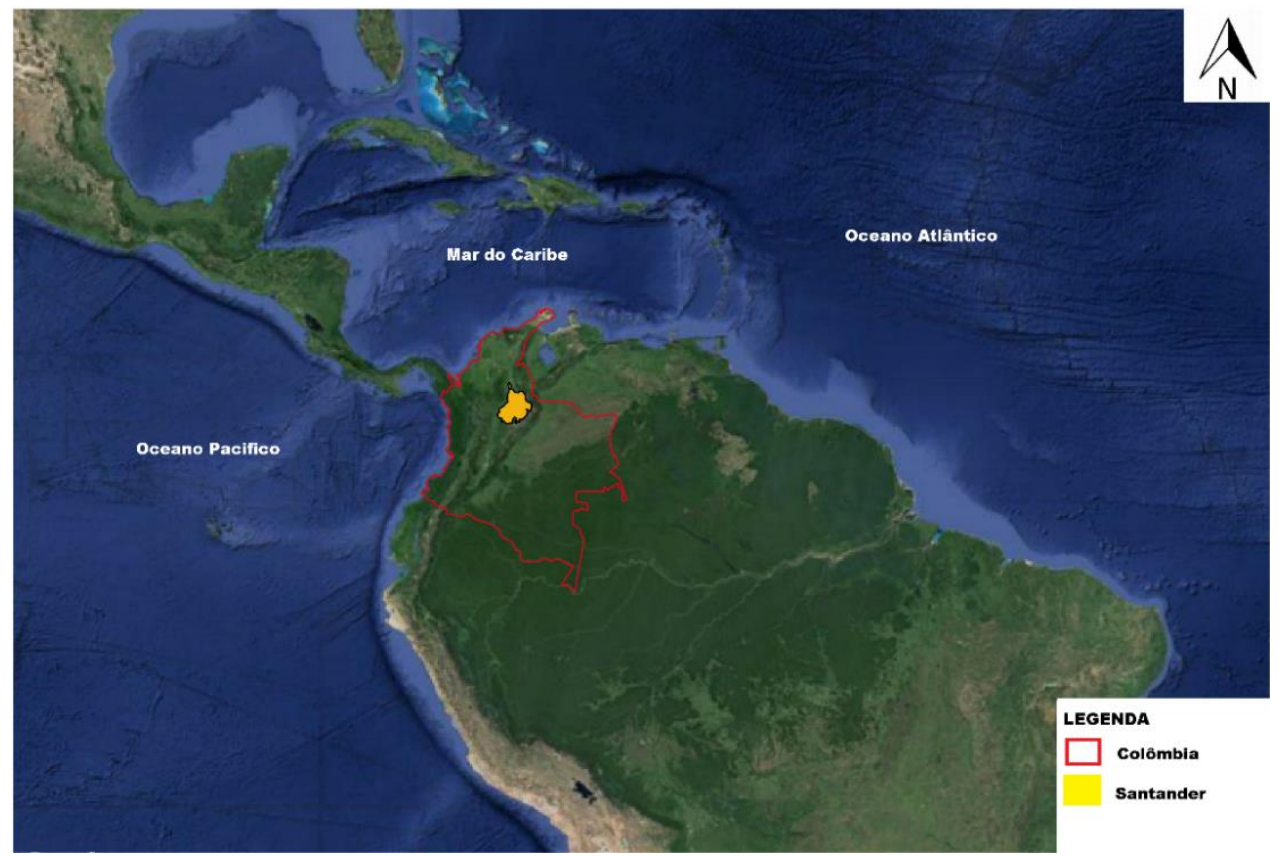

Figura 2.1 Localização da área de estudo no norte de Sul américa, na Cordilheira Oriental na Colômbia. A área de estudo encontra-se localizada na zona de influência das correntes de ar que proveem do Oceano Atlântico, Pacifico e o Mar Caribe. 
Pesquisas de quimio-estratigrafia com isótopos de oxigênio e carbono realizadas na Formação Rosablanca, mostram variações isotópicas entre -0.72 e $-13.34 \%$ de $\delta^{13} \mathrm{C}$, e entre $-3,61$ a $-11,97 \%$ em $\delta^{13} \mathrm{O}$, sugerem um ambiente de deposição com baixos níveis de oxigênio, alto teor de matéria orgânica e baixa produtividade (Bedoya e Nomesqui, 2013).

No marco estrutural a área de estudo é afetada principalmente por falhas e dobramentos, sendo a mais relevante a Falha Bucaramanga, Santa Marta no plano regional, e as falhas Landazuri e San Caetano mais localmente. A área também é influenciada pelo sinclinório de Jose Maria e Panamá, e os anticlinórios de Portones e Los Medios (Gómez et al, 2008) (Figura 2.4)

Falha de Landazuri: Sistema com direção SSW-NNE com mergulho ao oeste e afeta as sequências do Cretáceo da área. Este sistema de falhas são cavalgamentos com características geomorfológicas na drenagem e na topografia (Gómez et al, 2007).

Falha de San Cayetano: tem direção SSW- NNE, subparalelos aos cavalgamentos do sistema de falhas Landazuri. A estrutura apresenta pouco deslocamento vertical mas um importante componente no rombo, afeta principalmente as rochas cretáceas localizadas na área (Gómez et al, 2007).

Anticlinorio Los Medio: A direção geral das estruturas é N25ํ com uma assimetria no mergulho dos flancos, no núcleo se localizam formações do Cretáceo Inferior tais como a Formação Rosablanca. Nos flancos se observam dobramentos sobrepostos, subparalelos e oblíquos sobre as rochas do Cretáceo Superior (Gómez et al, 2007).

Sinclinorio Jesus Maria: O flanco oriental apresenta maior inclinação, cujo o eixo está em uma direção $\mathrm{N} 20^{\circ} \mathrm{E}$ comum comprimento aproximado de 50km (Royero et al, 2001; Gómez et al, 2007). Já a Formação Rosablanca especificamente é caracterizada por declives pronunciados e por escarpas, diferencia-a das formações contíguas pelos vales extensos com relativamente baixo relevo, alto grau de dissolução e uma superfície de articulação notável (Mendoza-Parada et al, 2009). A drenagem na área é paralela e sub-paralela, característica de áreas com substrato calcário como a Formação Rosablanca, propiciando a formação de cavidades de dissolução e de pequenos lagos sem abastecimento de água aparente. Nesses locais também se encontram desenvolvidas feições típicas de áreas 
cársticas, tais como dolinas, vales cegos, sumidouros, zonas vadosas e cavernas (figuras 2.2 e 2.3) (Mendoza-Parada et al, 2009).

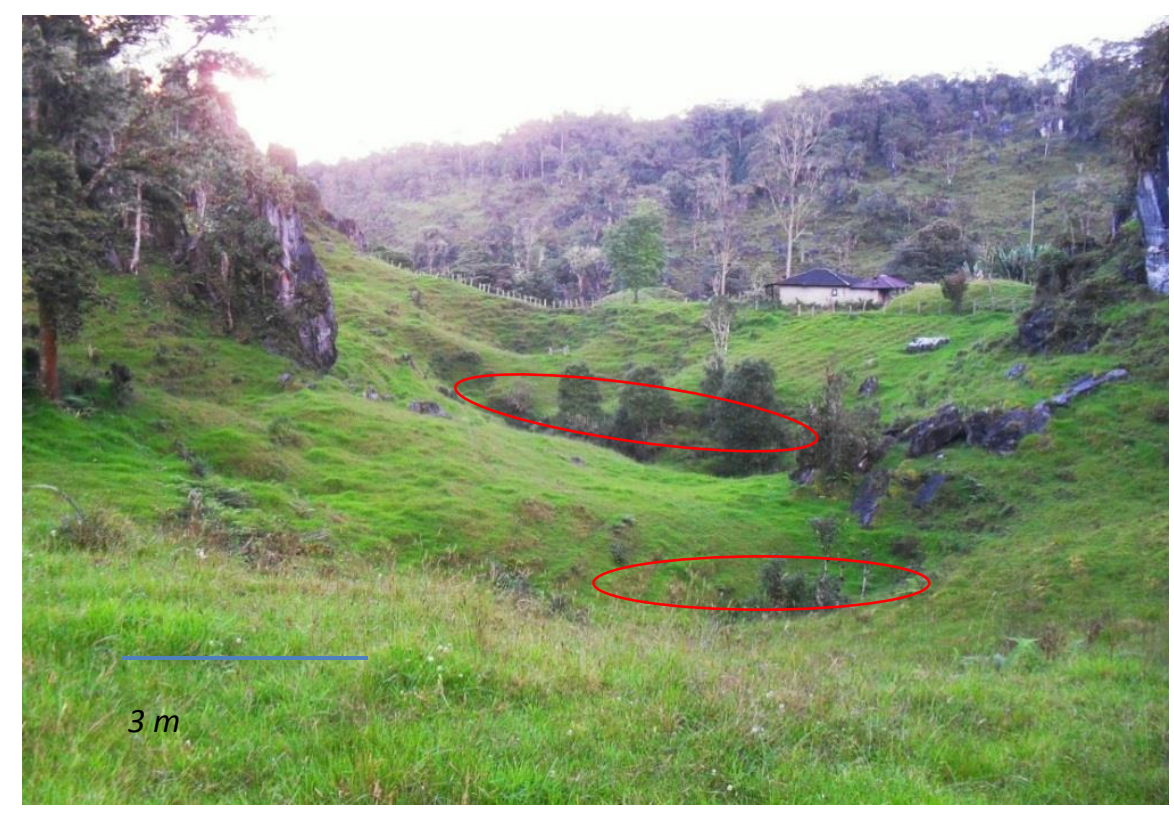

Figura2.2. Paisagem cárstica na área de estudo, observação de dolinas no setor próximo a caverna Caracos; área de percurso até a entrada da caverna no município de El Peñon.

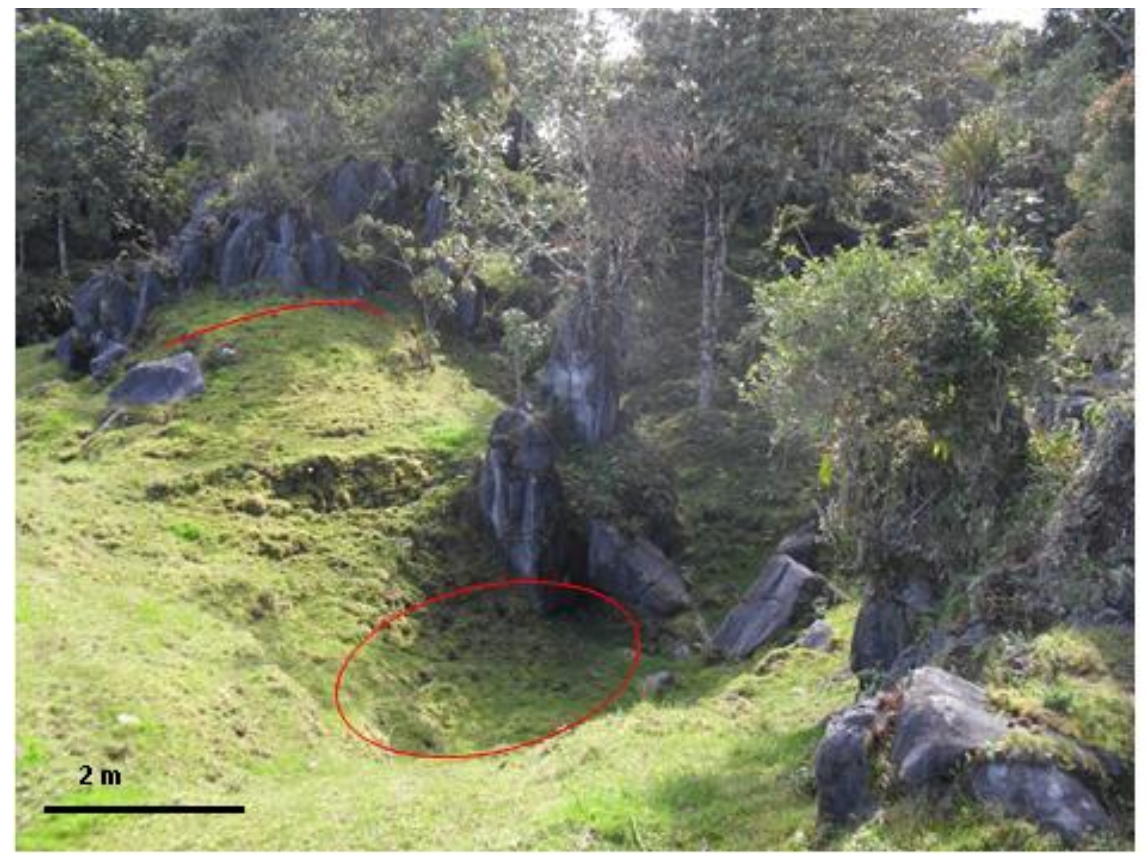

Figura 2.3 Dolinas na área de superficial do recorrido para a Caverna Caracos; também se observam taludes abruptos nas rochas carbonáticas. 


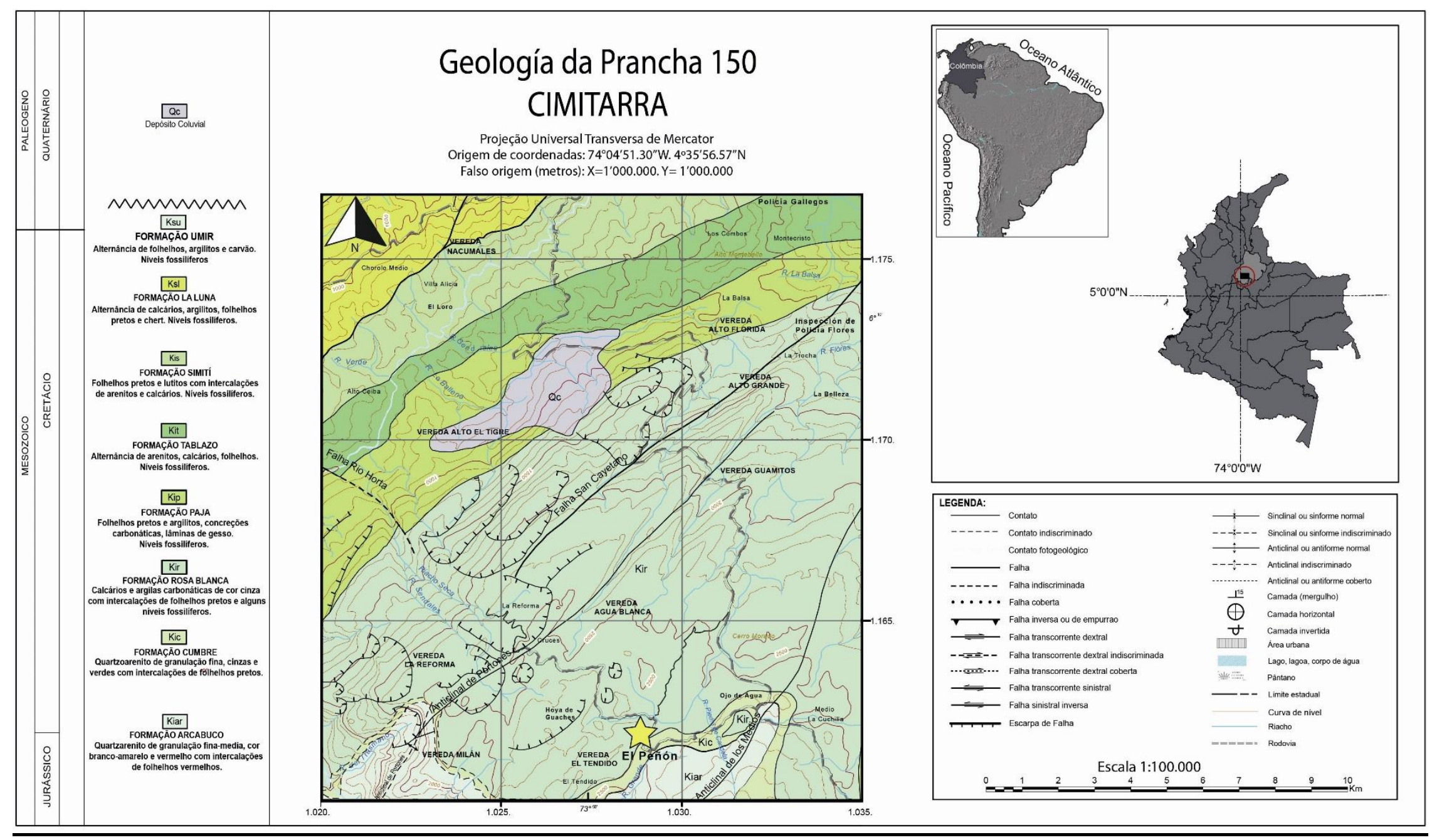

Figura 2.4. Geologia da área de estudo com a localização das cavernas visitadas no setor sudoeste do departamento de Santander. Na área observam-se estruturas com direção preferencial NE-SW, tais como falhas e dobramentos. Mapa adaptado de Gómez et al., (2008). 


\section{$\underline{\text { 2.2 Climatologia Atual }}$}

A área de estudo apresenta um clima temperado de regime equatorial, em uma altitude média de $2500 \mathrm{~m}$, precipitação média anual de $1500 \mathrm{~mm}$ e clima médio de $16^{\circ} \mathrm{C}$ o qual é constante entre os meses úmidos e secos. A variação de precipitação e temperatura na área é relacionada com o deslocamento meridional (sentido norte-sul) da Zona de convergência Intertropical (ZCIT), com as correntes convectivas provenientes do Caribe e Pacifico, e com os fluxos de ar do Atlântico.

A Colômbia está localizada na margem noroeste do continente Sul-americano, setor no qual a Cordilheira dos Andes divide-se em três cordilheiras. A Cordilheira Ocidental faz fronteira com o oceano Pacífico na área ocidental da Colômbia e apresenta uma altitude média de 2000 m (altura máxima 4764 m). Já a Cordilheira Central está entre os vales do rio Cauca e Rio Magdalena, os principais rios da Colômbia, alcançando uma altura de até $5750 \mathrm{~m}$. A Cordilheira Oriental vai até Venezuela e tem uma altura máxima de 5500 manm. As particularidades topográficas da área ao norte dos Andes geram características climáticas como microclimas devido à mudança na altitude, bloqueio de correntes de ar, áreas com maior nebulosidade e barreiras orográficas, bem como, influências nas diferentes fontes de umidade.

Os ciclos climáticos sazonais no norte do América do Sul, e especificamente na porção centro e-oeste da Colômbia, são marcados pelos movimentos da ZCIT. Esses deslocamentos se relacionam com a dinâmica dos ventos que vem do oriente e impactam nos oceanos e a massa continental. Os padrões atmosféricos locais e regionais, como os jatos de baixo nível, também influenciam as correntes de ar na área, como é o caso dos Jatos de Choco e San Andrés que entram pelo ocidente da Colômbia e trazem umidade proveniente do Pacífico e do Caribe (Figura 2.1) (Poveda et al, 2006; Poveda et al, 2014). Correntes de umidades da Amazônia durante o ano também podem influenciar na precipitação da área, no entanto sua relação não é tão marcada e sua quantificação não foi estudada ainda.

A oscilação meridional da ZCIT responde ao ciclo sazonal da insolação, ficando na posição zenital por um mês aproximadamente. Durante o verão austral a ZCIT encontra-se posicionada acima da bacia amazônica, no sul da Colômbia. A posição mais ao norte da 
ZCIT ocorre durante os meses do verão boreal, localizando-se sobre a Colômbia e parte da América Central. Os deslocamentos para norte ou sul da ZCIT e vice-versa, ocorrem durante os meses de outono e primavera. Devido os deslocamentos ocorridos sobre a área da cordilheira andina, a região apresenta um ciclo bimodal de chuvas e secas, com maiores níveis pluviométricos nos meses de março-maio e setembro-novembro, correspondendo este último período o intervalo do ano que ocorre chuvas com mais intensas(Poveda, et al., 2006) (Snow, 1976).

No litoral do Caribe colombiano e no flanco Pacífico do Istmo centro-americano, observase ciclos unimodal de chuvas entre os meses de maio e outubro, o qual reflete a posição mais setentrional da ZCIT no continente e Pacífico Oriental Equatorial (EEP pelas siglas em inglês). Um único pico de chuvas também é evidente principalmente no piemonte oriental dos Andes Orientais, devido à convecção de umidade da Amazônia relacionada com a barreira orográfica dos Andes com máximos de chuva entre junho e agosto (Poveda, et al., 2006) (Snow, 1976).

A distribuição anual das chuvas na área estudada apresenta duas estações chuvosas e duas secas, sem variações significativas na temperatura (Poveda et al., 2002). As temporadas de chuva são nos meses de marco- maio e setembro-novembro, os meses de seca dezembrofevereiro e junho- agosto, os períodos secos ainda tem chuvas, mas estas são menores que as dadas nos meses de chuvas. Os ciclos chuvas/secas são principalmente devido à dupla passagem da ZCIT acima da área dos Andes Nortes (Poveda et al., 2006). Em geral a intensidade em ambos os períodos de chuva são semelhantes, no entanto o segundo período há mais intensidade (Snow, 1976; Poveda et al., 2002).

\section{Jato de Choco}

É um fluxo de baixo nível o qual é dirigido termicamente pelo gradiente da temperatura superficial do mar (TSM) da corrente fria entre Peru - Equador e o Pacífico colombiano. Tal fluxo é favorecido pela mudança na direção das correntes austrais no equador onde são desviadas para oeste, e pela liberação do calor latente nas chuvas dos Sistemas Convectivos de Mesoescala (SCM). O jato de Choco ascende topograficamente nos Andes Ocidentais 
até o setor chamado Mistrado $\left(5^{\circ} \mathrm{N}\right)$ e mistura-se com os ventos de leste, aprofundando a convecção sazonal na área ocidental e central da Colômbia (Poveda et AL, 2002). Já o ocidente colombiano é amplamente influenciado pela força dos ventos de sudeste, os quais ao norte do equador são desviados para oeste, e como no jato de Choco que traz a umidade (Martínez, et al., 2003).

\begin{tabular}{lccccc}
\hline No. Name & $\begin{array}{c}\text { Latitude } \\
\text { North }\end{array}$ & $\begin{array}{c}\text { Longitude } \\
\text { West }\end{array}$ & $\begin{array}{c}\text { Height } \\
(\mathrm{m})\end{array}$ & $\begin{array}{c}\text { Average Rainfall } \\
\mathrm{mm}(\text { Period) }\end{array}$ & $\begin{array}{c}\text { Record } \\
\text { (mm/month) -Date }\end{array}$ \\
\hline 1. El Caraño & $5^{\circ} 43^{\prime}$ & $76^{\circ} 37^{\prime}$ & 53 & $7831(1960-1995)$ & $2030-07 / 1975$ \\
2. La Vuelta & $5^{\circ} 27^{\prime}$ & $76^{\circ} 32^{\prime}$ & 100 & $8545(1961-1995)$ & $1438-07 / 1969$ \\
3. Andagoya & $5^{\circ} 06^{\prime}$ & $76^{\circ} 42^{\prime}$ & 35 & $7268(1961-1995)$ & $1480-09 / 1974$ \\
4. Amargal & $5^{\circ} 35^{\prime}$ & $77^{\circ} 30^{\prime}$ & 30 & $7119(1993-1998)$ & $1633-08 / 1995$ \\
5. Managrú & $5^{\circ} 19^{\prime}$ & $76^{\circ} 44^{\prime}$ & 50 & $6343(1978-1998)$ & $1298-03 / 1996$ \\
6. Bellavista & $6^{\circ} 35^{\prime}$ & $76^{\circ} 35^{\prime}$ & 15 & $4950(1967-1998)$ & $1571-05 / 1978$ \\
7. Tagachí & $6^{\circ} 10^{\prime}$ & $76^{\circ} 44^{\prime}$ & 20 & $6540(1967-1997)$ & $1323-05 / 1971$ \\
8. Beté & $6^{\circ} 00^{\prime}$ & $76^{\circ} 47^{\prime}$ & 25 & $8680(1978-1997)$ & $2854-07 / 1980$ \\
9. Lloró & $5^{\circ} 30^{\prime}$ & $76^{\circ} 35^{\prime}$ & 90 & $7590(1984-1997)$ & $1472-08 / 1993$ \\
10.El Piñón & $5^{\circ} 40^{\prime}$ & $76^{\circ} 23^{\prime}$ & 715 & $7689(1959-1997)$ & $2906-11 / 1970$ \\
11.Lloró Granja & $5^{\circ} 30^{\prime}$ & $76^{\circ} 32^{\prime}$ & 120 & $12,541(1952-1960)$ & $2676-06 / 1954$ \\
\hline
\end{tabular}

Tabela 2.1. Medias de chuva nas municipalidades próximas na área de entrada do jato de choco na Colômbia durante 30 anos, as quais vão de 4950a $12541 \mathrm{~mm}$. O jato de Choco entra na Colômbia aos $5^{\circ} \mathrm{N}$, pelo sitio de Mistrato. Tabela de Poveda \& Mesa, 2000

Devido à interrupção quase periódica do padrão meridional da TSM causada pelo ENSO no EEP, o enfraquecimento do jato de Choco tem relação com os períodos de seca no norte dos Andes (Martínez, et al., 2003). Os registros paleoclimáticos do Pacífico mostram uma relação entre as condições de La Niña e o fortalecimento do jato de Choco durante o último período do Máximo Glacial (Martínez, et al., 2003)(Poveda, et al., 2006). A influência do jato de Choco na atualidade na área do Ocidente da Colômbia se evidencia nos registros de alta pluviosidade na área, as quais variam entre 8000 e $12000 \mathrm{~mm}$ ao ano (tabela 1) (Poveda \& Mesa, 2000).

\section{Jato de San Andrés e EMTEJ}

O jato de baixo nível dos ventos do Caribe (Jato de San Andrés) atua como uma ligação entre o Pacífico Oriental e o Caribe, numa escala de tempo interanual. A atividade do jato 
no Caribe tem efeitos potencias nos Sistemas Convectivos Tropicais, como as ondas do oriente e sua organização nos ciclones tropicais, nas latitudes entre $13^{\circ}-15^{\circ} \mathrm{N}$ apresentam velocidades mais altas em julho-agosto e dezembro-fevereiro, e menores entre setembronovembro e março-maio (Poveda, et al., 2006).

O EMTEJ exibe ciclos anuais quase inversos aos que apresentam os jatos de San Andrés e Choco (Tabela 2), tem maior intensidade durante os meses de março-maio e junho-agosto, com velocidades maiores aos $10 \mathrm{~m} / \mathrm{s}$, e menores aos $6 \mathrm{~m} / \mathrm{s}$ nos meses do enfraquecimento do jato. Este jato demonstra uma oscilação quase meridional, começando com a localização acima do equador durante março-maio e uma migração aos $2^{\circ} \mathrm{S}$ durante setembronovembro (Poveda, et al., 2006).

\begin{tabular}{lrllc}
\hline & \multicolumn{1}{c}{ MAM } & \multicolumn{1}{l}{ JJA } & \multicolumn{1}{l}{ SON } & \multicolumn{1}{l}{ DJF } \\
\hline EMTEJ jet & $-10(0)$ & $-10(0)$ & \multicolumn{1}{l}{$-6(0)$} & $-8(0)$ \\
San Andrés jet & $-8(1)$ & $-12(-4)$ & $-6(-2)$ & $-10(2)$ \\
Choco jet & $2(0)$ & $4(-1)$ & $6(-2)$ & $4(-2)$ \\
\hline
\end{tabular}

Tabela 2.2. Comparação das velocidades dos jatos que tem influência sobre Colômbia nos diferentes trimestres. Poveda et al, 2006.

\section{Variabilidade Interanual}

\section{ENSO}

É um dos principais mecanismos que influenciam na variabilidade climática na zona tropical de América do Sul em escala anual. El Niño refere-se ao aumento das temperaturas superficiais do mar (TSM) no centro e no leste do oceano Pacífico, com um enfraquecimento dos ventos superficiais. Durante os episódios de El Niño ocorrem mudanças no centro de convecção desde o oeste para o Pacífico Central, a oscilação do sul que acompanha a variação das massas atmosféricas produz uma gradiente de pressão entre o oeste e leste do Pacífico Equatorial, o qual caracteriza o índice da oscilação do sul (SOI pelas siglas em inglês)(Poveda, et al., 2006). Os ciclos que apresentam o ENSO mostram uma periodicidade entre 4 e 10 anos(Poveda, et al., 2006). Os valores negativos do SOI 
associam-se com eventos quentes (El Niño), enquanto os valores positivos acompanham os eventos frios (La Niña) e uma forte circulação na célula de Walker (oeste - este).

A oscilação do ENSO durante diferentes períodos, e a partir dos registros paleoclimáticos obtidos em diferentes estudos, mostram relação com as variações observadas em outros mecanismos climáticos que influenciam na área. As associações com os sistemas regionais são:

- A redução do gradiente do TSM no Pacífico Oriental enfraquece o fluxo do Jato de Choco, diminui o transporte da umidade ao interior do continente (Poveda, et al., 2006) (Martínez, et al., 2003). Estas anomalias na umidade transportada pelo jato de Choco são importantes na contribuição da precipitação no centro e oeste da Colômbia (Martínez, et al., 2003).

- Mundanças nas pressões acima da área Tropical de América do Sul contribuem ao deslocamento dos centros da convecção na ZCIT no Pacifico Oriental Equatorial para o oeste e sul de sua posição normal (Pulwarty \& Diaz, 1993).

- Redução na retroalimentação entre a precipitação e a superfície da convergência no Trópico na América do Sul, associada com a circulação das células de Hadley e os ventos alísios do Caribe(Poveda, et al., 2006).

- Rompimento de interações terra-atmosfera, devido à união regional entre as anomalias de precipitação, umidade do solo, da vegetação e da evapotranspiração. Redução evapotranspiração contribui ao decrescimento da precipitação a partir de reciclagem da evaporação(Poveda, et al., 2006).

- Durante o verão boreal no ano 0 (ano inicial da anomalia), os ventos alísios do nordeste intensificam se (enfraquecem) durante El Niño (La Niña), no entanto a de acordo com as mudanças na pressão de superfície durante o inverno boreal os campos são revertidos no ano +1 , o que provoca uma mudança na TSM no Caribe y no Tropico do Atlântico Norte (Curtis \& Hastenrath, 1995).

No contexto da Colômbia as análises da correlação mostram que o episódio de El Niño produz eventos secos e alta temperatura, e La Niña eventos mais úmidos e estações de chuvas mais longas (Poveda, et al., 2006). 


\section{Oscilacão do Atlântico Norte (NAO)}

Nas altitudes médias e altas do Hemisfério Norte (HN), especificamente durante os meses do inverno (novembro-abril), o padrão mais importante e recorrente na variabilidade atmosférica é a Oscilação do Atlântico Norte, a qual refere-se uma distribuição da massa atmosférica entre o Ártico e o Atlântico Subtropical. As mudanças entre uma fase e outra produzem oscilações na velocidade média do vento e a direção acima do Atlântico, o transporte de calor e umidade entre o Atlântico e os continentes vizinhos (Hurrell et al, 2003).

No norte de América do Sul e a sul da América Central, a Oscilação do Atlântico Norte é uma fonte regional potencialmente importante da umidade e controle da força dos ventos alísios, a propagação das ondas e tempestades tropicais, considerado como um dos indicadores do estado do sistema oceano-atmosfera acima da área marítima (Poveda et al, 1998; 2006) (Hurrell, et al., 2003).O modo NAO positivo ocorre quando se tem uma alta subtropical normalmente forte e baixa na Islândia é muito profunda, fazendo que os ventos do oeste do Atlântico Norte sejam mais fortes. Já durante a Não negativa ambos os centros são anormalmente fracos. Variações temporais na NAO são ligadas com mudanças climáticas na Europa, a leste dos Estados Unidos, e na bacia do Mediterrâneo, Rogers (1988) sugere que as precipitações no Caribe e América Tropical variam nos extremos da NAO devido sua influência na forca dos ventos alísios do Atlântico Norte (Hurrell, et al., 2003) (Poveda, et al., 2006).

Pesquisas feitas nas descargas dos rios e sua relação com a NAO na Colômbia (Poveda \& Mesa, 1996) indica um relacionamento entre as chuvas e este evento, o qual diminui de norte para o sul. Essas observações podem ser explicadas pela intensidade dos ventos alísios no Atlântico Norte Tropical e o Caribe, devido à influência na posição e força do Anticiclone do Atlântico Norte (Poveda, et al., 2006). As variações na NAO modificam a intensidade dos ventos alísios na área colombiana, que por sua vez está relacionada com os eventos de "veranillos" nas encostas do Pacífico e aumento da precipitação no Caribe, igualmente mostram uma relação com as variações do ENSO. 
A seca sazonal nas encostas do Pacífico e chuvas excessivas no Caribe associado com o Pacífico mais quente estão ligadas com períodos do Atlântico frio, isso implica uma maior pressão atmosférica e fortalecimento dos ventos. Nos casos de um aquecimento do Atlântico a seca na área da Colômbia é mais estendida, mas menos graves. Essas condições estão ligadas com um maior fluxo no litoral Pacifico e uma redução das chuvas sazonais no Caribe colombiano(Poveda, et al., 2006) (Poveda \& Mesa, 1996).

\section{Oscilação Multidecadal do Atlântico (OAM)}

A OAM está relacionada com a porção do Atlântico Norte da Circulação Termohalina (Thermohaline Circulation - THC), que forma águas profundas do Atlântico Norte devido às baixas temperaturas e alta salinidade da água, resultando em maior densidade. As variações de salinidade da água provavelmente afetam os padrões de TSM da OAM, resultando no caráter multidecadal deste modo climático (Grossman e Klotzbach, 2009) que tem oscilações entre 65 a 75 anos com ciclos de variação de $0,4^{\circ} \mathrm{C}$.

A fase positiva do OAM ocorre na máxima intensidade da THC, resultando em anomalias positivas de TSM no Atlântico Norte e negativas no Atlântico Sul. Na fase negativa o padrão é inverso e ocorre mínima intensidade da THC. Devido à duração dos ciclos da OAM os registros instrumentais mostram poucos ciclos completos, no entanto estudos com proxies paleoclimáticos foram feitos para melhorar o entendimento dos ciclos e mostram relações entre a OAM com anomalias interanuais de precipitação sobre a América do Norte e parece modular teleconexões do ENOS (Trenberth et al., 2007).

Estudos propõem relações entre a OAN e a OMA (Walter e Graf 2002) onde na fase negativa (fria) da OMA a TSM do Atlântico Norte é fortemente associado ao índice OAN, porém, na fase positiva (quente) da OAM o inverso não acontece, o índice OAN é apenas pouco correlacionado à TSM do Atlântico Norte. A relação entre a OMA, a ODP, mais a OAN de inverno, quando é mais intensa no Hemisfério norte (HN), tem coerências com a convecção tropical e temperaturas de superfícies sobre o Pacífico Central Tropical e na bacia Amazônica (Chelliah \& Bell, 2004). 


\section{Oscilacãa Decadal do Pacifico (ODP)}

A ODP foi definida por Mantua et al. (1997) como um padrão de variação climática do Oceano Pacífico que muda de fase com frequência multidecadal (20 a 30 anos, 50 a 70 anos), e é caracterizada por duas fases: a fase quente definida por anomalias positivas de TSM na costa oeste da América do Norte e região leste do Pacífico Equatorial; e anomalias de TSM negativas no Pacífico Norte central e oeste, o mesmo ocorrendo no Hemisfério Sul. $\mathrm{Na}$ fase fria, o inverso é verdadeiro, águas frias na costa oeste da América do Norte e Pacífico leste equatorial, e no Pacífico central e oeste (nos dois hemisférios) ocorrem águas quentes.

A ocorrência da ODP apresenta padrões similares aos presentes nas condições El Niño, pelo qual é caracterizado como um evento do tipo El Niño com frequências mais longas, a comparação entre o ODP e eventos El Niño não só se limita nos modos, também é feita para os mecanismos geradores (Newman et al, 2003). Embora a relação entre a OPD e o ENOS não seja inteiramente compreendida, vários estudos sugerem que a OPD pode ser uma variação residual do ENOS em baixa frequência (Newman et al., 2003).

Estudos na América do Sul documentaram o aumento da precipitação e da vazão dos rios no sudeste da América do Sul e sul da Amazônia ao mesmo tempo em que diminuiu a precipitação no norte da Amazônia comparando com as décadas anteriores no período entre 1976-1977. Esta mudança na precipitação na área é coerente com a mudança de fase da ODP no meio da década de 1970, de fria para quente (Garreaud, 2009). Depois da mudança de fase da ODP observa-se mudanças nos eventos ENOS, os quais se tornaram mais fortes e frequentes nas décadas de 80 e 90 em relação às três décadas anteriores.

\section{DADOS DE CHUVA IAEA-GIP}

Foram analisados os dados de chuva provenientes de estações de monitoramento pluviométricas localizadas nas regiões próximas ao sul do departamento de Santander. Como também as razões isotópicas de oxigênio e deutério das estações de monitoramento do IAEA-GIP. Esses dados foram coletados na Colômbia entre as décadas de 1970 e 2000. 
Entre as regiões monitoradas pela IAEA-GIP na Colômbia, utilizaram-se para as análises os dados de monitoramento da cidade Bogotá, devido à proximidade com a área de estudo, condições de altura e posição na Cordilheira Oriental. As séries históricas dos dados de chuva em Bogotá começaram no ano 1991 e vão até 2009, no entanto apresentam falta na informação entre os anos 1990 e 1998. Do mesmo modo, alguns meses não têm registros completos das análises isotópicas de $\delta^{18} \mathrm{O}$ e $\delta \mathrm{D}$.

Apesar da falta de dados do monitoramento em Bogotá em alguns anos, foi possível observar mudanças nas quantidades de chuva, por meio das razões isotópicas de oxigênio e deutério na área. Com base nas variações mensais em valores de precipitação e os valores médios de Oxigênio, se obteve uma relação entre a quantidade de chuva e os valores isotópicos da chuva, como pode-se ver nos gráficos 2.5 e 2.6.

A tendência obtida entre a precipitação e o conteúdo isotópico de oxigênio na chuva, como a variação mensal destas, mostram uma relação entre a quantidade de chuva e as variações isotópicas de oxigênio. Desse modo, maiores quantidades de chuva estiveram relacionadas com os valores isotópicos de oxigênio mais baixos, indicando que o efeito quantidade (amount effect)é principal controle da composição isotópica do oxigênio na chuva nos trópicos (Lachniet, 2009; Viulle et al, 2003; Brown, 2004).Nas áreas tropicais as variações sazonais da temperatura são pequenas e assim, a principal fonte de esgotamento isotópico do oxigênio na chuva, tendo em conta os sistemas convectivos locais, é o decaimento isotópico pela quantidade de chuva (Brown, 2004). 

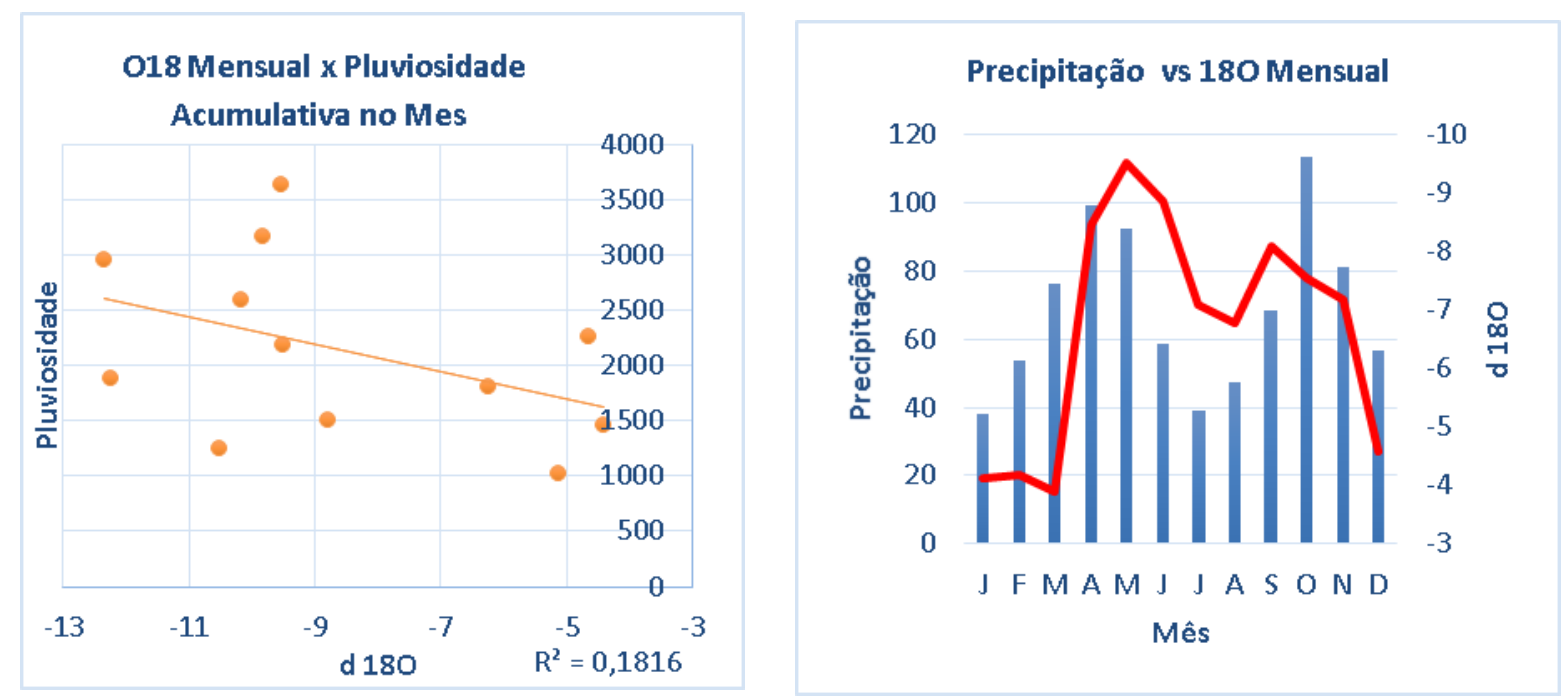

Figuras 2.5 e 2.6 Dispersões dos dados de $\delta^{18} \mathrm{O}$ com a quantidade de chuva em Bogotá, mostrando uma relação entre a quantidade de chuva e a variação isotópica das águas; no entanto alguns meses apresentam uma maior dispersão relacionada com o câmbio na fonte de umidade. A variação entre a quantidade de chuva e $\delta^{180}$ mostra igualmente uma relação entre a quantidade de chuva e o fracionamento isotópico do Oxigênio, sendo uma relação mais forte durante a primeira temporada de chuva do ano e mais fraca na segunda.

A figura 2.6 mostra a relação entre as variações isotópicas de oxigênio e a quantidade de chuva na estação de monitoramento em Bogotá, igualmente as flutuações na precipitação ajustam-se com as estradas de umidade à área pelos movimentos da ZCIT e dos sistemas de umidade que vem do Pacifico e Caribe, como se observa na figura 5. A composição isotópica de oxigênio mostra um ajuste com as variações na precipitação no primeiro período de chuvas na área que é entre os meses de março e maio. No entanto no segundo período de chuvas (setembro- novembro) as relações entre quantidade de chuva e isótopos de oxigênio mostram um sistema de fracionamento diferente ao primeiro período, podendo ser uma relação com outra entrada de umidade na área. 


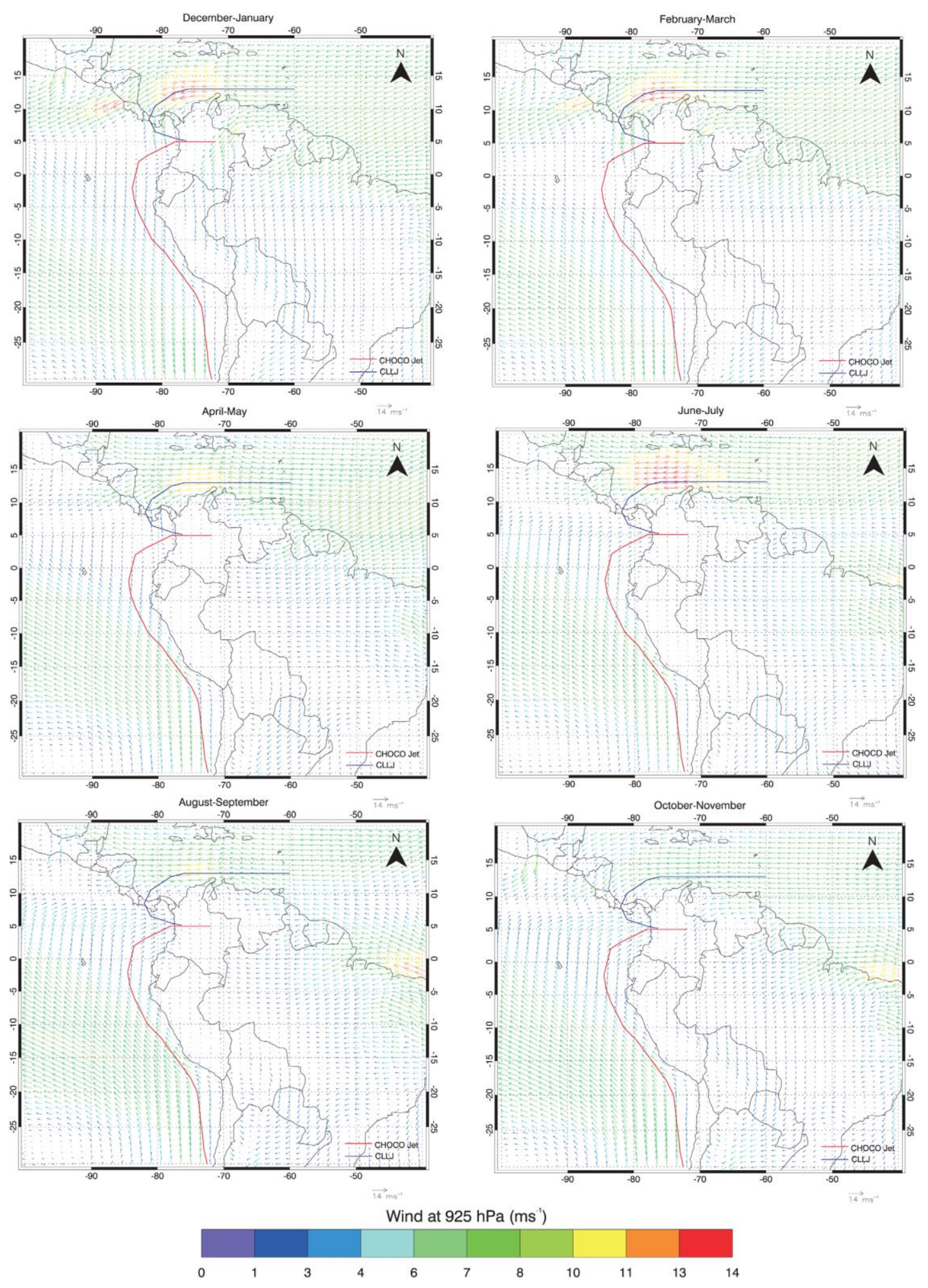

Figura 2.7 Mapas de fontes de umidade que tem influenciam na área da Colômbia na atualidade (Poveda et al, 2014). Proveniência das fontes de umidade e rios aéreos. 


\section{ISÓTOPOS ESTÁVEIS E A INFORMAÇÃO PALEOAMBIENTAL}

\section{$\underline{\text { 3.1 Formação de Cavernas }}$}

Os sistemas cársticos são determinados como a relação entre as camadas superficiais da litosfera, principalmente compostas por carbonato (CaCO3), a filtração das águas superficiais ou subterrâneas, as fraturas da rocha e alterações no pH do meio (Fairchild et al, 2006).Dentro destes sistemas, a zona de dissolução que ocorre entre o solo e o epicarste, é dominada pela dissolução dos carbonatos em contato com a água com uma elevada pressão parcial de $\mathrm{CO} 2$ ( $\rho \mathrm{CO} 2)$ derivada das plantas e de matéria orgânica do solo; por seu lado a zona de precipitação dos espeleotemas no sistema cárstico está localizada na área de supersaturação devido desgaseificação de $\mathrm{CO} 2$ da água que desce pelas fraturas das rochas. No entanto, a variação da temperatura no interior da caverna pode alterar a quantidade e química (Ph e elementos dissolvidos) da água filtrada, o que influencia a concentração de CO2 na atmosfera da caverna (Fairchild et al, 2006); este sistema de interação na formação do Carste, como se mostra nas Figuras 3.1 e 3.2, influencia os câmbios nas diferentes taxas de precipitação de carbonato em relação à variação sazonal (Fairchild et al, 2006). De acordo com as interações que ocorrem entre o $\mathrm{CO}_{2}$ e $\mathrm{H}_{2} \mathrm{O}$ dentro do carste, as seguintes reações ocorrem em diferentes áreas do processo:

- Na zona de dissolução, situado na zona do perfil do solo, se apresenta a interação entre a água que se infiltra pela zona de lixiviação e reage com o $\mathrm{CO}_{2}$ e o incorpora ao solo pela respiração das plantas ou em forma dissolvida na água meteórica, formando ácido carbônico (Scholz y Hoffmann, 2008):

$$
\mathrm{H}_{2} \mathrm{O}+\mathrm{CO}_{2(\mathrm{aq})} \rightarrow \mathrm{H}_{2} \mathrm{CO}_{3} \text { (Equação3.1) }
$$

- Na área superior do contato com a rocha fresca, se apresenta a reação entre a rocha de composição predominantemente de carbonato de cálcio e o dióxido de carbono gerado na zona superior. Isso produz a dissolução do carbonato e gera íons de livres de cálcio $(\mathrm{Ca} 2+)$ e HCO3, que podem viajar livremente através das fissuras da rocha (Fairchild et al., 2006).

$$
\mathrm{CO}_{2}+\mathrm{H}_{2} \mathrm{O}+\mathrm{CaCO}_{3} \rightarrow \mathrm{Ca}^{++}+2 \mathrm{HCO}_{3}^{-}(\text {Equação 3.2) }
$$


- Os resultados do equilíbrio entre os produtos da reação da água filtrada dependem de parâmetros tais como $\rho \mathrm{CO} 2$ da solução e a ocorrência num sistema aberto ou fechado (Fairchild et al, 2006) (Figura 3.1). A pressão do CO2 no ar de caverna é geralmente mais baixa do que a observada na atmosfera, de acordo com a ventilação dentro da caverna; assim o CO2 dissolvido na água no interior da caverna é desgaseificada, a água pode ficar supersaturada e precipitar se formando espeleotemas:

$$
\mathrm{Ca}^{2}+2 \mathrm{HCO}_{3}-\rightarrow \mathrm{CaCO}_{3}+\mathrm{H}_{2} \mathrm{O}+\mathrm{CO}_{2}(\text { Equação } 3.3)
$$

A precipitação de carbonato no cárstico tem como resultado a formação de diferentes tipos de espeleotemas, que têm sido utilizados como uma fonte de estudo para determinar as variações paleoclimáticos, sendo as principalmente estudadas as estalagmites com forma de vela as quais apresentam um crescimento quase contínuo, laminação visível e eixo de crescimento sem dissolução secundária; estas demonstraram um maior potencial para o estudo de registros paleoclimáticos, devido tanto à sua forma e a distribuição dos isótopos dentro do esquema de depósito, tal como descrito em na Figura 3 (Fairchild et al., 2006) (Figura 3.2). Embora tenham sido usados outros tipos de espeleotemas depositados em cavernas e têm sido utilizados para estudos paleoambientais, na presente pesquisa utilizamos estalagmites devido às características mencionadas acima. 


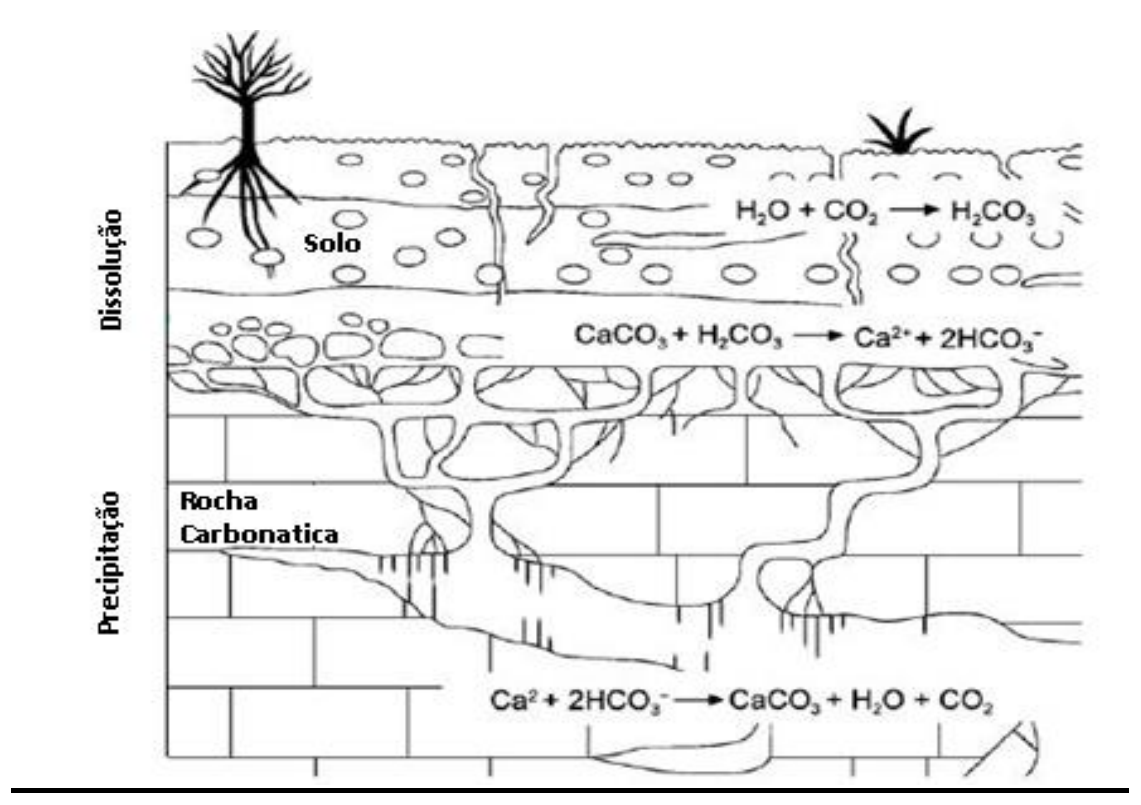

Figura 3.1 Regimes da dissolução e de precipitação do sistema cárstico. Modificado de Fairchild et al, 2006

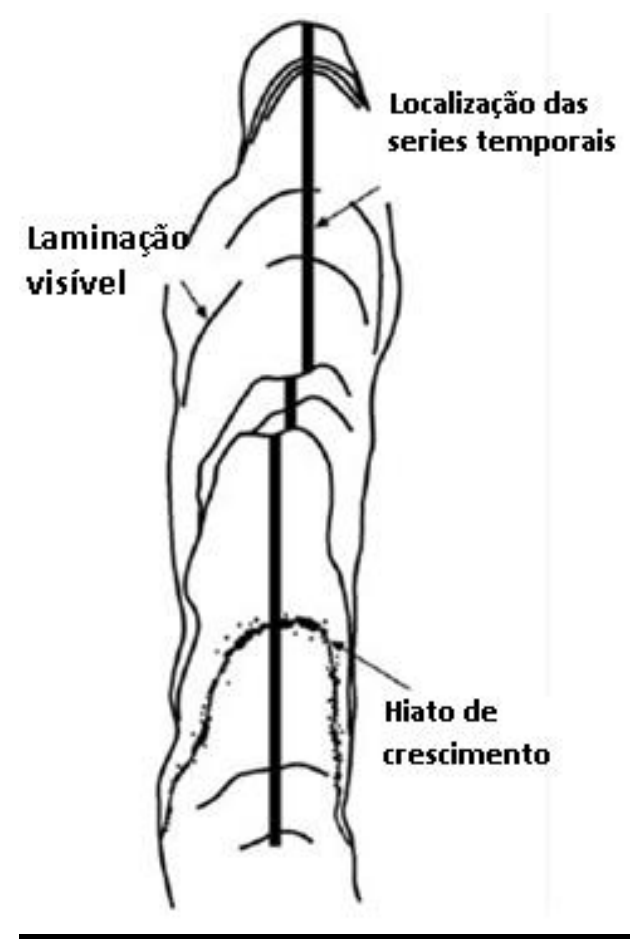

Figura 3.2 Relações de características de crescimento para a localização das séries de tempo; as estalagmites normalmente são estudadas em chapas polidas perpendicular à direção do seu crescimento máxima, mas secções transversais de estalactites também têm sido utilizadas. Modificado de Fairchild et al, 2006. 


\subsection{Isótopos de Oxigênio no ciclo Hidrológico}

O oxigênio é um elemento encontrado em diversos ambientes na terra, porém seus valores relativos dos índices ( $\delta 180$ ) dentro de cada subsistema são controlados por diversos fatores (Lachniet de 2009). Nas mudanças do Oxigênio no ciclo hidrológico como nas cavernas, é associado com fatores tais como a evaporação, precipitação, fonte, entre outros.

O 99,76\% do oxigênio que está na terra é uma espécie ${ }^{16} \mathrm{O}$, o ${ }^{18} \mathrm{O}$ representa apenas $0,20 \%$ do oxigênio presente; a proporção dos isótopos $18 \mathrm{O}$ e 160, comparado com um valor padrão, é expressa pela notação "delta" (ð) obtida a partir da equação 3 :

$$
\zeta^{18} \mathrm{O}=\frac{\left({ }^{18} \mathrm{O} /{ }^{16} \mathrm{O}_{\text {sample }}\right.}{\left.-{ }^{18} \mathrm{O} /{ }^{16} \mathrm{O}_{\text {standard }}\right)} \times 1000 \text { (Equação 3.4) }
$$

Os valores padrão para carbonatos é o Pee Dee Belemnite (PDB) e para a análise de água e carbonatos do Padrão Médio Oceano Hídricos (SMOW); valores padrões para as comparações são definidos nos ambos os casos como $0 \%$.

A evolução dos isótopos de oxigênio pode ser rastreada através do ciclo hidrológico, começando na superfície do oceano, seguida de evaporação, precipitação, condensação e de reciclagem de água, processos de transporte de água e vapor de água em zonas do interior (Lachniet, 2009); os valores $\precsim 180$ são controlados por mudanças de fase da água, durante a qual o conteúdo de equilíbrio cinético ou de processos de isótopos estáveis ocorre (Craig e Gordon, 1965; Rozanski et al, 1993; Lachniet, 2009).

No modelo de "sistema fechado" é assumido que em duas fases que estão em contato fracionamento isotópico ocorre em equilíbrio; este processo assume que o equilíbrio total acontece em relação expressa pela equação 3.5 (Brown, 2004):

$$
\underline{\mathrm{q}_{\mathrm{ic}}}=\frac{\alpha(\mathrm{T}) \mathrm{q}_{\mathrm{iv}}(\text { Equação 3.5) }}{\mathrm{q}_{\mathrm{c}} \mathrm{q}_{\mathrm{v}}}
$$


Em condições de equilíbrio isotópico a proporção de isótopos de oxigênio e carbonato depositado espeleotemas, é controlada pelas variações na $\jmath^{180}$ da água infiltrada, a temperatura no interior da caverna e da umidade relativa do ar (Fairchild, 2006; Lachniet, 2009; Strikis, 2011). O fracionamento isotópico entre a fase líquida e o vapor pode ser calculado pela equação3.6 e 3.7 :

$$
\begin{gathered}
1000 \ln \alpha_{\text {liquid }- \text { vapor }}=1.137\left(10^{6} / \mathrm{T}^{2}{ }_{\mathrm{k}}\right)-0.4156\left(10^{3} / \mathrm{T}_{\mathrm{k}}\right) \\
-2.0667 \quad \text { (Equação 3.6) }
\end{gathered}
$$

$\mathrm{T}={ }^{\circ} \mathrm{K}$ y se refiere a la temperatura de cambio de fase

$$
\begin{array}{cc}
1000 \ln \alpha_{\text {liquid }- \text { vapor }}=1.137\left(10^{6} / \mathrm{T}^{2}{ }_{\mathrm{k}}\right)-0.4156\left(10^{3} / \mathrm{T}_{\mathrm{k}}\right) \\
-2.0667 & \text { (Equação 3.7) }
\end{array}
$$

$\mathrm{T}={ }^{\circ} \mathrm{K}$ y se refiere a la temperatura de cambio de fase

O modelo da "Destilação Rayleigh" (figura 3.3) explica fracionamento isótopos em sistemas abertos, e assume que ele pode ser usado para descrever os processos que sofreram os isótopos; para este modelo de único equilíbrio isotópico entre a fase de vapor e o condensado recém-formado (Brown, 2004).

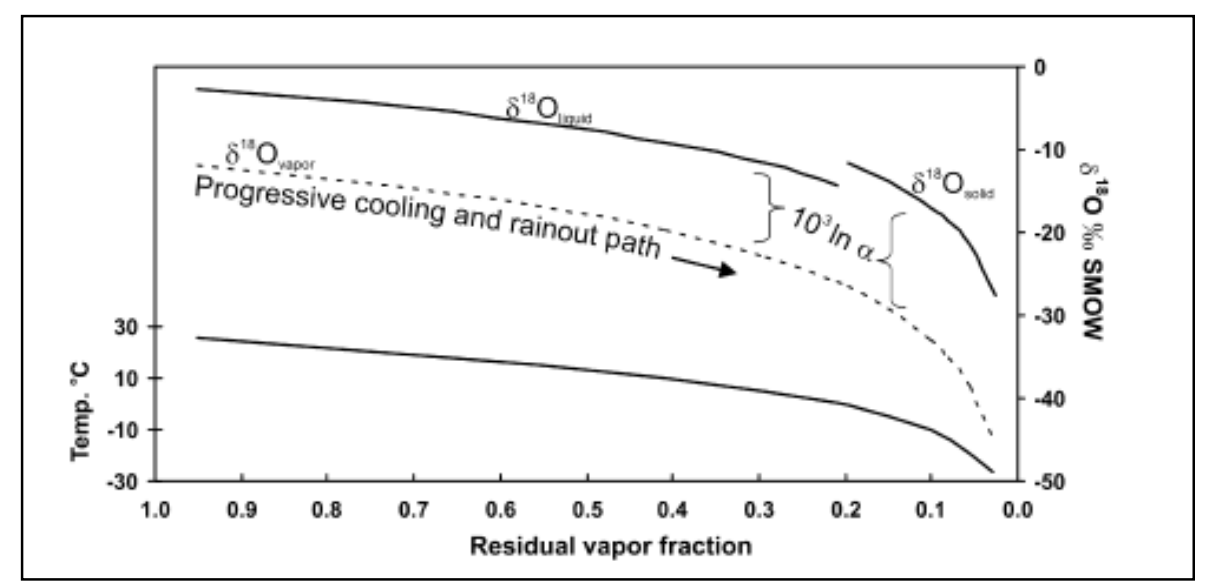

Figura 3.3. Variação de $\delta^{18} \mathrm{O} D$ pela fracção residual de vapor e a temperatura $\left({ }^{\circ} \mathrm{C}\right)$, no processo conhecido como Destilação Rayleigh; neste processo observa-se maior fracionamento do oxigênio pelo esfriamento progressivo e a chuva, além de ter relação com o descenso na temperatura. 
Quando a mudança de fase ocorre rapidamente fracionamento pode ser descrito em termos de cambio cinética, ou de não-equilíbrio, no qual fracionamento isotópico irá depender da taxa de difusão molecular das espécies isotópicas individuais em comparação com a molécula de água normal. Efeitos cinéticos ocorrer em ambientes com umidade relativa abaixo de $100 \%$, ou seja, onde há fortes ventos de superfície que removem o vapor (Merlivat e Jouzel de 1979, Brown, 2004).

Efeitos da temperatura, fonte, altitude, latitude e precipitação são consistentes com as variações nas proporções de isótopos ${ }^{18} \mathrm{O} /{ }^{16} \mathrm{O}$ da precipitação na área; em áreas localizadas nos trópicos os principais efeitos que ocorrem em ciclos interanuais nos isótopos chuva são as que dizem respeito a quantidade chuva e fonte de umidade (Brown, 2004); as temperaturas têm pouca variação sazonal no tropico, igualmente a altitude e a localização no continente são mantidos como constante, de modo que no ano as vaiáveis que mudam são as fontes de umidade e a quantidade de precipitação, refletido nas mudanças no fracionamento isotópico de oxigênio na área (Brown, 2004).

$\mathrm{O}$ efeito quantidade baseia-se na diminuição (esgotamento) dos valores de $\xi^{18} \mathrm{O}$ da água precipitada pelo aumento das chuvas; este efeito é dominante nos trópicos onde sistemas convectivos profundos (Craig e Gordon, 1965; Lachniet, 2009). Para os trópicos, este efeito tem sido bem documentado para estações específicas, mas também pode ocorrer em áreas extratropicais (Lachniet, 2009); as observações feitas pelo GNIP nas regiões tropicais os valores de ${ }^{18} \mathrm{O}$ são mais baixos em regiões com alta pluviosidade, incluindo a Zona de Convergência Intertropical (ZCIT) e Piscina Aquecida Pacífico Ocidental (Western Pacific Warm Pool) (Brown, 2004).

O efeito fonte é a observação de que deriva da mistura de fontes com valores de isótopos $\delta 180$ distintivo (Rozanski et al., 1993 Lachniet, 2009). Cada fonte de umidade tem valores de $\delta 180$ específicas ligadas aos processos de evaporação, umidade relativa e transporte a partir do site (Lachniet, 2009), pelo qual pode ser refletido nos valores na área de estudo. 


\subsection{Linha Meteórica de Água (MWL)}

$\mathrm{O}$ raio de difusão é aproximadamente a mesma em $\mathrm{HD}$ e $\mathrm{HO}_{2}{ }^{18}$ pelo qual o efeito cinético do fracionamento isotópico é semelhante, enquanto o fracionamento sobre o saldo HDO é 8 vezes mais elevado do que em $\mathrm{HO}_{2}{ }^{18}$ (Craig, 1961; Brown, 2004). Esta relação é descrita na correlação $\delta \mathrm{D}$ e $\delta^{18} \mathrm{O}$ na precipitação global, é dado pela linha de água meteórica global definida como (Figura 3.4):

$$
\delta \mathrm{D}=8 \delta^{18} \mathrm{O}+10 \% \text { o(Equação 3.8) (Daansgar, 1964) }
$$

$\mathrm{O}$ declive aproximado de 8 é determinada pelo raio de fracionamento em equilíbrio de $\delta \mathrm{D} / \delta 18 \mathrm{O}$ porque ambos respondem aos mesmos processos isotópicos (Lachniet, 2009); também resulta do processo de condensação e precipitação na destilação de Rayleigh, sob umidade relativa de cerca de $100 \%$ em um fracionamento em equilíbrio a $25^{\circ} \mathrm{C}$ (Brown, 2004).A intercepção da linha $+10 \%$ e o declive de 8 , é indicado como excesso de deutério é determinada pelo enriquecimento do vapor de água evaporado da superfície do oceano com uma umidade perto do $85 \%$ e uma temperatura de $20^{\circ} \mathrm{C}$ (Figura 3.4) (Dansgaard, 1964; Merlivatand Jouzel, 1979; Brown, 2004). A medida do excesso de deutério é:

$$
d=\delta \mathrm{D}-8 \delta^{18} \mathrm{O} \text { (Equação 3.9) }
$$

O excesso de deutério na precipitação pode ser de diagnóstico dos processos de evaporação, umidade, temperatura e velocidade do vento, e as condições climáticas do oceano que se situa como a área de origem da chuva; isto é possível se for assumido que os efeitos cinéticos de condensação e de pós-condensação não são significativos na área (Brown, 2004).Para as variáveis que influenciam o excesso de parâmetro deutério pode ser usado na determinação de fontes diferentes durante períodos úmidos sazonais ou ciclos anuais, é como uma impressão digital de fontes específicas (Lachniet de 2009).

As Linhas de Água Meteóricas Locais podem ser diferentes nos valores de intersecção e declive, em relação às medidas de isótopos ${ }^{18} \mathrm{O}$ e $\mathrm{D}$ característicos das variações regionais $\mathrm{e}$ temporais. Estas linhas meteóricas locais e seu desvio a partir da linha Global são 
importantes no estabelecimento de estudos paleoclimáticos com base em espeleotemas, pois permite avaliar a evaporação do solo e da água que se infiltra na caverna, no que diz respeito à precipitação limitando a resposta que o registro como eventos sazonais; da mesma forma permite observar relações das áreas de origem e mistura de umidade(Mattey et al., 2008;Lachniet, 2009).

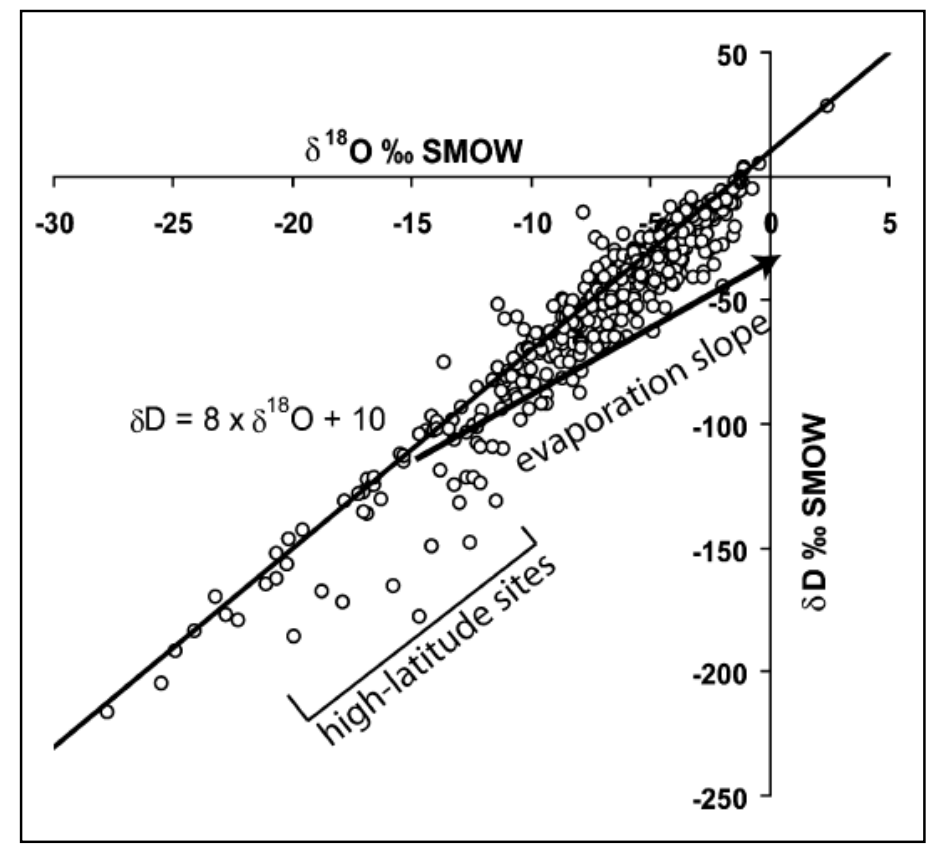

Figura 3.4 Linha Meteórica de Água Global que relaciona os dados de $\delta \mathrm{O}^{18} \mathrm{e} \delta \mathrm{D}$, feita com dados da Base de dados global da GNIP; contígua a Linha Meteórica de Água Global se tem a curva de variação dos valores de $\delta \mathrm{O}^{18}$ e $\delta \mathrm{D}$ nos processos de evaporação.

\subsection{Fatores que Afetam a Composicão Isotópica da Água de Gotejamento}

Após as mudanças que ocorrem na composição isotópica da água durante o ciclo hidrológico, que é o nosso interesse por causa de sua relação com as variações nos sistemas paleoclimáticos pode apresentar alguns outros processos de fracionamento isotópico de $\mathrm{O}$ e C, durante o tempo residência da água no solo e sua passagem pelo epickarste (Strikis, 2011). Os processos que podem levar ao fracionamento isotópico de $O$ e $C$ antes de ser precipitado espeleotemas e reflete na análise do sinal isotópico é o efeito reservatório 
vegetação / solo no carste aquífero e taxas de crescimento de espeleotemas(Strikis, 2011; Fairchild, 2006).

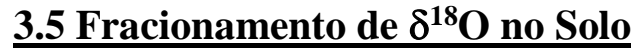

O fracionamento isotópico de $\delta 180$ no solo é mediada por processos de evaporação, transpiração, escoamento e intercepção de canais; igualmente os valores $\delta 180$ estarão relacionados com a quantidade de precipitação na área, evaporação e consumo de água pela vegetação para a evapotranspiração (Strikis, 2011).

Embora a quantidade de chuva na região faça com que os valores de $\delta^{180}$ mudem, a evaporação pode resultar num aumento d180 por processos de fracionamento explicado acima, enquanto isso, a evapotranspiração das plantas não modifique o sinal isotópico água porque nenhum fracionamento gera, no entanto influencia a quantidade de água no sistema Ao comer plantas (Lachniet, 2009; Strikis, 2011). O fracionamento isotópico associado com a evaporação pode ser equilibrado, em alguns períodos e áreas, pela intensidade das chuvas que podem recarregar o solo que tem baixos valores de $\delta^{18} \mathrm{O}$; no perfil do solo em áreas profundas os valores de $\delta^{18} \mathrm{O}$ são estáveis, devido à redução dos efeitos da evaporação na zona (Barnes e Allison, 1983; Lachniet, 2009).

Em áreas onde a cobertura vegetal é baixa e o clima é árido, estão sujeitos a valores $\delta^{18} \mathrm{O}$ maiores na água do solo; devido à alta taxa de evaporação, existem áreas em que a água subterrânea pode ser evaporada na sua totalidade; estas características são importantes para a compreensão dos padrões sazonais de crescimento sazonal de espeleotemas, especialmente em áreas com chuva e seca ciclos onde o crescimento está presente principalmente em períodos de elevada pluviosidade (Lachniet, 2009; Strikis, 2011).

Enquanto a vegetação não influencia o fracionamento isotópico pela evapotranspiração, uma alta densidade de vegetação na área pode afetar a evaporação da água através da sombra e da radiação solar que atinge no solo, o que influencia os valores de $\delta^{180}$ (Longinelli e Edmond, 1983; Gat, 1996; Lachniet, 2009). A relação entre os valores de $\delta^{18} \mathrm{O}$ nos processos das águas de chuva e de fracionamento que podem ser realizadas no 
solo podem ser medidos a partir de um monitoramento da água tanto dentro da caverna nas proximidades e no exterior, com que pode ser definida a relação entre a amplitude ou decaimento do sinal no sistema (Cruz, 2009; Strikis, 2011).

Com relação ao fracionamento isotópico $\mathrm{C}$, filtração de água, solo e tipo de vegetação são os fatores que influenciam principalmente. Em solo com elevadas concentrações de material orgânico tem uma maior formação de $\mathrm{H}_{2} \mathrm{CO}_{3}$, devido a altas concentrações de $\mathrm{CO}_{2}$ que é produzido pela vegetação e decomposição da matéria orgânica na área (Clark e Fritz, 1997; Strikis, 2011).

A composição de carbono orgânico (CO) em solos pode ser, entre outros, dependente do tipo de vegetação na área, como os valores de $\delta^{13} \mathrm{C}$ estão relacionados com o ciclo de metabolismo de plantas $\mathrm{C} 3$ e $\mathrm{C} 4$, os quais variam em intervalos definidos, mas que podem se sobrepuser. Plantas C3 estão associadas com plantas arbóreas com a característica de climas úmidos, e tem valores que variam entre -24 d13C \%o -30 \% (Pessenda, 1996); plantas C4 são gramíneas que são mais relacionadas a climas secos, e tem uma variação de d13C entre -10 a $-16 \%$ \%o (Pessenda, 1996).

Variações de valores $\delta^{13} \mathrm{C}$ em espeleotemas variam entre $2 \%$ e $-16 \%$ e estão associados com o carbono orgânico (CO) e carbono inorgânico dissolvido (DIC) na água de percolação que entrar na caverna (Strikis de 2011). Enquanto alguns autores relacionam a composição isotópica de C em espeleotemas com vegetação (Dorale et al, 1998),está também pode ter uma relação com a produtividade do $\mathrm{CO} 2$ biogênico e a erosão do solo, o que pode influenciar o $\delta^{13} \mathrm{C}$ dos espeleotemas(Cruz et al, 2006; Strikis, 2011).

\subsection{Recarga do Aquífero}

A composição isotópica da chuva em eventos específicos pode mudar ou ser mitigada através da mistura que ocorre com águas mais antigas localizadas na zona vadosa; teoricamente aquela mistura de água resulta num sinal isotópico diferente do presente na água da chuva. Em cavernas com pouca profundidade, onde a espessura da zona não saturada é pequena, o problema de misturar das águas novas com as velhas é minimizado 
pelo recorrido rápida das águas no sistema, a zona não saturada e precipitação em espeleotemas(Cruz et al, 2009; Strikis, 2011).

Cavernas com uma profundidade rasa geralmente são ideais para a realização dos estudos paleoclimáticos de alta resolução, devido que a água infiltrada no solo e que está na zona vadosa apresenta tempos de residência mais curtos. As cavernas com a zona vadosa mais profunda são aptas para estudos paleoclimaticos de uma resolução longa, igualmente o gotejamento de água nestas cavernas é mais constante ao longo do tempo e tem períodos temporais mais cumpridos (Cruz et al, 2009; Strikis, 2011). 


\section{MATERIAIS Y MÉTODOS}

\subsection{Coleta de Estalagmites}

Estalagmites coletadas na caverna Caracos foram coletadas como critérios de forma e evidência de atividade recente; foi dada preferência a formas cilíndricas que são ideais para estudos paleoambientais pela estratigrafia que podem mostrar (Fairchild et al, 2006). Os locais de amostragem das estalagmites foram localizados em salas e câmaras dentro das cavernas, com baixa circulação de ar e alta umidade para garantir a conservação do registro como foi explicado em capítulos anteriores.

A importância da escolha do local de amostragem é para a conservação do registro nas estalagmites, devido a redução do fracionamento cinético na precipitação de $\mathrm{CaCO}_{3}$ dentro do sistema (Fairchild et al. 2006); portanto, a coleta de amostras foi evitado em áreas

próximas às entradas da caverna, como fatores ambientais externos podem afetar a deposição de $\mathrm{CaCO} 3$ e registro isotópico dentro de espeleotemas, aumentando o fracionamento cinético pelo vento, umidade e as variações de temperatura (Lachniet, 2009). O rigor metodológico para a coleta das estalagmites é porque os critérios de seleção ajudam a garantir espeleotemas depositados continuamente com processos de baixa de dissolução.

\subsection{Preparacão de amostras para análise paleoclimáticas e amostras de datação radiométrica}

A preparação das amostras das estalagmites a datação e análises paleoclimática, começando com o corte longitudinal do espeleotemas, onde seja possível ver o eixo de crescimento e a estratigrafia, assim podem-se identificar os trechos de interesse para a obtenção das amostras para as datações. Ao cortar as estalagmites são utilizadas rodas de corte com pontas de diamante com espessura entre 1 e $2 \mathrm{~mm}$, para facilitar a observação das características mineralógicas e texturais das estalagmites, as amostras são polidas com a utilização do modelo de polidor Bosch GPO 12com polimento do grão de 220, 320 e 600, para o acabamento final.

Foram tomadas amostras das estalagmites para as datações geocronológicas principalmente no topo e a base, igualmente os trechos com hiatos na deposição ou mudanças no eixo de 
crescimento foram enfatizados. Nestas áreas específicas são amostrados os trechos anteriores e posteriores ao hiato, desta maneira pode-se localizar temporalmente a falta de registro. Na seleção das camadas para as datações, escolhem-se áreas onde os processos de dissolução não estão presentes e as colorações terrosas nas quais tem alto conteúdo de argilas são fonte de $\mathrm{Th}^{232}$ detrítico, que podem causar erros na obtenção de idades pelo método usado. A extração do $\mathrm{CaCO}_{3}$ das estalagmites para as datações através do método U/Th, foi feita por meio de um micromill de eixo flexível Dremel modelo; para cada amostra foi preciso 0,2 a $0,4 \mathrm{~g}$ de $\mathrm{CaCO}_{3}$.

Para o processo da toma das amostras para as analises paleoclimáticas primeiro foi calculada a taxa de crescimento para a definição da resolução da amostragem; logo da obtenção da resolução as amostras foram pegadas com resoluções que vão desde 0,14 mm até $0,4 \mathrm{~mm}$ segundo interesse nas temporalidades específicas.

\subsection{Datacão Geocronológica pelo método U/Th}

O processo de dissolução do carbonato de acumulação traz elementos traças nas águas de gotejamento que posteriormente vão estar nos espeleotemas formados; entre os elementostraço acumulados estão $\mathrm{Mg}, \mathrm{Sr}, \mathrm{Ba}$ e $\mathrm{U}$, e sua concentração depende principalmente da concentração na rocha hospedeira e são co-precipitados da calcita nos espeleotemas (Scholz e Hoffmann, 2008). A concentração de U em espeleotemas é relevante por causa do papel que desempenha na datação pelo método de decomposição U/Th (Scholz y Hoffmann, 2008).

Isótopos $\mathrm{U}^{234}$ e $\mathrm{Th}^{230}$ estão em equilíbrio na rocha hospedeira, no entanto, no processo de dissolução deste comportamento geoquímico de cada um deles é diferente do equilíbrio inicial; Th é naturalmente insolúvel em água de modo a que a sua concentração na água de gotejamento é zero, em contraste a relação entre $U^{234} / U^{238}$ é maior na água de gotejamento que ocorre no saldo de rocha original (Scholz e Hoffmann, 2008). A relação entre os isótopos $\mathrm{U}^{234} / \mathrm{U}^{238}$ na água por gotejamento depende da idade da rocha e do tempo disponível para sua dissolução, de modo que água de percolação lenta e elevado tempo de residência tem uma alta concentração de $U^{234} / \mathrm{U}^{238}$; Em contraste, a elevada precipitação 
que envolve uma alta percolação e baixo tempo de residência, leva uma baixa concentração de $U^{234} / U^{238}$ num sistema fechado (Scholz e Hoffmann, 2008).

Embora as premissas acima sejam as premissas básicas para a determinação da concentração dos isótopos de $\mathrm{U}^{234} / \mathrm{U}^{238}$ nas estalagmites, esses critérios nem sempre são cumpridos devido à contaminação por diagênese, contribuição de material detrítico, entre outras questões; igualmente os câmbios de um sistema fechado a um aberto fazem que as concentrações mudem, pois as condições antes mencionadas só aplicam nos sistemas fechados. No entanto o não cumprimento destas premissas não exclui a aplicação do método de datação por decaimento de $U^{234} / U^{238}$, e os procedimentos que têm sido sugeridos como: i) correção para contaminação Th detritico usando estimativas a priori da composição, e ii) determinação indireta da composição isotópica do Th (Scholz y Hoffmann, 2008).

Considerando-se os critérios para a concentração de $U$ e Th isótopos e suas exceções, considera-se que as camadas superiores são mais jovens do que a inferior, e que estes espeleotemas tem um crescimento desde o chão até o teto. No entanto, podem-se apresentar casos de inversão das idades da estalagmite, o que demonstra que ela: i) teve um sistema post-deposicional aberto, ii) correção inadequada pela contaminação detritica, iii) erro durante a análise ou a preparação das amostras (Scholz y Hoffmann, 2008).

As datações foram realizadas no Laboratório de Geocronologia, Departamento de Geologia e Geofísica da Universidade de Minnesota, nos Estados Unidos da América, com o espectrômetro de massa tipo ICP-MS (InductuvelyCoupled Plasma MassSpectrometry), modelos Finningan Elements e Finningan Neptune, de acordo com os procedimentos estabelecido por Shen et al. (2002). A preparação de amostras para as datações pelo método de decaimento de U/Th segue os protocolos mencionados por Strikis (2011).

A massa de $\mathrm{CaCO}_{3}$ analisada varia de acordo com a concentração de $\mathrm{U}$ estimada para cada estalagmite; normalmente utiliza-se $0.2 \mathrm{~g}$ de amostra, mas em casos de amostras contendo altas concentrações de $\mathrm{U}$ (> $1 \mathrm{ppm})$, utiliza-se por volta de $0.1 \mathrm{~g}$. A amostra é posta em um béquer de teflon e em seguida dissolvida com adição de HNO3 7N. Constatada a completa dissolução da amostra, adicionamos à solução o spike contendo ${ }^{236} \mathrm{U}_{-}{ }^{233} \mathrm{U}-{ }^{229} \mathrm{Th}$ e depois 4 
gotas de $\mathrm{HClO}^{4}$. O número de gotas de $\mathrm{HClO}^{4}$ varia de acordo com a relativa quantidade de matéria orgânica presente na amostra. Em algumas amostras as impurezas associadas à matéria orgânica são muito visíveis logo após a dissolução; nesses casos deve ser adicionado por volta de 7 gotas de $\mathrm{HClO}^{4}$. Para garantir a completa homogeneização entre a amostra e o spike, o béquer de teflon contendo a amostra é tampado e posto para aquecer por 20 minutos em uma chapa quente. Em seguida a tampa do béquer é removida e a amostra é posta para secar por completo. Ao final, um precipitado de cor branca é formado no fundo do béquer.

Tendo finalizado o processo de abertura e adição de spike, é feita a precipitação de Fe para concentração dos íons pesados e eliminação do Ca da amostra. O precipitado formado é dissolvido com $\mathrm{HCl} 2 \mathrm{~N}$ e então a solução é transferia para um tubo de ensaio onde adicionamos previamente cerca de 2 a 3 gotas de solução rica em ferro. Em seguida é feito o procedimento para precipitação de óxidos de Fe pela adição gradativa de gotas de $\mathrm{NH} 4 \mathrm{OH}$ até que a solução atinja o ponto de saturação. Na sequência, os tubos são cobertos com parafilme e postos para centrifugar. Após a centrifugação todo o sobrenadante é dispensado e, ao tubo de ensaio, é adicionada água deionizada e então a amostra é posta novamente para centrifugar. Esse procedimento é realizado 3 vezes. Ao término da última centrifugação o precipitado é redissolvido com $\mathrm{HNO} 37 \mathrm{~N}$ e retorna ao béquer de teflon.

Finalizada essa etapa, a amostra é posta para secar por completo em uma chapa quente ao final do processo um pequeno precipitado com dimensões milimétrico a submilimétrica é depositado no fundo do béquer. O precipitado é então dissolvido com aproximadamente 3 gotas de $\mathrm{HClO} 4$ e em seguida posto para secar por completo. A mesma amostra é dissolvida com aproximadamente 2 gotas de HNO314N, retorna à chapa quente até a solução evaporar por completo. Após repetir procedimento com a utilização de algumas gotas de HNO3 7N ela estará pronta para ser introduzida às colunas de troca aniônica.

Para a separação de U e Th são utilizadas pequenas colunas, com aproximadamente $7 \mathrm{~cm}$ de comprimento. As colunas são montadas com a resina SPECTRA/GEL® ION EXCHANGE Ix8. Antes de receber as amostras as colunas são condicionadas de acordo com o seguinte procedimento: 
- Adiciona-se água deionizada de modo a preencher todo o volume do reservatório superior por duas vezes. Na segunda vez é adicionada uma gota de HNO3 14N;

- Em seguida adiciona-se HNO3 7N em duas etapas. Cada uma delas com a adição de cerca de 2/3 do volume do reservatório da coluna.

Finalizada essa etapa, a coluna está pronta para receber a amostra. A amostra é então despejada com cuidado dentro da coluna e a eluição dos reagentes é realizada de acordo com os seguintes passos:

- Após toda a amostra ser adsorvida pela coluna, é adicionado $2 / 3$ do volume do reservatório com $\mathrm{HNO} 3$ 7N.

- Em seguida adiciona-se 1/3 do volume do reservatório com HNO3 7N.

- Após a última adição de HNO3 7N atravessar toda a coluna, troca-se o béquer usado para a coleta das soluções despejadas por um béquer de teflon devidamente limpo para dar início à coleta de coleta de Th.

- Para a coleta de Th adiciona-se 2/3 do volume reservatório com $\mathrm{HCl} 6 \mathrm{~N}$ e em seguida repete-se o procedimento.

- Após todo $\mathrm{HCl}$ 6N ter atravessado a coluna inicia-se a coleta de U.

- É feita a troca dos béqueres de teflon usado na coleta de Th por aqueles utilizados anteriormente na manipulação da amostra.

- Para a coleta de U adiciona-se água deionizada por quase todo o reservatório da coluna. Em seguida repete-se o procedimento mais uma vez e a coleta de U está feita.

Finalizada a coleta de $\mathrm{U}$ e Th, são adicionadas 2 gotas de $\mathrm{HClO} 4$ ao concentrado que segue para chapa quente para evaporar por completo. Após isso, nota-se a formação de um pequeno precipitado escuro submilimétrico que é dissolvido com 1 a 2 gotas de $\mathrm{HClO} 4$ e 
posto para evaporar por completo. Em duas etapas semelhantes adiciona-se mais 1 a 2 gotas de HNO3 14N para nova evaporação por completo. Por fim, são adicionadas algumas gotas de solução padrão para análise em ICP-MS (solução preparada em uma garrafa de $1 \mathrm{~L}$ formada por uma mistura de água deionizada com 1\% HNO3 14N e algumas gotas de HF). A partir desse ponto os concentrados de $U$ e Th estão prontos para as análises espectrométricas em ICP-MS. Os cálculos das idades foram, de modo geral, realizados com base nas razões isotópicos medidas e fatores de correção para eliminar efeitos de contaminação de Th detrítico (Edwards et al.1986; Richards; Dorale, 2003). As precisões obtidas, na maior parte das datações, foi dê $1 \%$ ou inferior, segundo estimativa $2 \sigma$.

A partir dos dados geocronológicos obtidos pelo método U-Th, são determinadas as taxas de crescimento das estalagmites, de modo que a resolução de amostragem para obter amostras de calcite para as análises dos isótopos estáveis de oxigênio e carbono são determinadas para fazer uma recolha contínua quanto possível.

A amostragem para as análises de $\mathrm{CaCO}_{3}$ foi feita com o micro-amostrador Sherline 5400, em conjunto com um medidor digital de distância entre os pontos, o qual permite resoluções de até $0.4 \mathrm{~mm}$; Cada ponto de amostragem é perfurado com uma broca de aço de carbono de 0,2 milímetros de diâmetro é extraído uma quantidade aproximada de 200 mg de pó.

As amostras são analisadas no Laboratório de Isótopos Estável do Centro de investigações geocronológicos (LIE - CPGeo) do Instituto de Geociências da Universidade de São Paulo (IGc-USP), no espectrômetro de massas de fonte gasosa modelo Delta Plus Advantage (Thermo Finningan). O princípio básico dos procedimentos analíticos na obtenção de isótopos de $\mathrm{O}$ e $\mathrm{C}$ é a remoção de $\mathrm{CO} 2$ libertado pela hidrólise ácida de $\mathrm{CaCO} 3$ com H3PO4, a uma temperatura controlada de $72^{\circ} \mathrm{C}$. Uma vez que as amostras são injetadas com Hélio (He) em cada um dos frascos, de modo a preparar o meio antes da libertação do produto a partir da reação do carbonato com os gases ácidos; subsequentemente é feito o gotejamento de $\mathrm{H} 3 \mathrm{PO} 4$. Um sistema constituído por um coletor triplo de O/C faz com que a determinação da composição isotópica de $\mathrm{CO} 2$ no espectrómetro através de uma fonte de iões; os resultados das análises são baseados na análise de dez repetições de cada amostra e comparação com amostras padrão. 
As razões isotópicas são expressas com a notação de delta ( $\delta$ ), que é determinada como a diferença entre o valor medido da amostra e do padrão de referência (equação 1), para nossas analises foram utilizadas quatro amostras de referência cuja composição foi calibrada em relação ao padrão internacional V-PDB (Vienna Pee Dee Belemnite), usado para rochas carbonáticas.

$$
\begin{aligned}
& \delta^{18} \mathrm{O}=\left(\left(^{18} \mathrm{O} /{ }^{16} \mathrm{O}\right) \text { amostra }-\left({ }^{18} \mathrm{O} /{ }^{16} \mathrm{O}\right) \text { padrão }(\text { Equação 4.1) }\right. \\
& \left({ }^{18} \mathrm{O} /{ }^{16} \mathrm{O}\right) \text { padrão } \\
& \delta^{18} \mathrm{O}=\underline{\left({ }^{18} \mathrm{O} /{ }^{16} \mathrm{O}\right) \text { amostra }}-1 \text { (Equação 4.2) } \\
& \left({ }^{18} \mathrm{O} /{ }^{16} \mathrm{O}\right) \text { padrão }
\end{aligned}
$$

\subsection{Analises da Água Chuva}

Para as análises dos isótopos de deutério e oxigênio, foram coletadas amostras de água da chuva uma vez por semana na cidade de El Peñon (Santander) em frascos de 10, 15, 30, 60 ou $120 \mathrm{ml}$, armazenadas no coletor de chuva instalado no município; a obtenção de uma fraç̧ão representativa de precipitação durante o período de tempo, tendo em vista que a composição isotópica de água no coletor é homogênea. A coleta de chuva semanal de água na área foi realizada a partir de dezembro de 2012 a janeiro de 2014, para um total de 58 amostras, o que lhe permite ver as variações na precipitação e seus registros de isótopos por um ano.

A preparação das amostras para análise de deutério e oxigênio isótopos na água de chuva é levado num vial de 2 ul de tamanho; as amostras são analisadas no espectrômetro tipo PICARRO, o qual se baseia na evaporação de 1ul de água, e a partir do sinal de laser e o decaimento no infravermelho são determinados os valores de $\delta^{18} \mathrm{O}$ y $\delta \mathrm{D}$. Para a verificação dos dados são usados 9 padrões de referência para a comparação, algum com caráter internacional e outros nacionais; estes padrões são denominados VSMOW, GISP, NANOP, SLAP, ALAB, PG-1, e apresentam amplos valores que possam abranger rangos 
importantes das variações nas amostras analisadas, assim pode-se ter uma maior confiança estatística.

\begin{tabular}{|c|c|c|}
\hline Padrão & d(18_16)Mean & d(D_H)Mean \\
\hline NANOP & 0,0 & $-28,8$ \\
\hline VSMOW & 3,6 & $-6,7$ \\
\hline GISP & $-20,0$ & $-185,4$ \\
\hline SLAP & $-50,2$ & $-420,7$ \\
\hline ALAB & $-1,9$ & $-41,2$ \\
\hline PG-1 & 3,5 & $-3,5$ \\
\hline
\end{tabular}

Tabela 4.1 Valores dos padrões de comparação dos dados da água de chuva no processo da analises no espectrômetro tipo PICARRO no Laboratório de Geocronologia da Universidade de Brasília (UnB). Os padrões de comparação apresentam amplos registros de valores de $\delta \mathrm{O}^{18} \mathrm{e} \delta \mathrm{D}$, para um maior ajuste estatístico.

Os intervalos de valores aceitáveis para as leituras de dados de oxigênio e deutério feitos pelas análises do PICARRO estão entre 17000 e 23000 ppm, quando os valores saem destes intervalos as análises não estão dentro do rango de confiança os resultados obtidos pela equipe não são precisos. Cada amostra é lida cinco vezes, como processo estatístico padrão feito pelo equipamento.

Subsequente com os resultados obtidos pelo PICARRO, os resultados são analisados no software estatístico Chemical Correcta partir do qual a repetição dos resultados das amostras, os intervalos dos valores de vapor analisados e as variações entre os resultados obtidos no equipamento, obtidas razões isotópicas de oxigênio e deutério em amostras de água da chuva.

\subsection{Método de tratamento de séries temporais}

Uma série temporal é qualquer conjunto de dados organizados de acordo com um intervalo de tempo, o que ajuda na análise e identificação de propriedades fundamentais para a 
quantificação de uma série de recursos que ajudam a compreender os ciclos do passado e prever o comportamento futuro do sistema analisado (Novello, 2012).

Intervalos de tempo presente da série paleoclimáticos entre pontos são marcadas pela resolução do registo; os dados são então interpolados linearmente entre o namoro geológico, de modo que o registro passa a ser composto de séries temporais entre as datações (Novello, 2012). A análise de séries temporais construídos com o registro paleoclimáticas contribui, sobretudo para determinar:

- Comportamentos periódicos ou aleatórios da série;

- Em caso de comportamento periódico, determinar a frequência desses ciclos, quando a frequência aumenta ou diminui.

- Períodos em que os ciclos são mais intensos

- Para quantificar a relação de semelhança entre diferentes registros ou índices, tanto em frequência como o respectivo comportamento da série histórica.

\subsection{Transformada de Fourier}

A análise a partir da Transformada de Fourier e sua aplicação mais prática o FFT (Fast Fourier Transform) tem o objetivo de transformar uma função de tempo "f(t)" em uma função dependente da frequência, de modo que você possa verificar a contribuição de energia de determinadas frequências para determinar uma série temporal (Novello, 2012).

Qualquer função periódica pode ser escrita em forma de uma somatória de senos e cossenos, tal como:

$$
F(x)=a_{0}+\Sigma_{k=l}\left(a k \cos (k x)+b_{x} \operatorname{sen}(k x)\right)(\text { Equação 4.3) }
$$

Os coeficientes $a_{0}$, ake $b_{k}$ podem ser calculados a partir de integrais dafunção $f(x)$, inserindo parâmetros de contorno (Butkov, 1988). A transformada deFourier da função $f(x)$ é definida por: 


$$
F(\omega)=\int_{-\infty}^{\infty} f(t) e^{-i \omega t} d t
$$

A frequência obtida a partir da transformada de Fourier, são comparados com os gráficos de ondoletaspara determinação de ciclos principais presentes no registro depaleoclimatico. Para mais informações sobre as funções implementadas na análise de séries temporais com Transformada de Fourier pesquisa de paleoclima, pode ser visto no trabalho Novello (2012).

\subsection{REDFIT}

A análise por REDFIT é uma série de procedimentos implementados por SCHULZ; MUDELSEE (2002) baseados no peridiograma de Lomb, para obter um espectro de densidade espectral semelhante ao FFT. Nessa análise são consideradas sobreposições de "janelas" formadas pela divisão dos dados, com base em um ajuste para altas frequências ou ruído vermelhoe testes para oscilações aleatórias que não tenham significado no que diz respeito ao comportamento do sinal, conhecido como ruído branco. Os testes de significância dessa análise são baseados nos métodos de Monte Carlo e $\chi^{2}$ (Ghil et al., 2002; Novello, 2012).

\subsection{Analises de Coerência}

A função de coerência mede entre dois sinais testando se eles apresentam frequências similares. A magnitude da coerência é medida de uma escala que vai de 0 a 1 , onde a semelhança dos dois sinais o valor é 1 , e quando se a coerência é igual a 0 , os sinais são totalmente não relacionados para aquela frequência (Novello, 2012).

A coerência pode ser definida por:

$$
C_{x y}(\omega)=\frac{\left|S_{x y}(\omega)\right|^{2}}{S_{x x}(\omega) S_{y y}(\omega)}
$$


(Equação 4.5)

Onde é a energia da densidade espectral de correlação entre os dois sinais distintos $\mathrm{x}$ e $\mathrm{y}$, enquanto e são as densidades espectrais de x e y, respectivamente. $S_{x y}, S_{x x}$ e $S_{y}$.

Os sinais são quebrados em várias seções decompostos por frequências usando a análise a FFT. O tamanho da seção da FFT, o tipo e tamanho da janela, e o número de superposições dos dados podem afetar o resultado. Dessa forma, as escolhas são feitas de acordo com o sinal de entrada.

\subsection{Análise de Ondoletas}

Análise de Ondoletas com dados paleoclimáticos tem como objetivo a exibição de períodos onde ocorrem eventos cíclicos no registro, além da intensidade destes. Na análise do sinal é decomposto em níveis de resolução e ajustada para uma determinada função de onda através de uma transformação da série e uma função de onda (Novello, 2012); em estudos paleoclimáticos a função mais utilizada para as análises de ondoletas é tipo Morlet, uma função não ortogonal onda modulada por um plano de Gauss (Strikis, 2011). O termo ondoleta refere-se a um conjunto de funções de ondas " $\Psi(t)$ " geradas por dilatação, $\Psi(\mathrm{t}) \rightarrow \Psi($ at $)$, e translação $\Psi(\mathrm{t}) \rightarrow \Psi(\mathrm{t}+\mathrm{b})$.

$$
\Psi_{0}(n)=\pi^{-1 / 4} e^{i w} 0^{n} e^{-n 2 / 2}(\text { Equação } 4.6)
$$

Onde $w_{0}$ é uma frequência não y $n$ é um tempo não dimensional. A transformada de ondoleta continua de uma serie $X n$ é definida como a convolação de $X n$.

O resultado da análise de ondoletas é um gráfico tridimensional, em que a intensidade de eventos periódicos é mostrada em um índice de cor; o eixo vertical mostra os períodos em 
uma escala exponencial (de base 2 geralmente), e o eixo horizontal mostra o tempo que é a mesma série de paleoclima. 


\section{RESULTADOS}

\subsection{Resultados Geocronológicos e Taxas de Crescimento}

As estalagmites coletadas para este estudo foram selecionadas com base em critérios de deposição ativa dentro das cavernas a fim de cobrir os registros do Holoceno. Diante do exposto foram selecionados 3 espeleotemas CAR1, CAR2 e CAR3. As três estalagmites pertencem à caverna Caracos, localizada no departamento de Santander, Colômbia; junta, as três estalagmites recobrem o intervalo de tempo compreendido pelo Holoceno Meio e Tardio. Ao todo foram realizadas 25 datações pelo método U-Th para os últimos 5300 anos, com um erro instrumental próximo de $1 \%(2 \sigma)$. Igualmente, para os efeitos da presente pesquisa, foram selecionadas estalagmites com altas taxas de crescimento, a fim de se obter resoluções anuais e decenais para o período de tempo estudado.

As idades das estalagmites estão distribuídas em uma sequência crono-estratigráfica normal, na qual as idades mais antigas estão localizadas na base e as mais recentes no topo. Localmente, em algumas seções da sequência, a estratigrafia pode ser interrompida ou mesmo serem registrados inversões geocronológicas em virtude de processos de dissolução ou suspensão da precipitação do carbonato; nestes trechos a amostragem para datação é feita de modo a contornar os hiatos temporais, coletando-se amostras no topo e base do hiato, no sentido de melhor delimitar temporalmente o evento de alteração da amostra. O hiato deposicional mais amplo obtido para as três estalagmites ocorre entre 761 e 672 anos BP, no período da Anomalia Climática Medieval (MCA) e durante a Pequena Idade do Gelo (LIA pelas siglas em Ingles).

A distribuição de idade para as três estalagmites com os hiatos e interposição de amostragem são apresentados na figura 5.1. Na estalagmite CAR1 foram realizadas 10 datações pelo método U/Th, fornecendo um registro que se estende desde 1497 anos BP até o ano 2011, quando a estalagmite foi coletada. A seção mais antiga de CAR1 é depositada

entre 1497 até 761 anos BP. Neste trecho foram realizadas sete datações ao longo do período de tempo compreendido pela Anomalia Climática Medieval (ACM entre $~ 900 \mathrm{e}$ $1100 \mathrm{AD}$ ou 850 e 1050 B.P. ) com resultados de 936, 1047, 1124 B.P.; a seção mais recente para essa estalagmite ocorre entre 251 anos BP até o presente, com taxa de 
crescimento variando entre $0,2 \mathrm{~mm} / \mathrm{ano}$ a $0,42 \mathrm{~mm} /$ ano no trecho recente, e $0,2 \mathrm{~mm} /$ ano no trecho mais antigo.

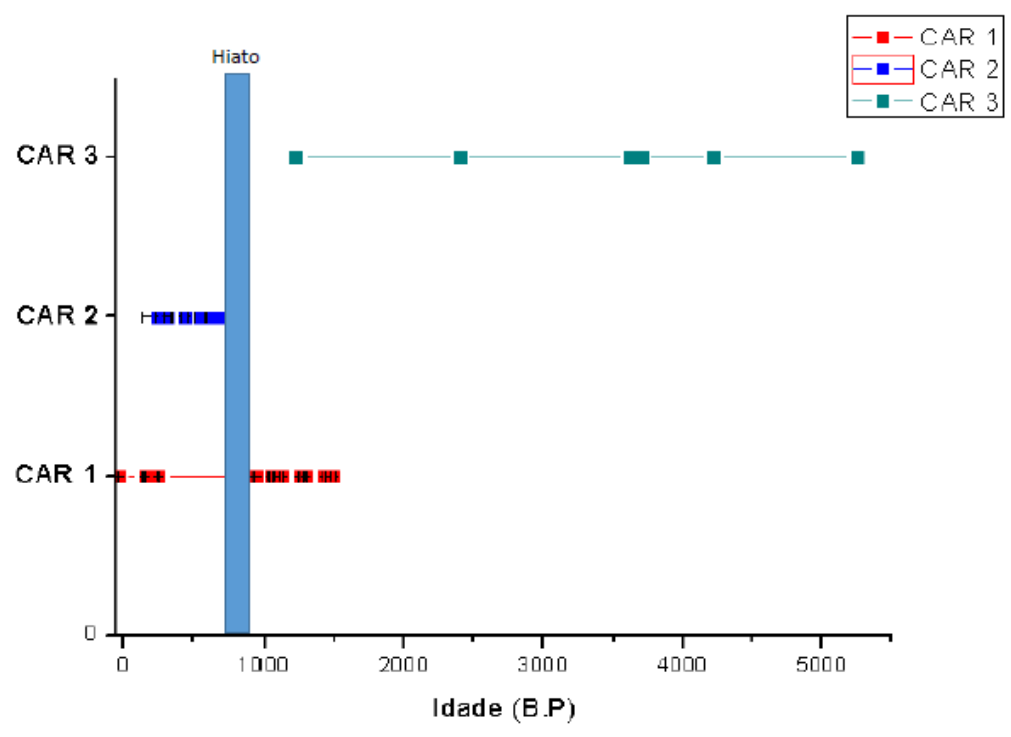

Figura 5.1 Intervalos de deposição das estalagmites coletadas na região de El Peñon (Santander, Colômbia) que apresentaram idades holocênicas, com o nome dos espeleotemas no eixo vertical. Os pontos destacados são referentes a posição das idades U-Th. 
a)

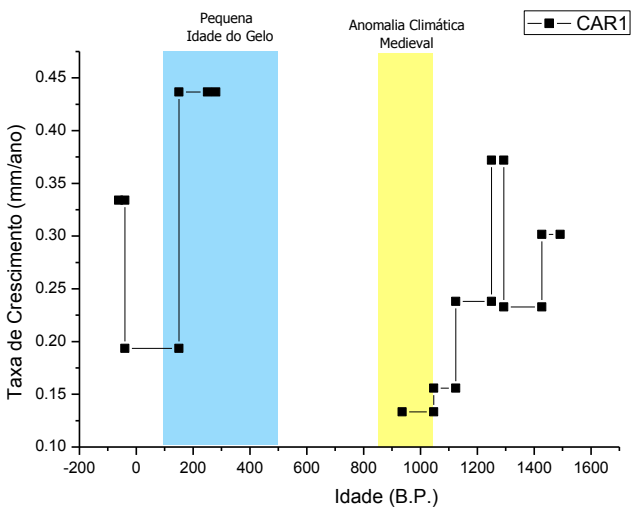

c)

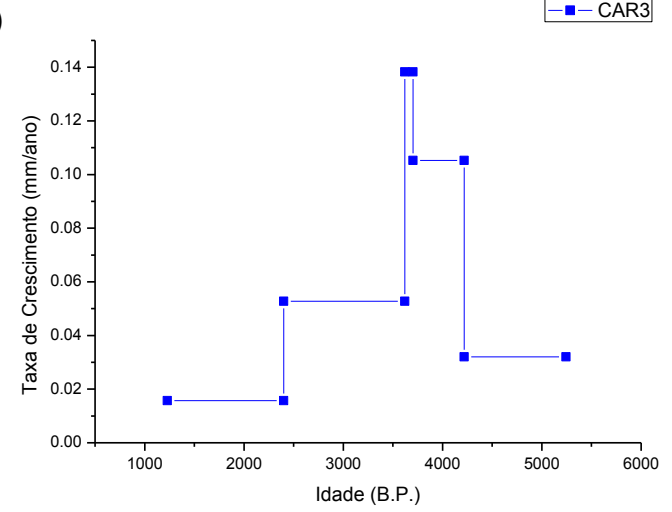

b)

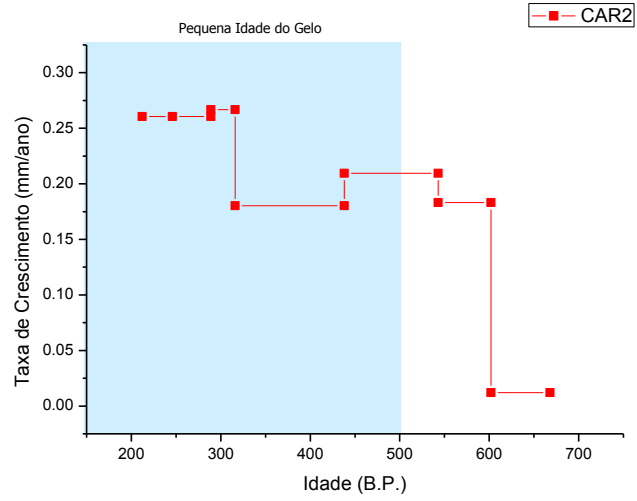

d)

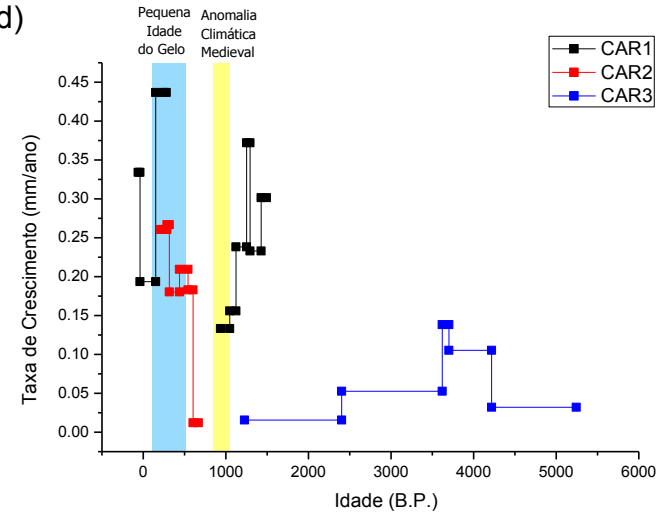

Figura 5.2. Taxas de crescimento das estalagmitesCAR1, CAR2 e CAR3: a) Taxas de crescimento de CAR1 com variações entre $0,2 \mathrm{~mm} /$ ano até $0,42 \mathrm{~mm} / \mathrm{ano}$, apresenta um hiato entre 761 e 251 anos BP.; b) A estalagmite CAR 2 tem uma deposição continua entre 602 até 246 anos BP, a taxa de crescimento aproximada é de $0,2 \mathrm{~mm} /$ ano.; c). A deposição da estalagmite CAR3 é continua entre 5244 até 1227 anos $0,034 \mathrm{~mm} /$ ano no setor mais antigo, seguido por taxas de 0,103 e $0,052 \mathrm{~mm} / \mathrm{ano}$, e 0,07 ; d) variação da taxa de crescimento ao longo dos últimos 5 mil anos para o conjunto de estalagmites estudadas.

O registro da estalagmite CAR 2 compreende o intervalo entre 212-672 anos B.P, com uma deposição contínua ao longo da estalagmite. Ao todo, para essa estalagmite, foram realizadas 8 datações $\mathrm{U} / \mathrm{Th}$ com erros ao redor de $1 \%(2 \sigma)$. O registro de CAR2 cobre parte do período de tempo referente ao hiato deposicional registrado na estalagmite CAR1, no entanto permanece um hiato entre o período no qual se encerra o registro da CAR2 e o início da sessão mais antiga da CAR1 (figura5.2d). A taxa de crescimento da estalagmite CAR 2 é aproximadamente de 0,4 mm/ano, com taxas de crescimento relativamente constantes ao longo da maior parte do tempo (Figura 5.2b). 
O período registrado pela estalagmite CAR 3 vai desde 1227 a 5244 anos B.P, com uma deposição contínua ao longo do registro. Ao todo foram realizadas 7 datações U/Th cobrindo o intervalo de tempo de 4000 anos do registro (Figura 5.1). O número de datação para este exemplo não permite a análise de alta resolução tal como o proposto para as estalagmites CAR1 e CAR2, no entanto, variações abruptas das taxas de crescimento obtidas para essa estalagmite apontam para a ocorrência de eventos de escala centenial no controle das taxas de deposição. As variações mais significativas estão concentradas na transição entre o Holoceno Médio e Tardio, como pico ao redor de 4.2 e 3.6 mil anos BP, cerva de mil anos após o Ótimo climático do Holoceno (Renssen et al., 2009). As taxas de crescimento de CAR3 apresentam variações da ordem de 0,034mm/ano a 0,103 mm/ano (Figura 5.2).

As variações na deposição dos espeleotemas são relacionadas às mudanças nas condições ambientais do sistema cárstico (Clark e Fritz, 1997; Fairchild et al., 2006; Boch et al., 2011) tais como: umidade do ar, atuação de correntes de ar na caverna, Ph da solução de infiltração e, mudanças da concentração de CO2 da atmosfera da caverna que, por sua vez, exerce grande influência na deposição de carbonato controlando a taxa de degaseificação (Fairchild et al., 2006; Boch et al., 2011).

Determinar as taxas de crescimento das estalagmites pode ser útil no sentido de estabelecer relações entre as taxas de deposição de carbonato no sistema cárstico com variações do regime hidrológico na área de estudo. Como é possível observar na figura 5.3, variações da taxa de crescimento, sobretudo nas estalagmites CAR2 e CAR3 apresentam boa relação com variações dos dados isotópicos de $\delta^{18} \mathrm{O}$. Durante a LIA e no Holoceno médio, no evento próximo de 3.9 mil anos BP, excursões abruptas mais negativas de $\delta^{18} \mathrm{O}$, relacionadas a períodos de aumento de umidade, encontram boa relação com aumento da taxa de crescimento dos espeleotemas analisados. No entanto, nem sempre a variação nas taxas de crescimento tem relação direta com as variações de precipitação e com a água disponível no sistema. Outros processos que afetam o crescimento das estalagmites são: a quantidade de água infiltrada, a temperatura regional, $\rho \mathrm{CO} 2$ no solo e na concentração de cálcio na solução de infiltrados (Strikis, 2011). Pesquisa no Brasil (Cruz et al, 2006 e 
Strikis de 2011) e na França (Drysdale et al, 2004), encontraram uma relação entre as taxas de deposição e produtividade biológica no solo.
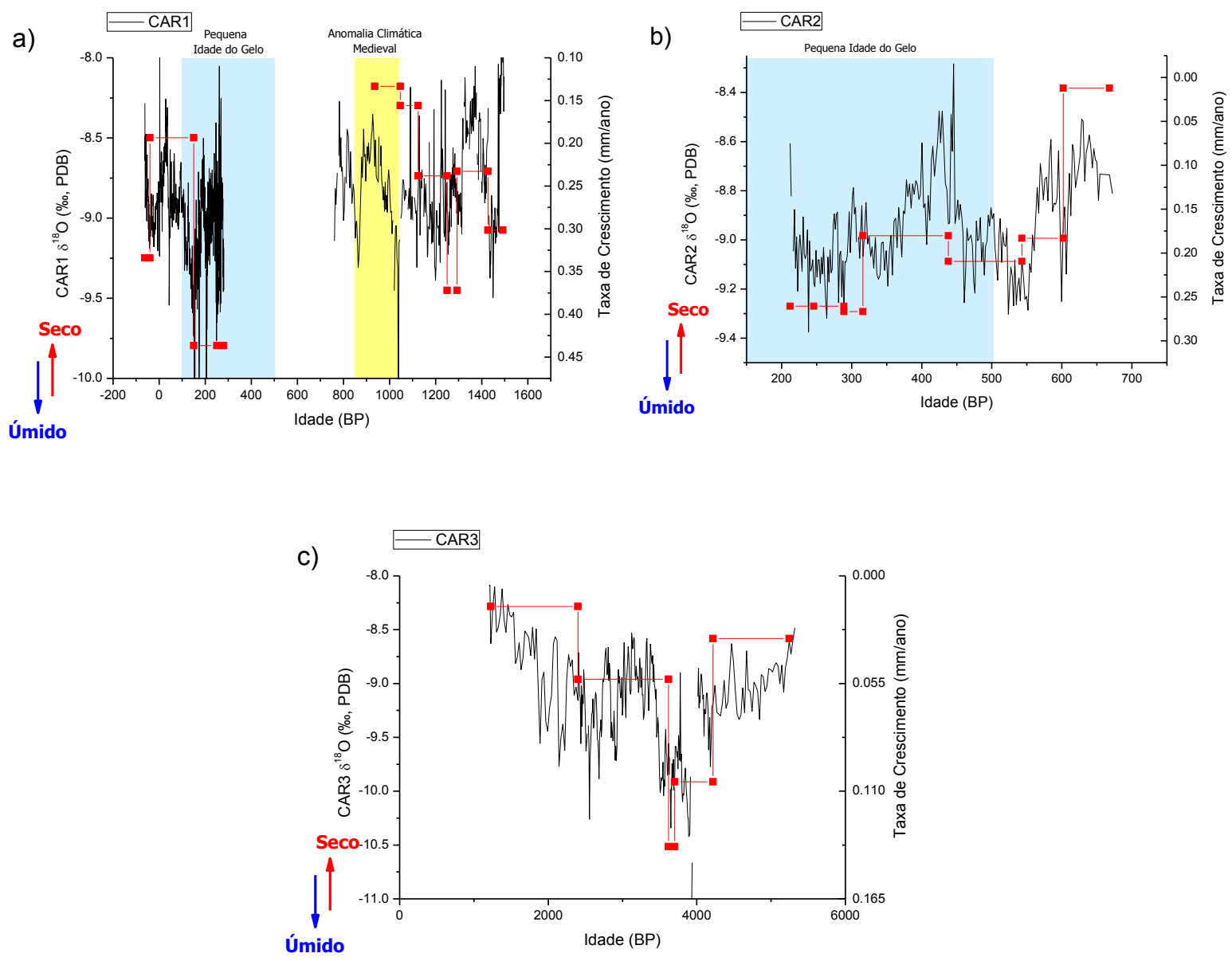

Figura 5.3 - Comparação entra as taxas de crescimento em (mm/ano) com o sinal isotópico de $\delta^{18} \mathrm{O}$ das estalagmites CAR1 (a), CAR2 (b) e CAR3 (c). Note a inversão da escala da taxa de crescimento.

Os períodos assinalados anteriormente, referentes às variações de $\delta^{18} \mathrm{O}$ e taxa de crescimento para as estalagmites CAR2 e CAR3, apresentam relação coerente com as variações de $\delta^{13} \mathrm{C}$. Como é possível observar na figura 5.4 e 5.5 os valores de $\delta^{13} \mathrm{C}$ apresentam covariação positiva com os dados de $\delta^{18} \mathrm{O}$ e covariação negativa com a taxa de crescimento. Durante a LIA (estalagmite CAR2) e o Holoceno médio (estalagmite CAR3) o aumento da taxa de crescimento é concomitante com o decréscimo nos valores de $\delta^{13} \mathrm{C}$ e 
vice-versa (Figura 5.4). A boa relação estabelecida entre $\delta^{18} \mathrm{O}$ e $\delta^{13} \mathrm{C}$ para os espeleotemas analisados (figura 5.5) reforça a hipótese que relaciona a variação do $13 \mathrm{C}$ com produtividade orgânica dos solos e liga as variações da taxa de crescimento a taxas de dissolução do carbonato encaixante.

a)

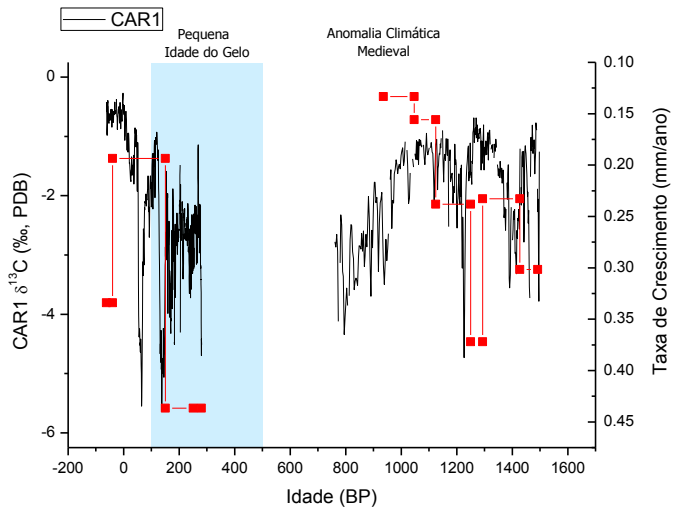

b)

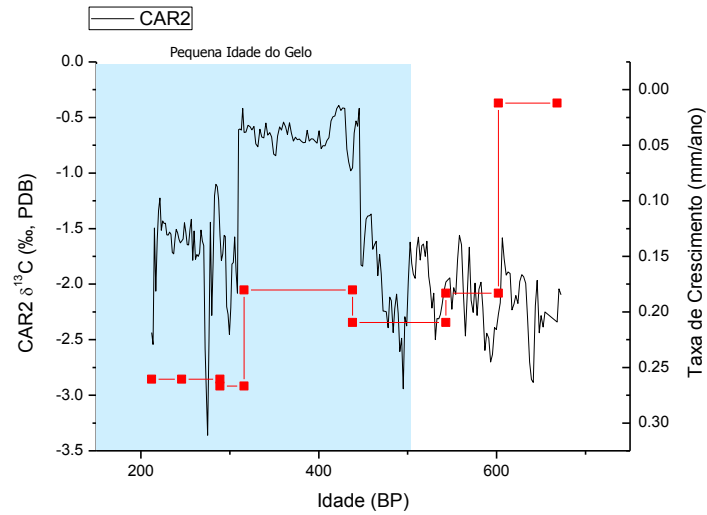

c)

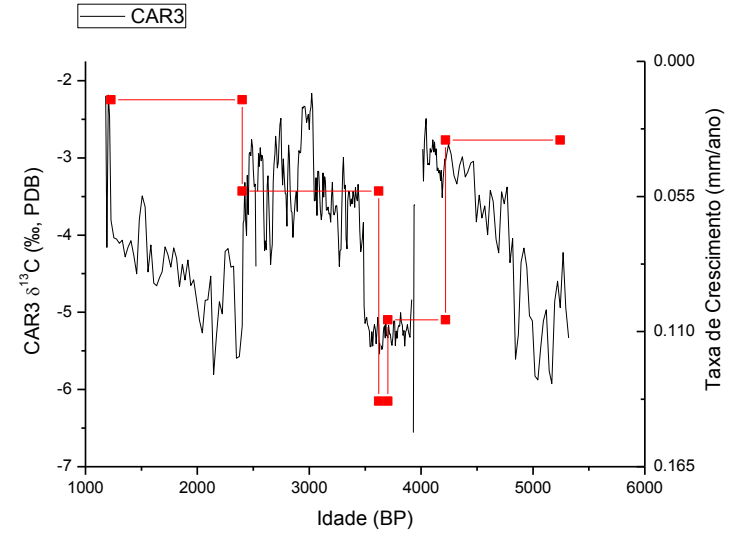

Figura 5.4 - Comparação entra as taxas de crescimento em ( $\mathrm{mm} / \mathrm{ano}$ ) com o sinal isotópico de $\delta^{13} \mathrm{C}$ das estalagmites CAR1 (a), CAR2 (b) e CAR3 (c). Note a inversão da escala da taxa de crescimento. 

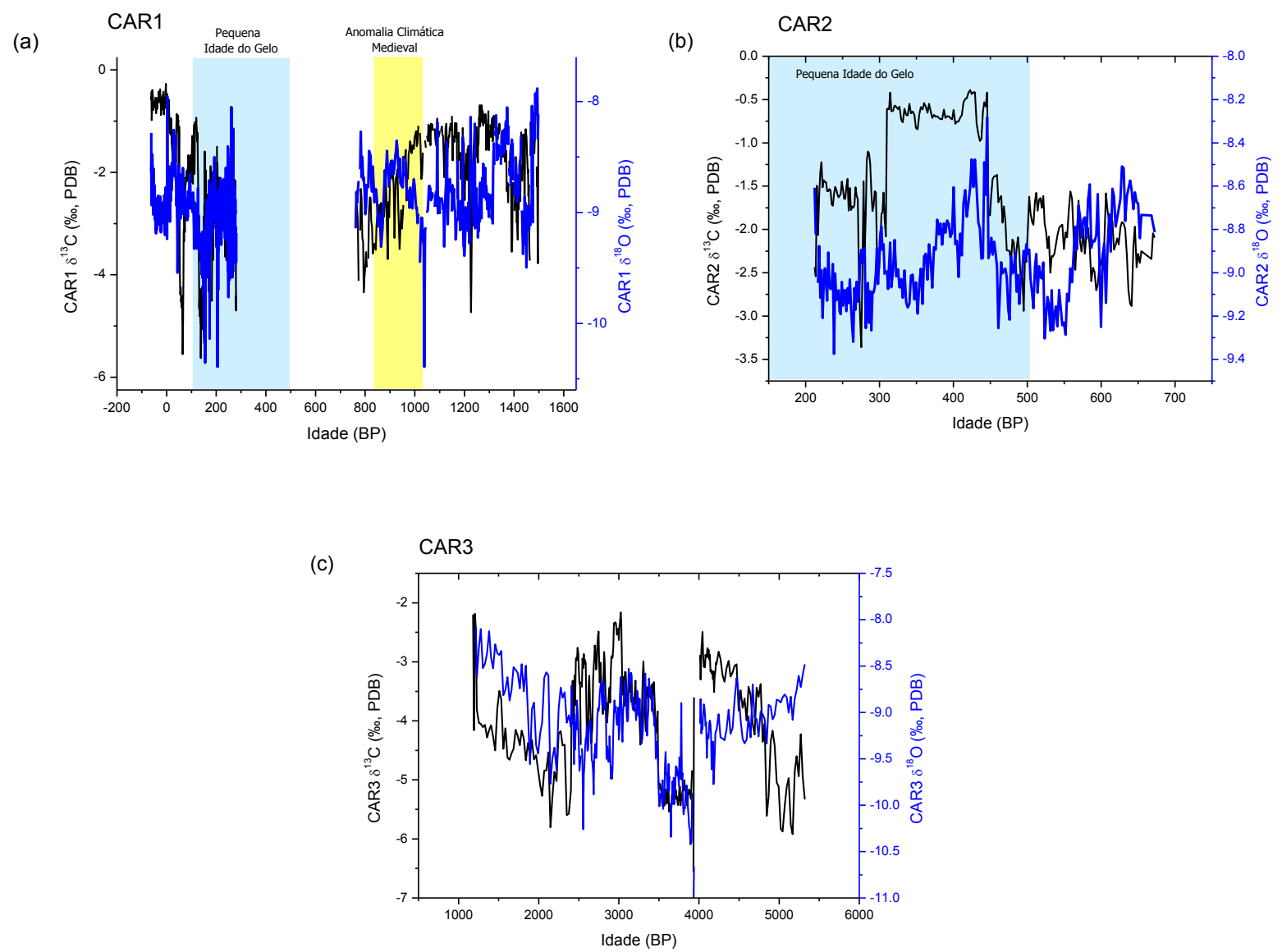

Figura 5.5 - Comparação entre os resultados isotópicos de $\delta^{18} \mathrm{O}$ e $\delta^{13} \mathrm{C}$ das estalagmites CAR1 (a), CAR2 (b) e CAR3 (c).

\subsection{Monitoramento de Chuva na Área}

No sentido de caracterização os processos de fracionamento isotópico atuantes sobre precipitações de chuva da área estudo, foi montado um programa de monitoramento isotópico da água de chuva, realizado entre dezembro de 2012 e janeiro de 2014. Também foram analisados os registros de precipitação e isótopos de hidrogênio e oxigênio na região de Bogotá ao longo dos últimos 40 anos pela Agência Internacional de Energia Atômica (AIEA, por sua sigla em Inglês).Bogotá está localizado ao sul da área de estudo, no planalto Cundiboyacence a uma altitude de 2600 metros, na Cordilheira Oriental da Colômbia. Na cidade foram tomados dados de precipitação mensal e isótopos de hidrogênio e oxigênio pela AIEA desde 1971 continuamente até 1990, posteriormente retomada amostragem 1998-2009. 
A precipitação anual em Bogotá varia entre 800-1100 mm de água e está ligada a variações nos sistemas de umidade que entram do Atlântico, Pacífico e, em menor medida, no Amazonas. Esta mistura de fontes, bem como variações na precipitação, é representada nas razões isotópicas de $\delta^{18} \mathrm{O}$ e $\delta \mathrm{D}$ da água da chuva. As chuvas ocorrem praticamente ao logo de todo ano, com registros de precipitações em todos os meses (Figura 5.6). Os períodos de menor precipitação são observados entre junho e agosto e entre dezembro e fevereiro (Figura 5.6). Por sua vez os períodos mais chuvosos ocorrem entre de março a maio e retomado entre setembro e novembro (figura 5.6).

No monitoramento isotópico realizado em Bogotá os valores $\delta^{18} \mathrm{O}$ da água da chuva mostram variações mensais entre $-4 \%$ e $-13 \%$. Os meses com os maiores valores ocorrem entre dezembro e março, quando são registrados os menores acumulados de chuva na área. Os valores mais negativos entre -11\%o e -13 \%o são observados entre abril e julho, meses nos quais são registrados os maiores acumulados de chuva. Durante os meses de agosto-novembro o $\delta^{18} \mathrm{O}$ exibe variação entre $-8 \%$ e $-11 \%$.A variação mensal dos valores de $\delta^{18} \mathrm{O}$ está inversamente relacionado com os volumes de precipitação de chuva na área, conforme explicado em capítulos anteriores sobre os processos de fracionamento isotópico do oxigeno no ciclo hidrológico.

A relação entre quantidade de chuva e a razão de $\delta^{18} \mathrm{O}$ na água coletada mostra uma tendência linear na maioria dos valores de referência (figura 5.7). Exceções podem ser observadas para os meses de abril e outubro cujas variações relativas de acumulados não encontram boa correspondência com os valores isotópicos de $\delta^{18} \mathrm{O}$ (Figura 5.6).Os dados de $\delta^{18} \mathrm{O}$ obtidos no monitoramento de Bogotá também foram comparados com as variações de temperatura na região no sentido de determinar possíveis relações entre o fracionamento isotópico e a temperatura. Contudo, em função da baixa amplitude térmica comumente observada para as zonas tropicais $\left(\sim 5^{\circ} \mathrm{C}\right)$ a relação entre essas variáveis é quase zero. 


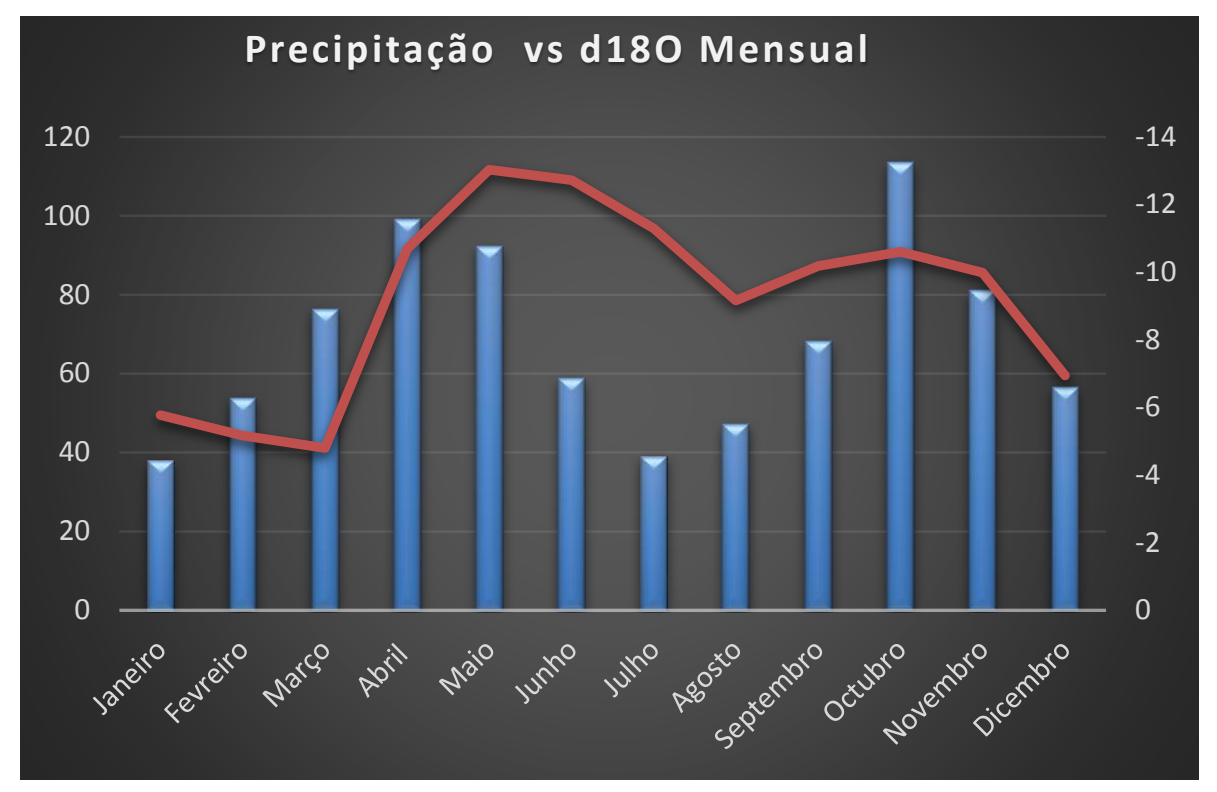

Figura 5.6 Variações da quantidade de chuva mensal em Bogotá (Colômbia) comparada com as mudanças no registro de $\delta^{180}$ na água de chuva no mesmo período. Observa-se uma relação entre a quantidade de chuva e o fracionamento isotópico do Oxigênio, no entanto no segundo período de chuvas na área (Setembro até Novembro) a relação da quantidade de chuva e fracionamento isotópico do Oxigênio varia sendo mais fraca possivelmente pela influência na mudança de fonte de umidade.

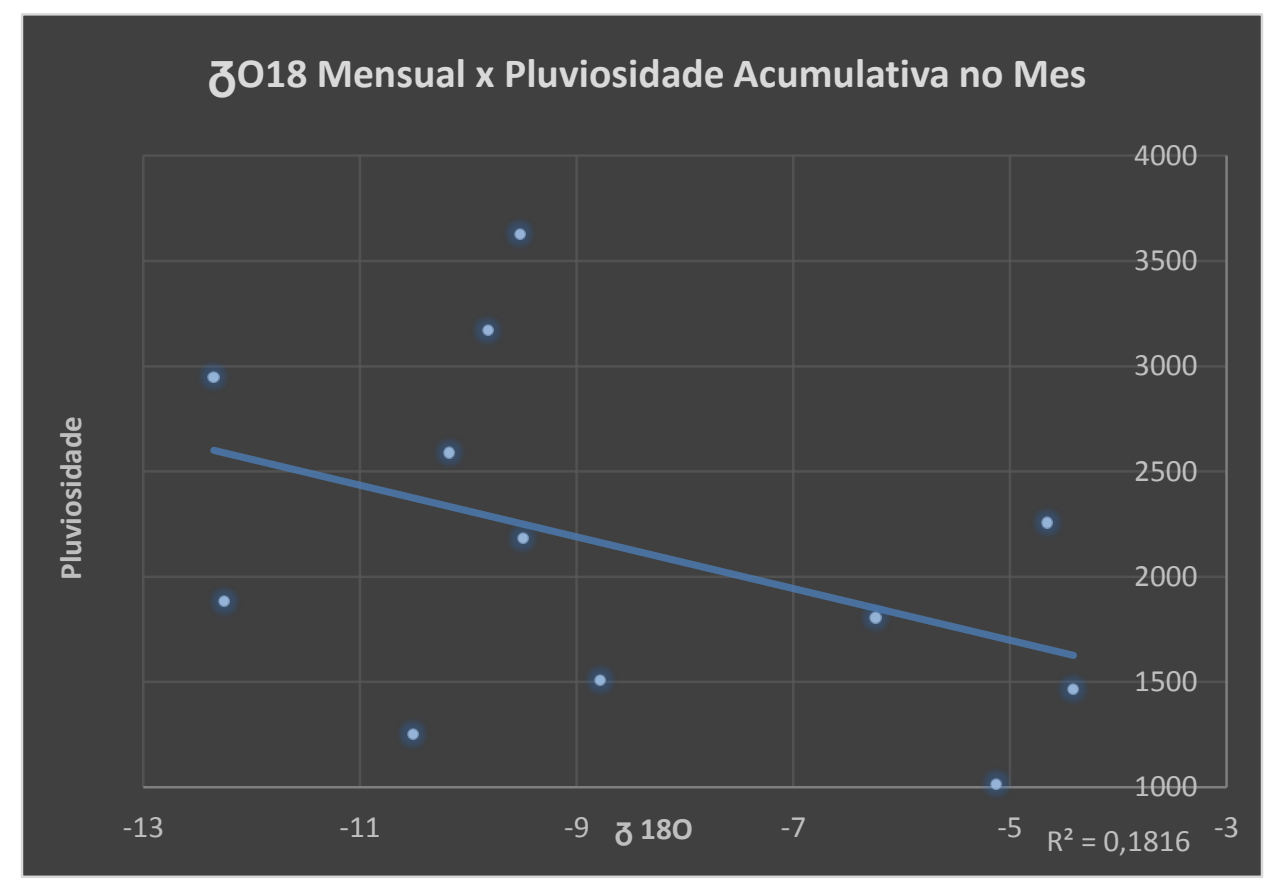

Figura 5.7 Covariância do acumulado de quantidade de chuva mensal e o fracionamento isotópico de Oxigênio para cada mês, mostrando relacionamento entre ambas variáveis; porém alguns meses apresentam um desvio da reta pela relação com a mudança de fonte 
Na área de estudo, localizada no município de El Peñon (Santander), o monitoramento da água da chuva começou desde dezembro de 2012 até janeiro de 2014. Os dados isotópicos de $\delta^{18} \mathrm{O}$ da água da chuva apresentam valores entre $-1 \%$ e $-15 \%$. Os valores mais elevados de $\delta^{18} \mathrm{O}$ são observados durante os meses de dezembro a março, quando são registrados os menores acumulados mensais da série de monitoramento. Do mesmo modo, durante os meses de abril-agosto os valores de $\delta^{18} \mathrm{O}$ são mais negativos, perto de $-15 \%$, concordante com o pico de precipitações registrado em maio no início da estação chuvosa. Nos meses que se seguem entre agosto e novembro os valores de $\delta^{18} \mathrm{O}$ apresentam valores intermediários entre -7 \%o e -9 \%o e estabelecem um platô concordante com o volume dos acumulados.

Os gráficos comparativos entre chuvas e o fracionamento do $\delta^{18} \mathrm{O}$ mostram uma relação entre os isótopos de chuva com o efeito quantidade, sendo está mais forte durante a segunda temporada de chuvas, quando são registrados os maiores acumulados (Figura 5.8). Entretanto, a amplitude de variação da razão isotópica de $\delta^{18} \mathrm{O}$ é consideravelmente maior durante a primeira temporada de chuvas. A relação entre chuva e $\delta^{18} \mathrm{O}$ tem uma tendência linear (figura 5.9) com índice de correlação de Pearson de -0.59. Essa relação é mais forte para os dados do primeiro semestre, entre janeiro a junho. Já para os dados da segunda metade do ano, as variações do $\delta^{18} \mathrm{O}$ não é afetado tão fortemente pelo efeito quantidade.

Quando comparadas com os dados de excesso de deutério, as variações de $\delta^{18} \mathrm{O}$ registradas na segundo metade do ano apontam para a influência de diferentes fontes de umidade entre as chuvas da primeira com a dá segundo metade dos anos para a área de estudo. Estas fontes de umidade que atuam em El Peñon podem gerar relações discrepantes entre o $\delta^{18} \mathrm{O}$ e a quantidade de chuva em comparação a estação de Bogotá. Em adição a baixa amplitude térmica intersazonal registrada em El Peñon, em torno de $2{ }^{\circ} \mathrm{C}$, exclui o efeito da temperatura no controle sazonal da composição isotópica das precipitações (Figura 5.10). 


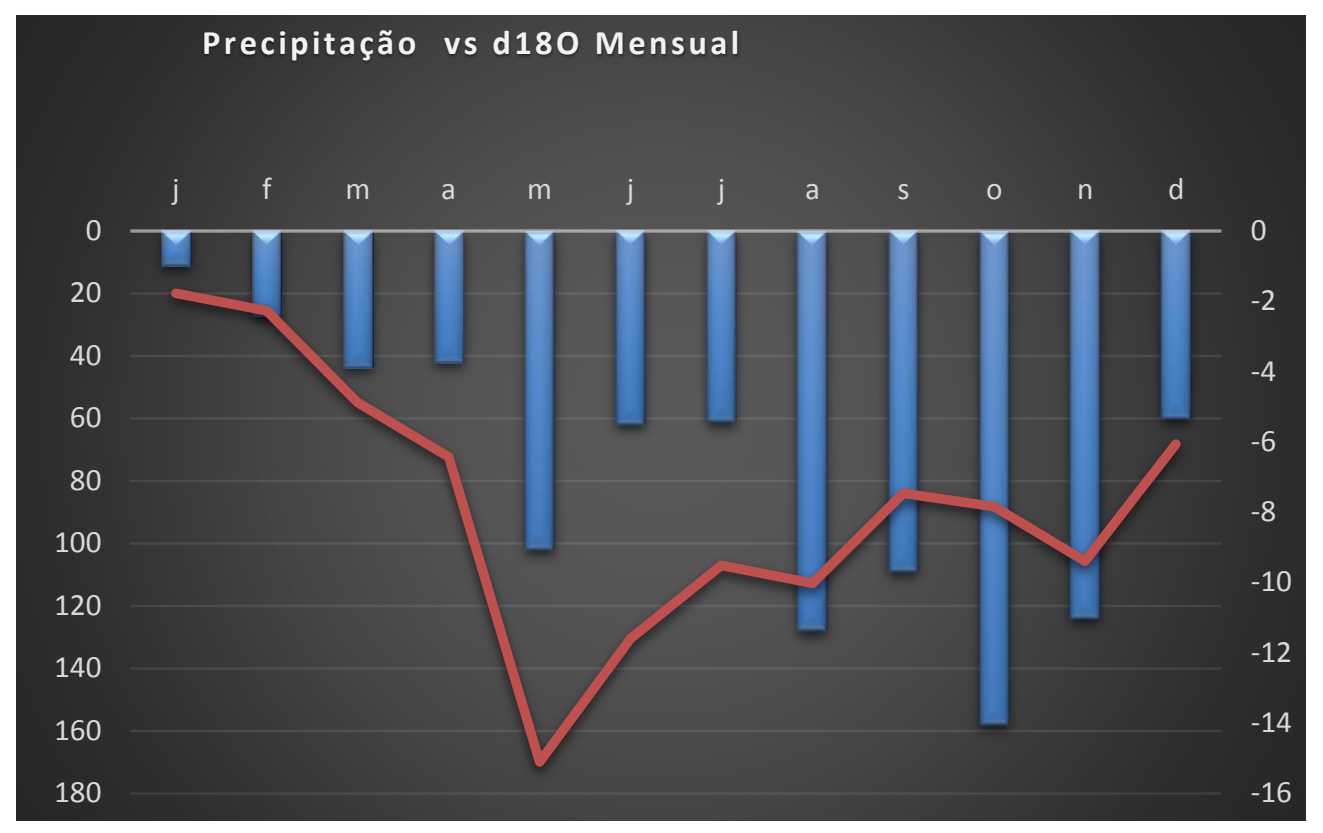

Figura 5.8 Variação da quantidade de chuva mensal em El Peñon (Colômbia) comparada com as mudanças no registro de $\delta^{180}$ na água de chuva no mesmo período. Observa-se uma relação entre a quantidade de chuva e o fracionamento isotópico do Oxigênio, no entanto no segundo período de chuvas na área (Setembro até Novembro) a relação da quantidade de chuva e fracionamento isotópico do Oxigênio varia sendo mais fraca possivelmente pela influência na mudança de fonte de umidade, justamente no período de influência das fontes provenientes do Pacifico pelo Chorro de Choco.

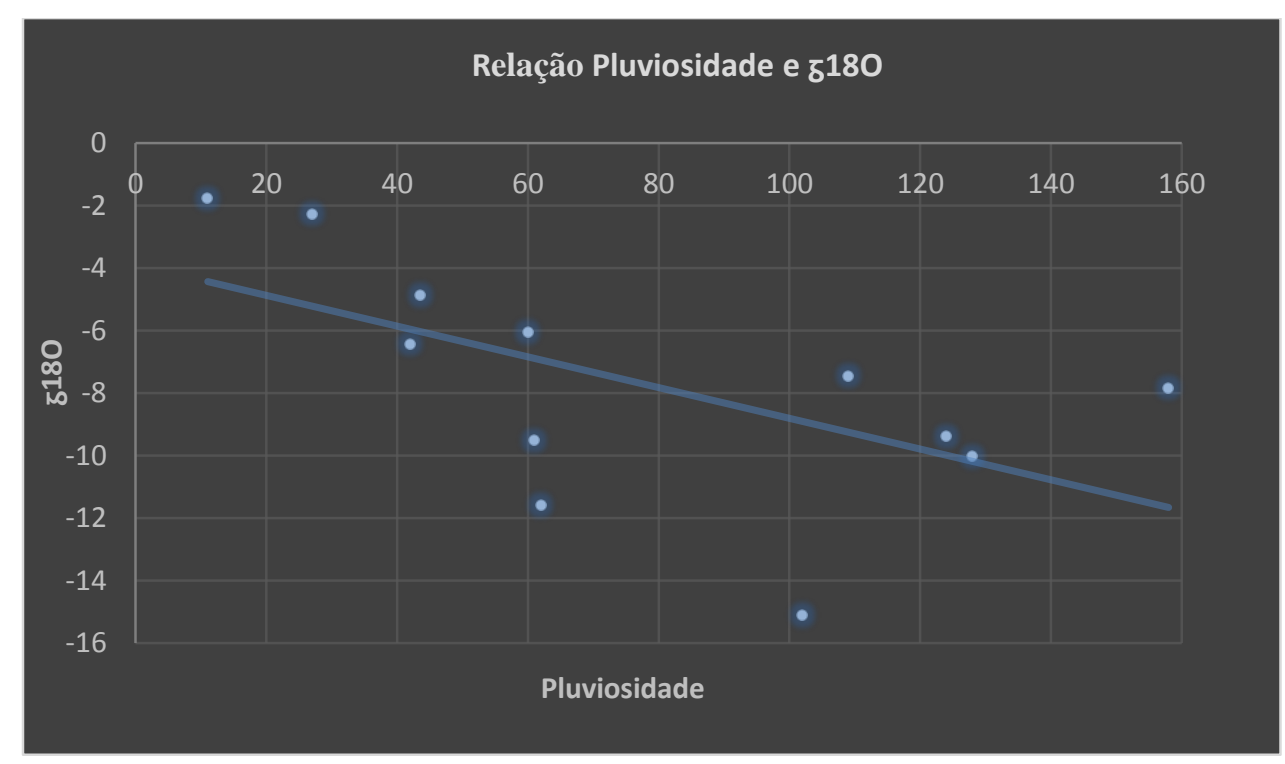

Figura 5.9 Covariância do acumulado de quantidade de chuva mensal e o fracionamento isotópico de Oxigênio para cada mês em El Peñon (Colômbia), tendo um relacionamento entre ambas variáveis; porém alguns meses apresentam um desvio da reta pela relação com a mudança de fonte 


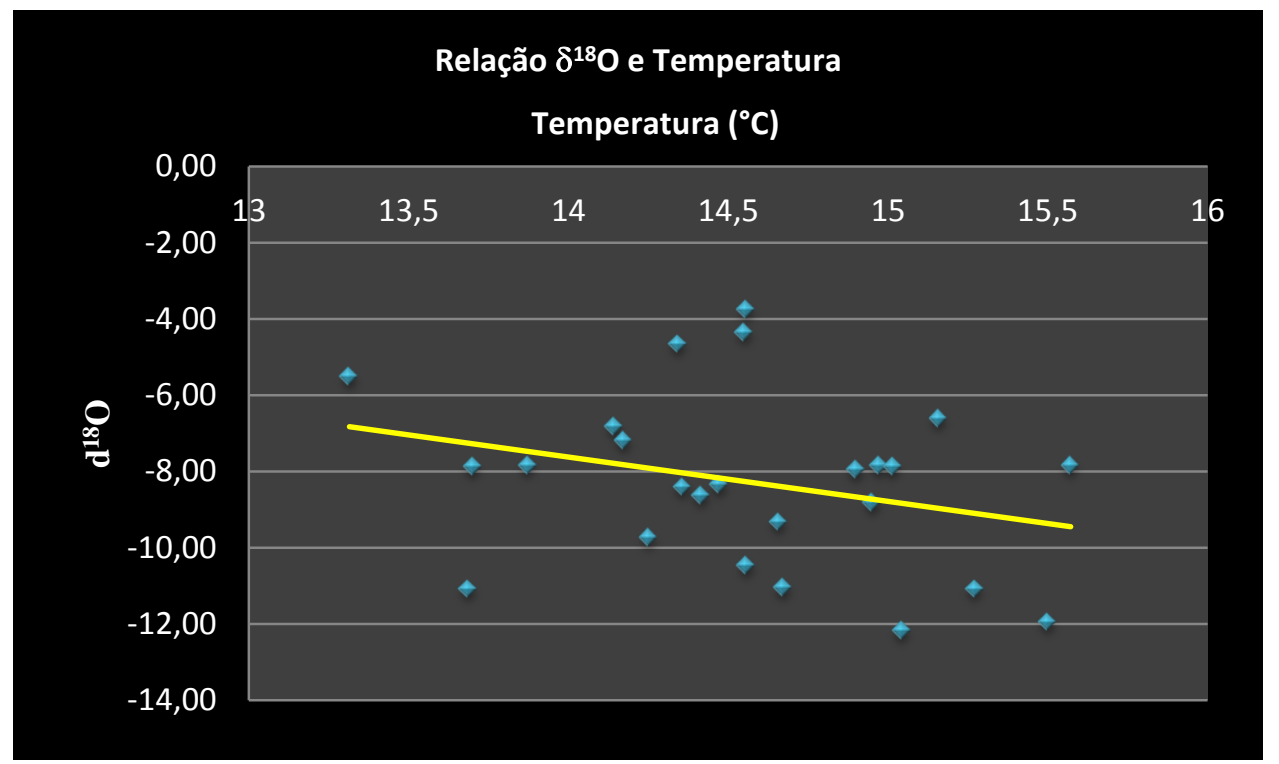

Figura 5.10 Relações na variação do $\square^{18} \mathrm{O}$ e a temperatura em El Peñon (Colômbia), mostrando uma falta de influência no fracionamento isotópico e os câmbios na temperatura; a localização da área de estudo no tropico faz que a variação sazonal da temperatura seja menor de $3^{\circ} \mathrm{C}$.

\subsection{Linha Meteórica Local}

Atualmente os valores $\delta^{18} \mathrm{O}$ e excesso de deutério em águas meteóricas, mostram uma relação estreita com alguns padrões climáticos, tais como a evaporação, umidade relativa e temperatura do ar (Rozanski, 1993) tanto na origem como nos processos subsequentes a que estão submetidos a água na atmosfera, como explicado nos capítulos anteriores.

A correlação linear entre $\delta^{18} \mathrm{O}$ e $\delta \mathrm{D}$ das precipitações que ocorrem no planeta define a linha meteórica global, representada pela sigla GMWL do inglês "Global Meteoric Water Line”. Essa linha traduz o fato das precipitações de chuva ocorrerem em condições de equilíbrio termodinâmico, de modo que a razão isotópica de oxigênio e deutério da chuva são controladas pelo fator de fracionamento $\alpha$ entre a fase vapor e líquido e que, no caso do deutério, é 8.13 vezes maior que o do oxigênio (Rozanski et al., 1993; Clark e Fritz, 1997; Lachniet, 2009). Em caso de evaporação parcial da água amostrada, seja por evaporação durante a fase de infiltração no solo, ou durante a coleta ou ainda por mau funcionamento do coletor, a perda de massa de água por evaporação fará com que a composição isotópica da água caia fora da GMWL, definindo uma linha meteórica local (LMWL) cujos pontos 
irão cair acima da GMWL e, por consequência, apresentaram coeficiente angular < 8 (Lachniet, 2011).

A partir das amostras de água recolhidas na cidade de El Peñon (Santander), obteve-se a linha meteórica para a área que apresenta uma tendência semelhante com a GMWL (figura 5.11). Entretanto os valores específicos de $\delta^{18} \mathrm{O}$ e excesso de Deutério variam de acordo com as condições da área fonte de água transportada e ao fracionamento cinético que lhe foi apresentado.

Os valores da linha meteórica de água em El Peñon variam entre -16 \% e -1\%o para o $\delta^{18} \mathrm{O}$, e entre $10 \%$ a $-120 \%$ para o $\delta \mathrm{D}$. observa-se uma estreita relação entre os valores de Deutério e Oxigênio, apresentando uma tendência similar com a Linha Meteórica Global. Os valores da Linha Meteórica Local mostram as condições de fracionamento a que foi submetida às águas da chuva, de modo que os valores de $\delta^{18} \mathrm{O}=8,6206$ (inclinação da reta) mostram processos pontuais de evaporação mais forte da água da chuva na área fonte. O excesso de deutério (intersecção da linha) apresenta valores de 18.07 o que evidencia processos de evaporação (figura 5.11).

Ao calcular uma linha meteórica local para cada mês, os valores do coeficiente angular $\operatorname{do} \delta^{18} \mathrm{O}$ como bem como os valores de excesso de deutério variam significativamente. Essa relação pode ser associada com variações na fonte de umidade que contribuem para a precipitação de chuva na área. No entanto, a quantidade de dados e a representação temporal que eles têm não são suficientes para poder determinar com segurança essa relação. 


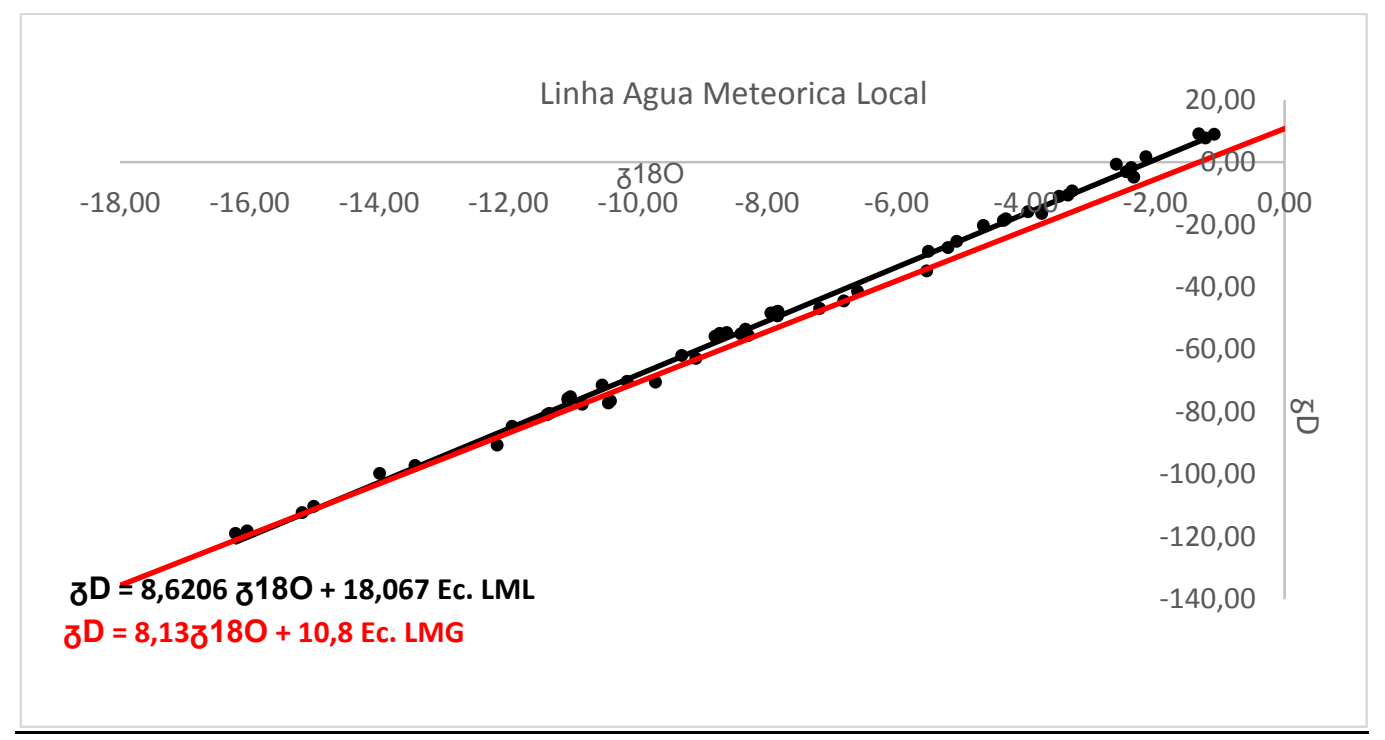

Figura 5.11 Linhas de Água Meteórica Local dos dados analisados de El Peñon (Colômbia), com a LWML pode-se identificar condições de fracionamento a que foi submetida às águas da chuva além de associar com processos na fonte de umidade pelo excesso de deutério

\subsection{Registro Isotópico de $\delta 180$ y $\delta 13 \mathrm{C}$}

Com base na discussão na fundação teórica e em os dados de chuvas obtidos no monitoramento na área de estudo, as mudanças em $\delta^{18} \mathrm{O}$ estão principalmente associadas com a quantidade de chuva e da variação da fonte de umidade, de modo que os valores mais negativos têm relação com maiores quantidades de chuva e vice-versa. As variações dos valores de $\delta^{13} \mathrm{C}$ referem-se a disponibilidade de $\mathrm{CO}_{2}$ biogênico no solo que são atribuídos à atividade biológica, que também pode ser ligada a alterações na disponibilidade de água no carste (Clark e Fritz, 1997; Fairchild et al., 2006).Para a reconstrução da paleopluviosidade na Colômbia a partir dos registros $\delta^{18} \mathrm{O}$ e $\delta^{13} \mathrm{C}$ em espeleotemas foram analisadas 2000 razões isotópicas de $\delta^{18} \mathrm{O}$ e $\delta^{13} \mathrm{C}$ num grupo de 3 estalagmites coletadas na caverna Caracos, na cidade de El Peñon (Santander, Colômbia). A resolução de amostragem variou de acordo com as taxas de crescimento apresentadas nas estalagmites em cada setor bem como na relevância de terminados intervalos de tempo no contexto dos estudos paleoclimáticos. Desta forma a resolução de amostragem média dos últimos 400 anos variou entre $0,3 \mathrm{~mm}$, no intervalo de tempo compreendido pela LIA até 1.500 anos BP, fornecendo uma resolução de amostragem média é de 2 anos. No restante do registro, até 5.300 anos BP, a resolução amostral média foi de 10 anos. 
A estalagmite CAR1 apresenta informações do presente até 281 anos BP, seguido por um hiato de 480 anos e um período de crescimento entre 762-1.497 anos B.P. Na primeira seção foram realizadas 675 amostras de carbonato, com resolução amostral de 0,14 mm, o que forneceu uma resolução temporal de 0,3 anos. Para a segunda sessão a resolução amostral aumentou para 0,4 mm, fornecendo resolução temporal de 2 anos. A estalagmite CAR1 em seus dois períodos de crescimento registra variações climáticas no período da LIA e o trecho mais antigo registra a ACM.

A CAR 2 registra o período de tempo no qual está localizado o hiato da estalagmite CAR1. A estalagmite apresenta registro isotópico no intervalo entre 212-672 anos BP, com uma resolução de amostragem de 0.4 equivalente a 2 anos. Ao todo foram tomadas em total 233 amostras. O espeleotema CAR2 registra mudanças na paleopluviosidade durante o LIA.

A estalagmite CAR3 representa o maior intervalo temporal do registro da caverna Caracos entre 1350-5400. Entretanto, em virtude da baixa taxa de crescimento média, ao redor de $0.07 \mathrm{~mm} /$ ano, a estalagmite CAR é a que apresenta a menor resolução amostral. Ao todo, para esse espeleotema, foram realizadas 336 analises isotópicas com uma resolução temporal média de 12anos. A estalagmite CAR3 registra variações significativas na pluviosidade no Holoceno Médio e Tardio o que permite fazer comparações com outros registros de Sul América que mostram os deslocamentos da ZCIT durante o mesmo intervalo temporal.

Perfis isotópicos obtidos para os 3 espeleotemas apresentam variações gerais entre -7,75\%o e $-10 \% \delta_{0}^{18} \mathrm{O}$, que representam principalmente as variações na quantidade de chuva na região, mas também pode numa menor quantidade refletir as variações nas fontes de umidade que entrar na área, tais como foi explicado antes. As variações $\delta^{13} \mathrm{C}$ são entre 0,5\% a $-5,75 \%$, que estão associadas com as mudanças na disponibilidade de carbono orgânico no solo.

Foram feitos análises de correlação entre os dados de $\delta^{18} \mathrm{O}$ e $\delta^{13} \mathrm{C}$ mostrando uma baixa correlação linear (Figura 5.12), o que representa que a deposição da calcita dentro da caverna foi em condições de equilíbrio preservando a sinal isotópico da chuva dentro do espeleotema, como é sugerido por Handy (1971); no entanto, este critério não é decisivo 
para determinar a qualidade dos dados para estudar $\delta^{18} \mathrm{O}$ e variações $\delta^{13} \mathrm{C}$ das chuvas na região, como foi demonstrado por pesquisas em cavernas nos Estados Unidos (Mickler et al, 2003).

Valores $\delta^{13} \mathrm{C}$ de em CAR1 têm amplitudes entre -0,5 \%o e -5,5\%o, e -7,75 \%o até 10,5 \%o para $\delta^{18} \mathrm{O}$ apresentando os valores mais amplos das três estalagmites estudadas. CAR2 apresenta valores mais positivos que a CAR3, mas combinando com os valores obtidos para CAR1, estas são entre $-0,5 \%$ e $-3,5 \%$ para $\delta^{13} \mathrm{C}$ e $\delta^{18} \mathrm{O}$ variar entre -8,0 \% e - $9,8 \%$ o. Os valores de CAR3 se relacionam com os valores mais negativos apresentados $\delta^{13} \mathrm{C}$ em CAR1 e dificilmente se sobrepõem valores de CAR2; o registro de $\delta^{13} \mathrm{C}$ varia de $-2,5 \%$ até $-6,0 \%$ e $\delta^{18} \mathrm{O}$ tem variações entre $-1 \%$ e $-10,0 \%$ (Figura 5.12)

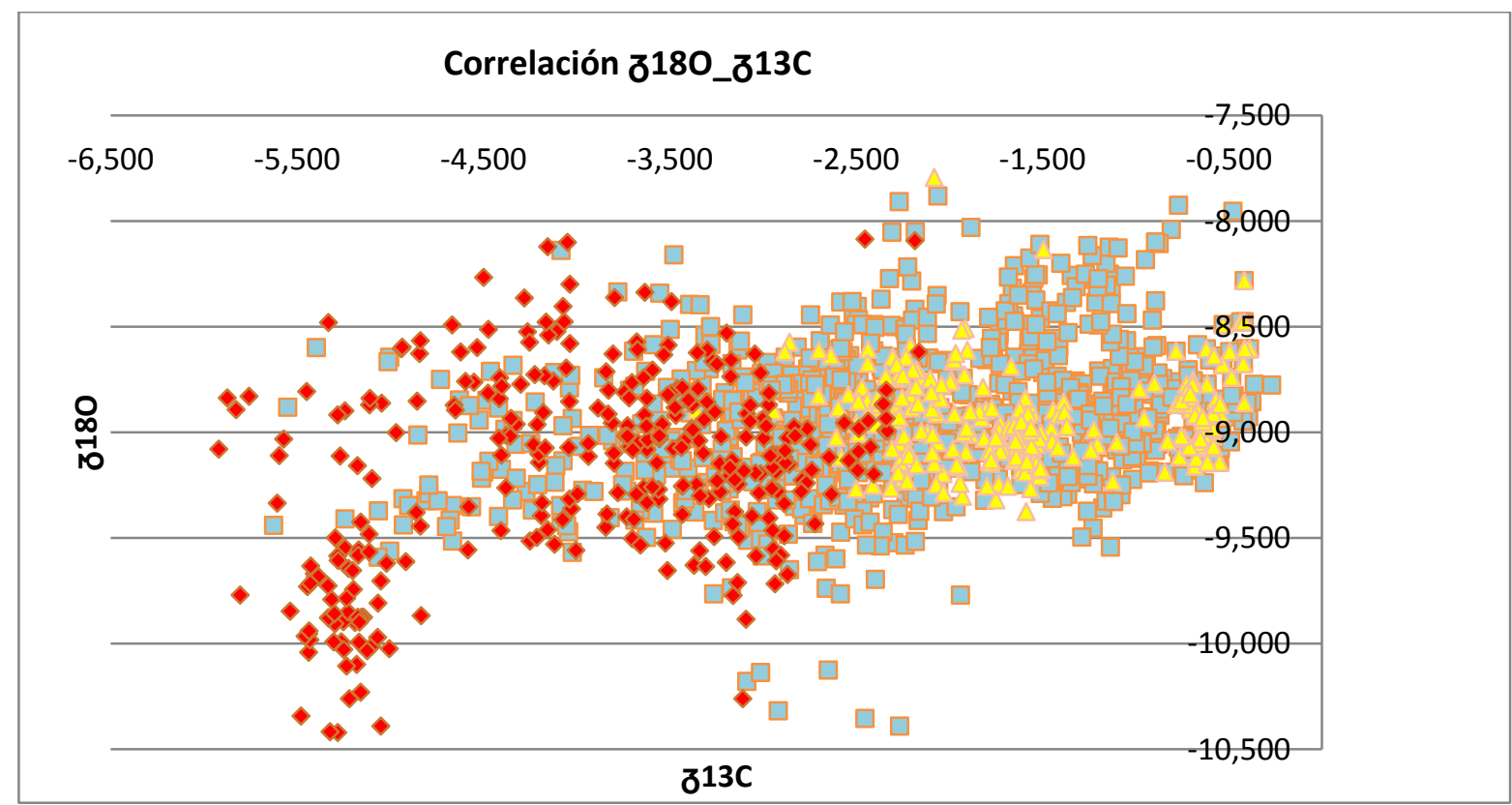

Figura 5.12 Correlação dos valores de $\delta^{18} \mathrm{O}$ e $\delta^{13} \mathrm{C}$ nas estalagmites CAR1(azul), CAR2 (amarelo) e CAR3 (vermelho), mostra relação entre as variações às amostras em cada uma das estalagmites, mas tem diferenças entre os valores gerais de CAR1, CAR2 e CAR3. 
Os valores isotópicos para a reconstituição paleoclimática dos últimos 5.300 anos na Colômbia apresentaram valores médios de $-8,99 \%$ para $z^{18} \mathrm{O}$ e de $-2,44 \%$ para $\delta^{13} \mathrm{C}$. CAR 3 mostra variações entre $-8,54 \%$ e $-10,42 \%$ para $z^{18} \mathrm{O}$; o registro começa com valores de $8,46 \%$ de $z^{180}$ que depois cai para valores mais negativos apresentados em todo o registro que apresenta valores de $-10,46 \%$ de $\mathrm{z}^{180}$ em torno aos 3950años BP, este período registra os valores mais baixos de ${ }^{180}$ e posteriormente mostram uma mudança abrupta de valores com uma subida até valores de $z^{180}$ perto de $-8,6 \%$ no ano 3382 BP até cerca de 1087 anos BP, os valores mostram curtos períodos regulares de declínio, sem ser tão negativo como os apresentado no período anterior. A partir deste período os valores começam a cair novamente, o mais negativo são $-9,9$ \%o e $-8,77$ \%o mais acima, apresentando uma variação de amplitude de 1,2 \%o. Enquanto os registros mostram uma tendência geral para um maior fracionamento isotópico entre 5300-3500 anos BP, após este período mostram-se valores de $\delta^{18} \mathrm{O}$ mais positivos até 2500 anos $\mathrm{BP}$, no entanto dentro deste período são observados ciclos internos onde se apresenta valores isotópicos mais baixos; os intervalos dos valores nesta temporalidade são entre $-8.57 \%$ e e $-9.9 \%$, com o maior valor perto de 3141 anos BP.

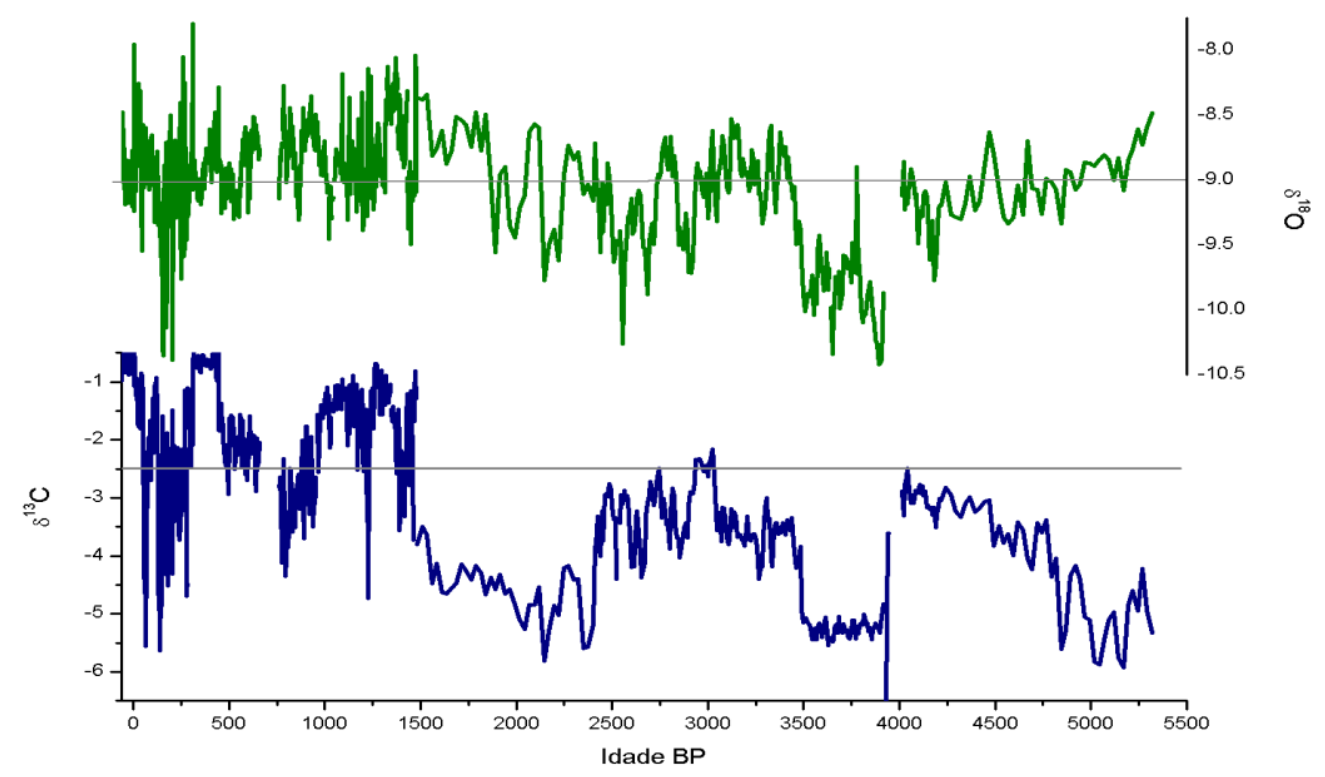

Figura 5.13 Curva isotópica de variações de $\delta^{13} \mathrm{C}$ e $\delta^{18} \mathrm{O}$ nas estalagmites CAR1, CAR2 e CAR3 entre 5500 anos B.P até o presente. 
O registro obtido dos últimos 1500 anos tem variações nos valores de $\delta^{18} \mathrm{O}$ principalmente entre $-8,13 \%$ e $-9,86$ \%o, no entanto tem períodos anômalos que saem deste intervalo e são determinados como picos isolados tanto de valores positivos como negativos. Os valores $\delta^{13} \mathrm{C}$ mostram variações entre $-1,15 \%$ e $-4,26 \%$, o que pode associados com as mudanças na vegetação da área. Os valores isotópicos para a reconstrução paleoclimática dos últimos 1500 anos mostram registros mais positiva no período entre 1455-1385 anos BP, antes da ACM (Anomalia Climática Medieval), com valores variando entre -8,20\%o e -8,49\%o no período. Entre 238 a 151 anos BP está gravando os menores valores entre -9,26 \%o e -9,54 \%, em um período que está terminando a LIA.

Os principais períodos de variações de paleoprecipitação em nosso registro são localizados na ACM entre 1200-900 anos BP, e na LIA entre 550-100 anos BP; durante estes períodos as variações dos valores isotópicos $\delta^{18} \mathrm{O}$ e $\delta^{13} \mathrm{C}$ têm diferentes amplitudes no registro. A ACM apresenta dois picos de mais baixo de fracionamento de $\delta^{18} \mathrm{O}$ entre 1021-932 anos $\mathrm{BP}$, com valores que variam de 8,71\%, com um valor de pico de -8,39\%, e 886-821 anos BP com valores entre -8, $69 \%$ e -8,33\%; entre esses dois períodos de valores de fase positivas observa-se maior fracionamento isotópico, a primeira entre 1104-1055 anos BP com valores de $z^{180}$ de $8,91 \%$ e 9,41\%, e um segundo período de maior fracionamento entre 926 e 892 anos AP, com valores no intervalo de 8,87\% - 9,25\%o. Nos últimos 150 anos no recente período de aquecimento, denominado CWP (Current Warm Period), os valores de $\jmath^{180}$ estão entre $-8.33 \%$ e $-9.25 \%$; os valores mais altos estão localizados ao início do século $\mathrm{XX}$, seguido por um período mais úmido até os valores da atualidade perto de $-8.6 \%$ de $\delta^{180}$ como se observa na figura 5.13 .

Devido a resolução de amostragem que se aplica aos últimos 1.500 anos, foi possível a análise de ondoletas para determinar a prevalência de ciclos em momentos diferentes no registro, assim foram feitas análises de ondoletas para desde 1500 anos BP até o presente que é 2012 quando foram pegadas as amostras y até onde chega nosso registro, igualmente foram feitas analises de ondoletas com maior detalhe para os últimos 450 anos. Nas análises de ondoletas, foi possível identificar os ciclos de escalas centenárias (aproximadamente 200 anos) a escala anual (4 a 6 anos), mostrando as relações entre a ocorrência e o desaparecimento entre os ciclos. 
Para os últimos 1500 anos observa-se uma prevalência dos ciclos maiores de 200 anos, sendo isso um registro constante durante todo o gráfico de ondoletas. Entre 64 e 90 anos se tem ciclos quase contínuos no registra, no entanto são pouco evidentes entre $500-700 \delta \mathrm{C}$ e 1530-1724 anos de AD; o desaparecimento desses ciclos em nosso registro está ligado com o aparecimento de ciclos mais curtos, entre 30 e 40 anos, que por vezes são temporariamente deslocados, mas são reforçadas em caso de redução dos ciclos mencionados acima, especialmente entre 576 -770 e 1637 - 1724 anos AD. Os ciclos de tempo curto, ou seja entre 4 a 8 anos, apresentaram um registro descontínua, sendo mais forte no período anterior e durante ao ACM e mais forte principalmente na LIA entre 1637 e 1813 AD; durante o CWP a influência destes ciclos de curta duração não é muito forte, no entanto apresenta períodos de fortalecimento como na década de 1920 e no final do registro (Figura 5.13).

Durante os dois principais períodos de estudo nos últimos 1.500 anos que mostram variações significativas de chuva na área, as mudanças são observadas nas intensidades dos ciclos que afetam a área; assim observa-se no ACM a prevalência de ciclos entre 64 e 90 anos de idade, com pouca influência dos ciclos entre 30 e 40 anos, e uma total ausência de ciclos curtos (entre 4 e 8 anos). Durante a ocorrência da LAI a situação oposta ao que é mostrado no período anterior, ou seja, um enfraquecimento dos ciclos entre 60 e 90 anos são apresentados, no entanto há um reforço dos ciclos entre 30 e 40 anos, e ciclos entre 4-8 anos (Figura 5.13)

Com o registro dos últimos 450 anos também foi realizado analises de ondoletas para a determinação de ciclos; para este período observa-se o fortalecimento dos ciclos próximos aos 65 anos desde 1724 até o presente; ciclos entre 20 e 30 anos são reforçados durante 1730 e 1950 AD; os ciclos curtos são reforçados entre 1680 e 1790 AD, após a sua influência na região é baixa, no entanto na década de 1920 e nas últimas décadas do registro estes ciclos estão novamente presentes (Figura 5.13) 


\section{DISCUSSÃO}

\subsection{Alteracão no deslocamento da ZCIT durante o Holoceno Superior}

De acordo com os dados de isótopos estáveis de estações do GNIP bem como das amostras coletadas no sítio de estudo é possível afirmar que os valores de $\delta^{18} \mathrm{O}$ registrados nos espeleotemas estudados são influenciados, primariamente, pelas variações na quantidade de chuva. Isso se explica através do fracionamento tipo Raleight descrito nos capítulos anteriores. Este efeito é caracterizado pela diminuição geral dos valores de $\delta^{18} \mathrm{O}$ com o aumento das chuvas ou com uma estação chuvosa mais prolongada em relação às chuvas que ocorrem nos meses mais secos. Como a área de estudo está diretamente sob a influência da ZCIT, pode-se relacionar as variações de $\delta^{18} \mathrm{O}$ às mudanças na posição e atividade deste sistema climático na região de estudo com o tempo.

A área fonte da umidade que adentra a região de estudo também influi significativamente nos valores de $\delta^{18} \mathrm{O}$ da precipitação, como se observa nas análises isotópicas das amostras de chuvas realizadas no local de estudo no ano de 2013. Com base nestes dados, observamse valores mais negativos para as massas de ar úmido provenientes do Atlântico que afetam o clima da região durante o verão boreal e causa chuvas abundantes entre maio, junho e julho. Já as chuvas no segundo semestre apresentam valores significativamente mais altos do $\delta^{18} \mathrm{O}$ devido à influência do jato de umidade conhecido com "El Chorro Del Choco", proveniente do oceano Pacífico durante os meses chuvosos do ano, entre agosto e outubro (Figura 2.7). Embora os valores de $\delta^{18} \mathrm{O}$ das chuvas deste período sejam relativamente mais altos durante o fenômeno "Chorro Del Choco", nota-se que eles ainda são significativamente mais negativos dos que os valores observados nos meses mais secos do ano, durante a maior parte do inverno boreal, entre dezembro e abril. Portanto, interpreta-se que os valores mais negativos de $\delta^{18}$ Orepresentam aumento das chuvas de verão, com contribuição maior da umidade provenientes do Caribe e Amazônia devido a maior atividade da ZCIT na região de estudo. No entanto, devido à influência de duas fontes de umidade (Atlântico e Pacífico), os dados de $\delta^{18} \mathrm{O}$ não podem ser simplesmente interpretados como função do volume de acumulado de chuva. Por exemplo, o aumento de chuva, caracterizado pela diminuição dos valores de $\delta^{18} \mathrm{O}$, pode ser subestimado em períodos em que o fenômeno "Chorro Del Choco" for mais importante. 
Os registros de $\delta^{18} \mathrm{O}$ na área de El Peñon, Colômbia, mostram variações na pluviosidade durante os últimos 5300 ky com valores que variam entre - 7,75 e -10,5\%, cujo valor médio é de -8,99\%o. Desde aproximadamente 5300 ky a 3900 ky B.P. é observado decréscimo de $8.48 \%$ até $-10.3 \%$, o que evidencia tendência de aumento das chuvas relacionadas com a ZCIT na região, principalmente devido ao aporte de umidade proveniente do Caribe e Amazônia (Figura 2.7). No entanto, essa tendência é interrompida por eventos seco entre 4466 e 4038Ky B.P. Após este período existe novamente uma predominância de valores mais baixos de $\delta^{18} \mathrm{O}$ entre 3900 entre $3500 \mathrm{ky}$ B.P., marcado por condições mais úmidas com variações cíclicas multidecadais. Entre os anos 3418-2948 ky B.P. predominam condições mais secas e após 2948 ky B. Paté por volta de 1900 ky B.P. existe uma alternância de eventos, ora de seca ora mais úmidos, com durações de várias décadas (Figura 5.13). Deste período em diante é observado intensificação das condições mais secas com pico em 1367 BP e marcante ciclicidade de aproximadamente 130 anos, caracterizada também por eventos úmidos de duração de algumas décadas. O clima mais seco predomina desde os anos 1300 B.P. até o presente, em relação ao clima que se observa no registro antes de 2000 B. P. Em relação às condições climáticas durante os eventos denominados de Anomalia Climática Medieval (MCA, 150 - 450 BP 800 - 1200 BP, sigla em inglês) e Pequena Idade do Gelo (LIA, 150 - 450 BP, sigla em inglês), são observadas condições de menor umidade no MCA e depois grande variabilidade climática no qual se identifica alternância de eventos abruptos secos e úmidos durante o LIA (Figura 6.1). 


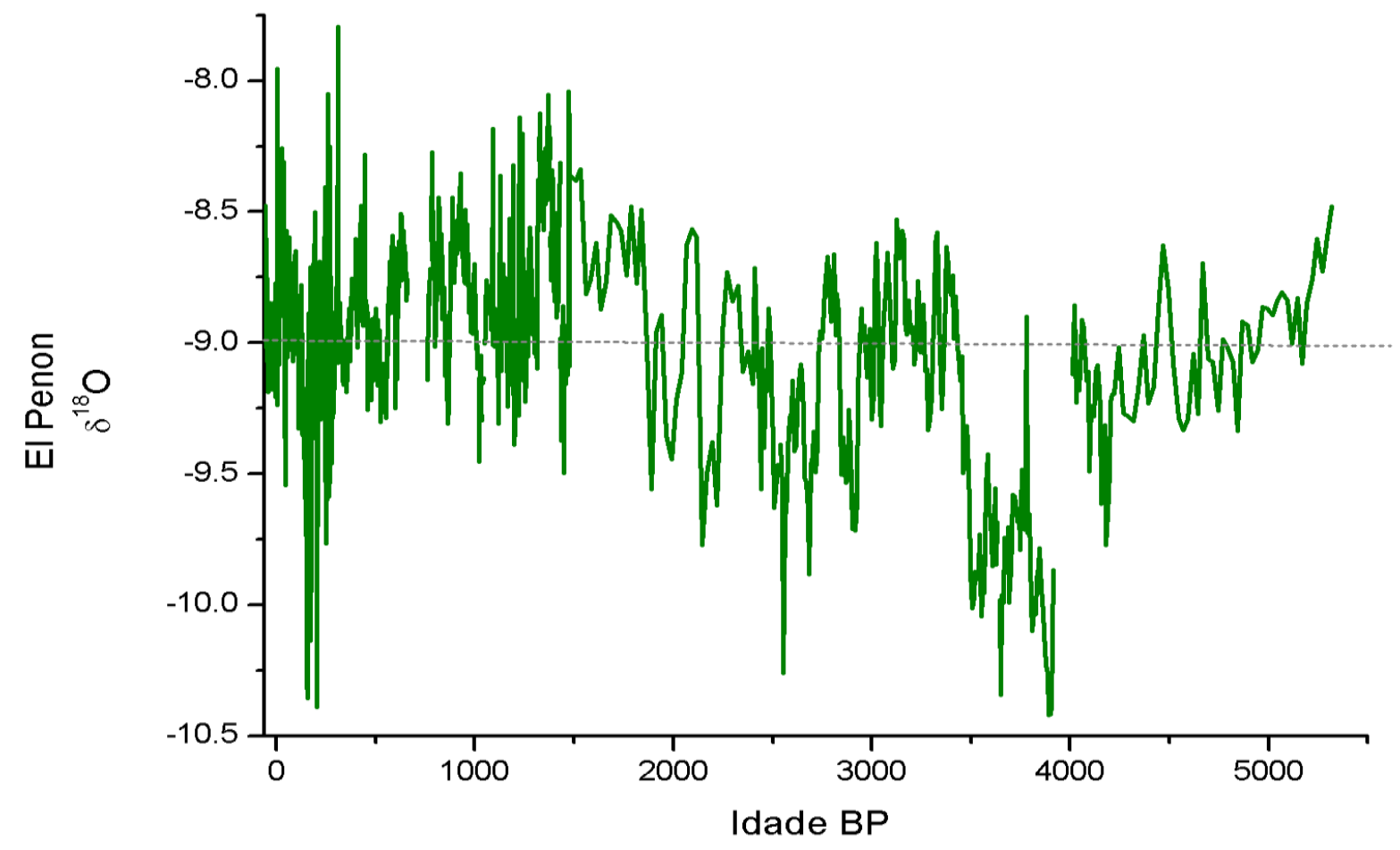

Figura 6.1. Registro das variações de $\delta^{18} \mathrm{O}$ na área de El Peñon (Santander, Colômbia) durante os últimos 5300 anos. Os valores mais baixos de $\delta^{18} \mathrm{O}$ estão associados ao aumento de chuvas, principalmente durante o verão boreal. O traço pontilhado representa o valor médio de todo registro, em torno de $-9,0 \%$, a partir do qual se identifica períodos mais secos e úmidos.

As variações de pluviosidade na área de estudo na Colômbia durante o período recoberto pelo registro de $\delta^{18} \mathrm{O}$ podem ser relaciona com o deslocamento do sistema ZCIT ao longo do Holoceno médio e superior. Essa relação, discutida nos capítulos anteriores, é bem conhecida na climatologia moderna e foi utilizada em outros estudos, por exemplo, em Haug et al. (2001). Também, a zona onde está localizado o município de El Peñon (estado de Santander, Colômbia), apresenta influências de massas de umidade provenientes do oceano Pacífico, que intensificam as chuvas no outono boreal e podem ser impactadas por eventos El Niño/La Niña na área de estudo, como discutido no capítulo 2.

A comparação do registro de El Peñon com os registros da Bacia de Cariaco, na Venezuela indica semelhanças em relação às mudanças no regime de chuvas devido ao posicionamento e intensidade da ZCIT durante o Holoceno Médio e Tardio (Figura 6.2), 
embora as variações de chuva devido à influência da insolação não sejam tão evidentes no registro isotópico dos espeleotemas colombianos. Já em Cariaco, existe um claro decréscimo dos valores de \% Ti nos últimos 5300 anos desde valores de $0.35 \%$ até $0.15 \%$, os quais representam menor transporte fluvial de sedimentos em suspensão em direção ao presente (Figura 6.2). Mesmo assim, o clima entre os anos 5300 a 2400 BP nos registros de El Peñon e Cariaco apresentam em uma relação geral em antifase com tendência de aumento de pluviosidade na área de El Peñon e diminuição em Cariaco em longo prazo, sendo as variações mais abruptas no período entre 3000 e 2500 anos BP, que corresponde ao final de um evento tipo Bond (Figura 6.2). Desde 2500 anos BP os registros de El Peñon e Cariaco indicam condições de maior pluviosidade na Venezuela e menor na Colômbia, sendo nesta última ainda mais marcadas por uma maior amplitude de variação isotópica. Tal relação pode ser explicada por um leve deslocamento da ZCIT para sul em decorrência de fase de insolação mais baixa (alta) no hemisfério norte (sul) ou eventos de esfriamento (aquecimento) no oceano Atlântico norte (sul).

Ao contrário do período entre 3000 e 2500 anos BP, o clima durante o LIA apresenta uma predominância de relação em fase entre o clima da Colômbia e Venezuela, marcada por menor intensificação da ZCIT nestas áreas, o qual também apresenta natureza mais abrupta de oscilações relacionadas às mudanças no regime hidrológico (Figura 6.2).

Estas mudanças abruptas no clima observadas entre 3000 e 2500 anos B.P. e durante o LIA estão provavelmente ao enfraquecimento da célula de revolvimento meridional do oceano Atlântico (AMOC, sigla em inglês) gerada pelo aporte de água doce em zonas de altas latitudes do Atlântico Norte (Swingedouw et al., 2008). Estas variações de intensidade da AMOC impactam fortemente o regime de chuva na área sob o domínio climático da Zona de Convergência Intertropical (Wan et al., 2010). O enfraquecimento da célula de revolvimento meridional oceânica atrasa o transporte de água quentes provenientes do oceano Atlântico Sul para as zonas de altas latitudes do Atlântico norte. A consequente mudança do gradiente interhemisférico de temperatura da superfície do mar (TSM) impulsiona o transporte de umidade relacionada com o ZCIT para sul do equador (Meelhl et al., 2009; Bond et al., 2001). No entanto, a comparação entre os registros de Cariaco e El Peñon, sugere mudanças em fase de pluviosidade entre a Colômbia e Venezuela também na escala orbital. Nessas regiões o clima fica mais úmido durante as fases de insolação alta no 
HN bem como na a maior parte dos eventos Bond. A exceção nessa relação acontece na fase final dos eventos Bond, quando a ZCIT parece retornar para posição mais a norte, deixando a região de Santander ainda úmida, ao passo que a Venezuela, mais a norte, continua ainda seca. Estes eventos tipo Bond, causados por mudanças na circulação oceânica, podem resultar em mudanças climáticas em escala multidecadal a secular, associadas ao deslocamento da ZCIT para sul (Bond et al, 2001; Timmermann et al, 2007).

Durante um evento Bond entre 3500 -2500 años BP são registrados períodos secos tanto em El Peñon como na Bacia de Cariaco (Haug et al, 2001) (Figura 6.2). Variações climáticas semelhantes foram registradas na Colômbia em áreas como El Páramo de Frontino (Velásquez et al, 2013), Laguna de Fúquene (Vélez et al, 2007) e nos Llanos Orientales (Vélez et al, 2006). Nestas áreas são registradas mudanças significativas na vegetação devido a mudanças na pluviosidade, muito embora o efeito das secas não ocorra na mesma amplitude nem direção, possivelmente, em contada influência de fatores ambientais locais nos Andes colombianos. O mesmo acontece durante o LIA, quando ocorre um novo evento de esfriamento geral do oceano Atlântico Norte com duração de mais de 200 anos, marcado em El Peñon por aumento da variabilidade climática caracterizada por eventos abruptos úmidos de curta duração em escala multidecadal.

Os períodos de esfriamento no HN coincidentes com os eventos Bond (\%HGS), especialmente entre 3500-2500 anos BP, se associam a períodos de secas na Colômbia, enquanto em áreas distais mais a sul no Peru e Brasil ocorrem intensificação das monções sul-Americanas, tendo a vista que o esfriamento no $\mathrm{HN}$ contribui para o deslocamento da ZCIT para sul (Broccoli et al, 2011). Bond et al. (2001) associa esses eventosa períodos de mínimos de atividade solar, o poderia causar amplificação dos padrões atmosféricos e oceânicos (Stríkis, 2011; Novello, 2012). Esta relação entre variações nas condições climáticas do HN e movimento da ZCIT também tem sido registrado na África, que é caracterizada por mais chuvas a sul com o abaixamento da Temperatura da Superfície do Mar no Atlântico Norte. 


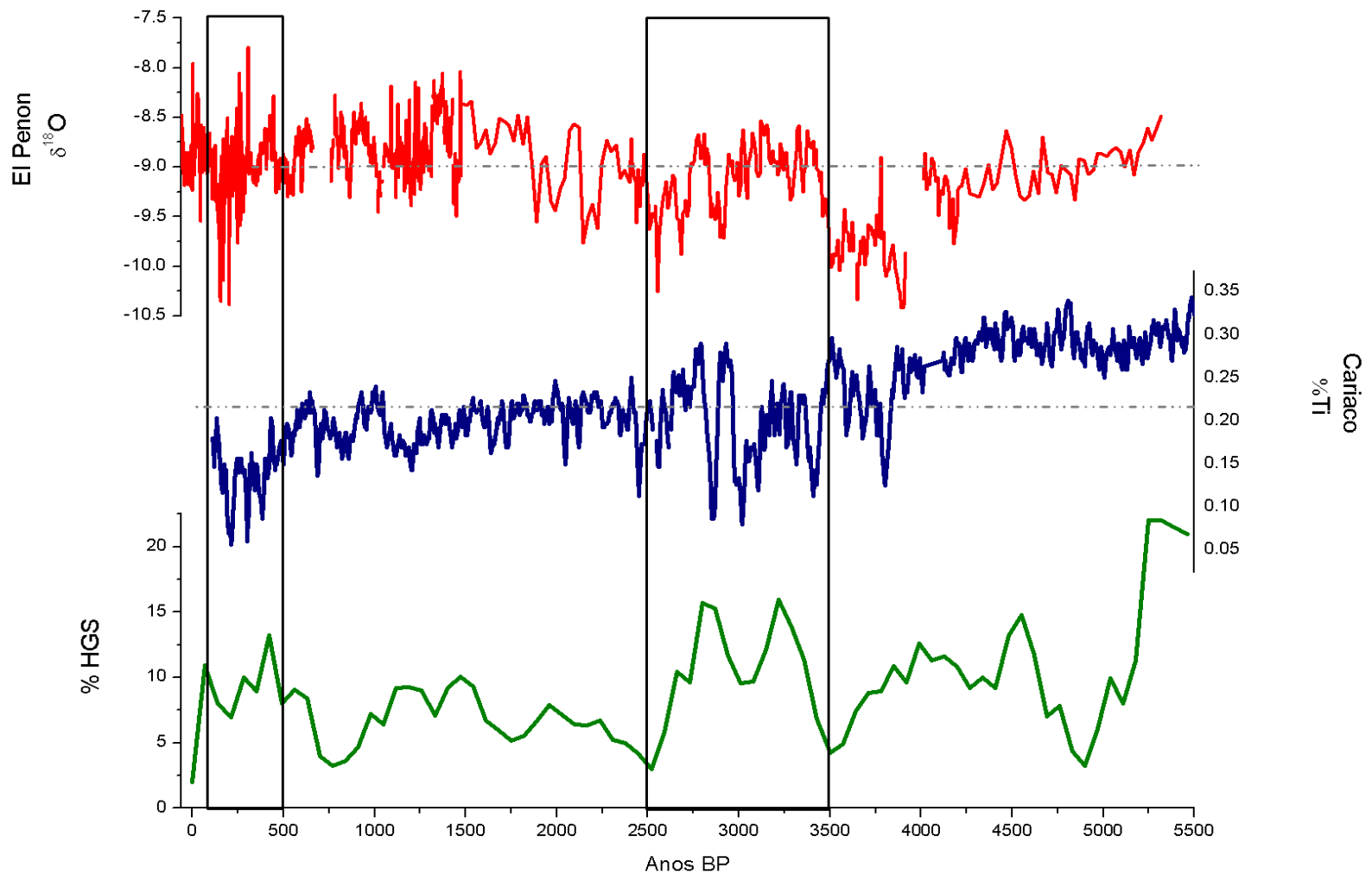

Figura 6.2. Curvas comparativas dos registros de Cariaco na Venezuela (Haug et al, 2001), El Peñon na Colômbia e variações icebergs no Hemisfério Norte a partir do índice \%HGS (Bond et al, 2001). Observamse variações no Holoceno Médio (5500 anos BP) marcadapor sincronias nas variações entre 3500-2500 anos BP e durante a Pequena Idade do Gelo, períodos caracterizados por aumento de HSG, ou seja, esfriamento do Atlântico Norte.

A alta resolução temporal do registro de El Peñon nos últimos 1000 anos, em média anual, permitiu detectar alta variabilidade climática na Colômbia, especialmente durante o LIA, feição não tão evidente no registro de Ti \% de Cariaco (Figura 6.2). Talvez essa seja a razão para fraca relação entre Ti \% e dados de TSM (Black et al., 2007) nos registros de Cariaco (Figura 6.3). Durante o período entre 500-50 BP (1450- 1900 AD) o registro de El Peñon apresenta tendência geral de secas, devido a valores isotópicos mais altos que a média do registro, embora ocorram intercalados eventos úmidos, com entre 180-104 anos BP (1770-1846AD), marcado por ampla e abrupta variação isotópica (Figura 6.3). 
Entre 467- 380 B.P. anos (1467-1570 AD) ocorrem condições mais secas na área de El Peñon com pico mais pronunciado no ano de 430 B.P. (1520 AD), o qual se relaciona com o aumento da temperatura da TSM no oceano na Bacia de Cariaco (Black et al, 2007) de aproximadamente $0.5^{\circ} \mathrm{C}$ (Figura 6.3). O contrário ocorre entre anos 380 - 280 B.P. (15701670 AD), com leve aumento geral de chuvas em El Peñon que coincide com leve diminuição da TSM em Cariaco. No entanto, neste mesmo período, existe um curto evento de seca centrado em306 anos B.P. (1644 AD) que também coincide com o pico de aumento de TSM em Cariaco. 


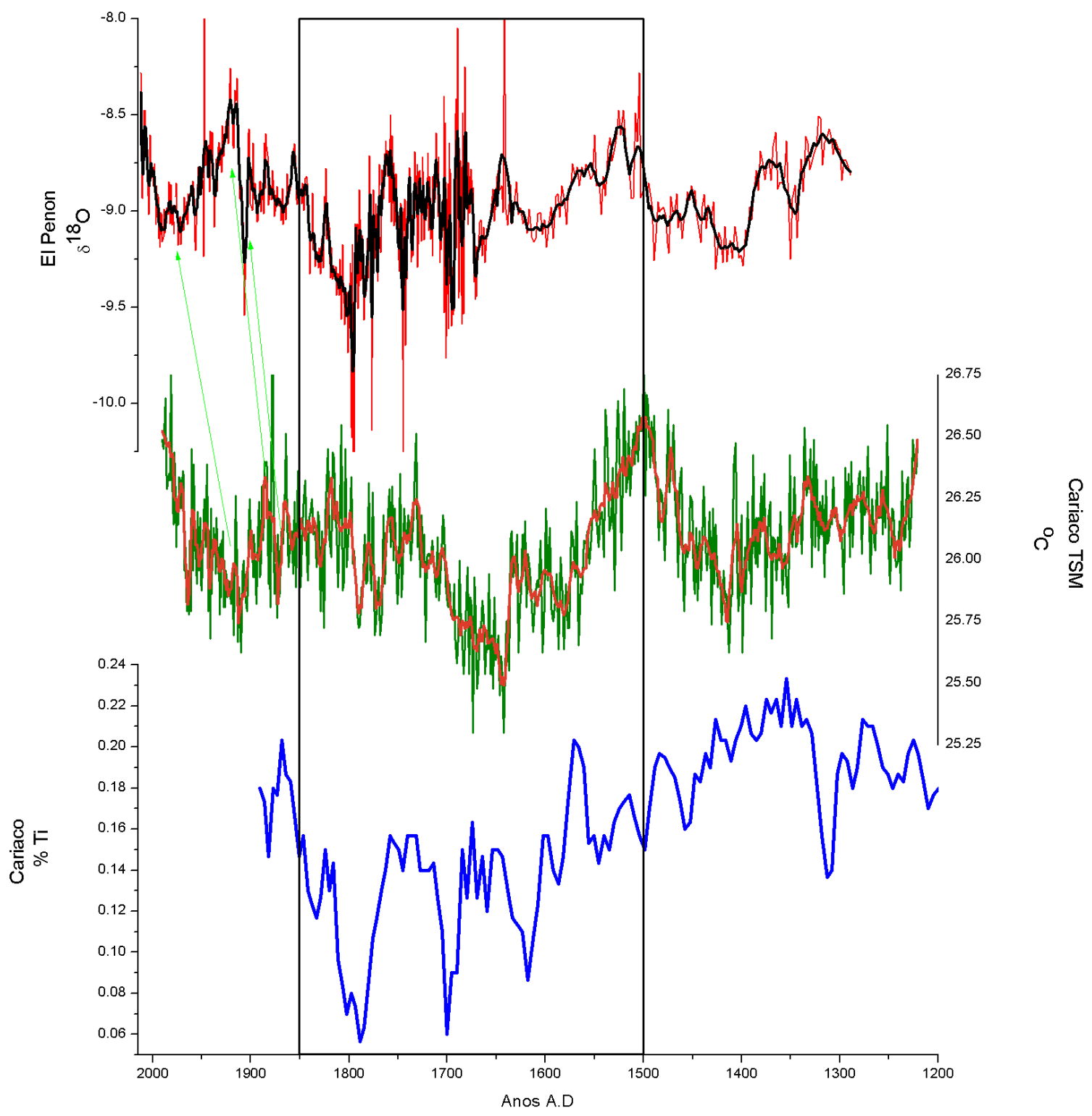

Figura 6.3. Comparação do registro de $\delta 180$ de El Peñon dos últimos 800 anos, variações de TSM do Oceano Atlântico (Black et al, 2007) e os registros de Ti \% da Bacia de Cariaco.

Entre 283 e 154 anos B.P. (1667 até 1796 AD) o registro da Colômbia apresenta uma mudança para condições de menor pluviosidade, marcada por uma variação abrupta no registro. Tal mudança se relaciona, em parte, com aumento da TSM em Cariaco, no entanto as variações de TSM ocorrem de forma mais gradual numa taxa de aproximadamente $0.25^{\circ} \mathrm{C}$. Notam-se também eventos de aumento da chuva e diminuição da temperatura que 
são registrados em ambas as áreas, praticamente de modo simultâneo, a exemplo do observado em 1698 AD, 1743AD e 1776AD. Já a 154 anos B.P. (1796 AD) ocorre um evento abrupto de diminuição da TSM em Cariaco concomitante com o registro de condições de maior pluviosidade em El Peñon, que corresponde aos valores isotópicos mais baixos de todo o registro (Figura 6.3).

Desde entre 154 a 31 anos B.P. (1796 até 1919AD) o registro de El Peñon mostra uma tendência geral de menor pluviosidade relacionada a atividade da ZCIT, sendo o evento de estiagem mais severo registrado no ano de 1919AD; o registro da TSM em Cariaco mostra variações semelhantes neste período (Figura 6.3). Após este período os registros de El Peñon e Cariaco mostram um deslocamento temporal dos eventos de variações na pluviosidade e TSM, indicado por setas na Figura 6.3. O deslocamento temporal pode ter relação com o menor controle cronológico observado no registro marinho de TSM de Cariaco (Black et al., 2007).

A relação entre os eventos secos registrados em El Peñon com eventos de esfriamento do Atlântico Norte sugere deslocamento da ZCIT relacionada com a intensificação dos ventos alísios de NE tal como já havia sido indicado por diversos autores (Timmermman et al, 2007; Stríkis et al., 2011).

$\mathrm{O}$ registro de $\delta^{18} \mathrm{O}$ obtido em estalagmites de El Peñon para os últimos 1500 anos possui alta resolução temporal o que permite a identificação de eventos climáticos abruptos e, por conseguinte, a comparação com outros registros de alta resolução do Atlântico e do Pacífico bem como registros continentais dos trópicos sob a influência da ZCIT, a exemplo dos trabalhos realizado no México (Medina Elizalde et al, 2010), Guatemala (Stansell et al, 2012), Venezuela (Haug et al, 2001), Peru (Bird et al, 2001) e Equador (Conroy et al, 2008).

É de grande relevância investigar a relação entre as variações isotópicas e os modos de variabilidade climática de origem nos oceânica. Por exemplo, a provável teleconexão climática entre as variações de precipitação na Colômbia com os padrões de TSM do Atlântico do tipo AMO e NOA/OA em escala multidecadal a decadal, respectivamente. A Figura 6.4 apresenta uma boa relação visual entre estes modos climáticos e as variações de precipitação em El Peñon nos últimos 1500 anos intervalam de maior resolução no registro 
de espeleotemas. Essa relação é, em geral, caracterizada por valores isotópicos mais altos durante fases positivas tanto da AMO quanto da PDO e vice-versa.

A relação com ciclos climáticos multidecadais é claramente observada na análise estatística de séries temporais das amostras CAR1 e CAR2, representado por forte sinal do ciclo de 60 anos, persistente nos últimos 1500 anos do registro (Figura 6.5). Essa relação com a AMO pode ser explicada pela influência do gradiente de TSM do Atlântico no posicionamento médio da ZCIT, que segue a faixa mais quente do oceano (Gray et al, 2004). O posicionamento da ZCIT também é significativamente influenciado pela variação da TSM na zona onde se desenvolve o fenômeno ENSO (Timmermann et al, 2007).

Em alguns períodos parece existir uma relação simultânea com ambas PDO e AMO reconstituídas por Mann et al., (2009), por exemplo, durante os eventos MCA e LIA, os quais supostamente influem na precipitação da região de El Peñon (Figura 6.4). Durante o MCA, AMO e PDO apresentam fases positivas, tendência esta que se modifica próximo de 1110 AD, quando começa a fase negativa destes registros. Durante o LIA as variações das fases da PDO, AMO e o registro de El Peñon são similares, no entanto pode haver relações antifásicas em curtos períodos, o que pode resultar de problemas cronológicos em algum destes registros (Figura 6.5). Sobre tudo durante o LIA a AMO parece ser o principal modo de variabilidade climática atuante no controle das precipitações de chuva em El-Peñon. Na Figura 6.6 o registro isotópico da estalagmite CAR1 é comparado com a curva de AMO, por sua vez, deslocada em 25 no sentido de obter melhor ajuste. 


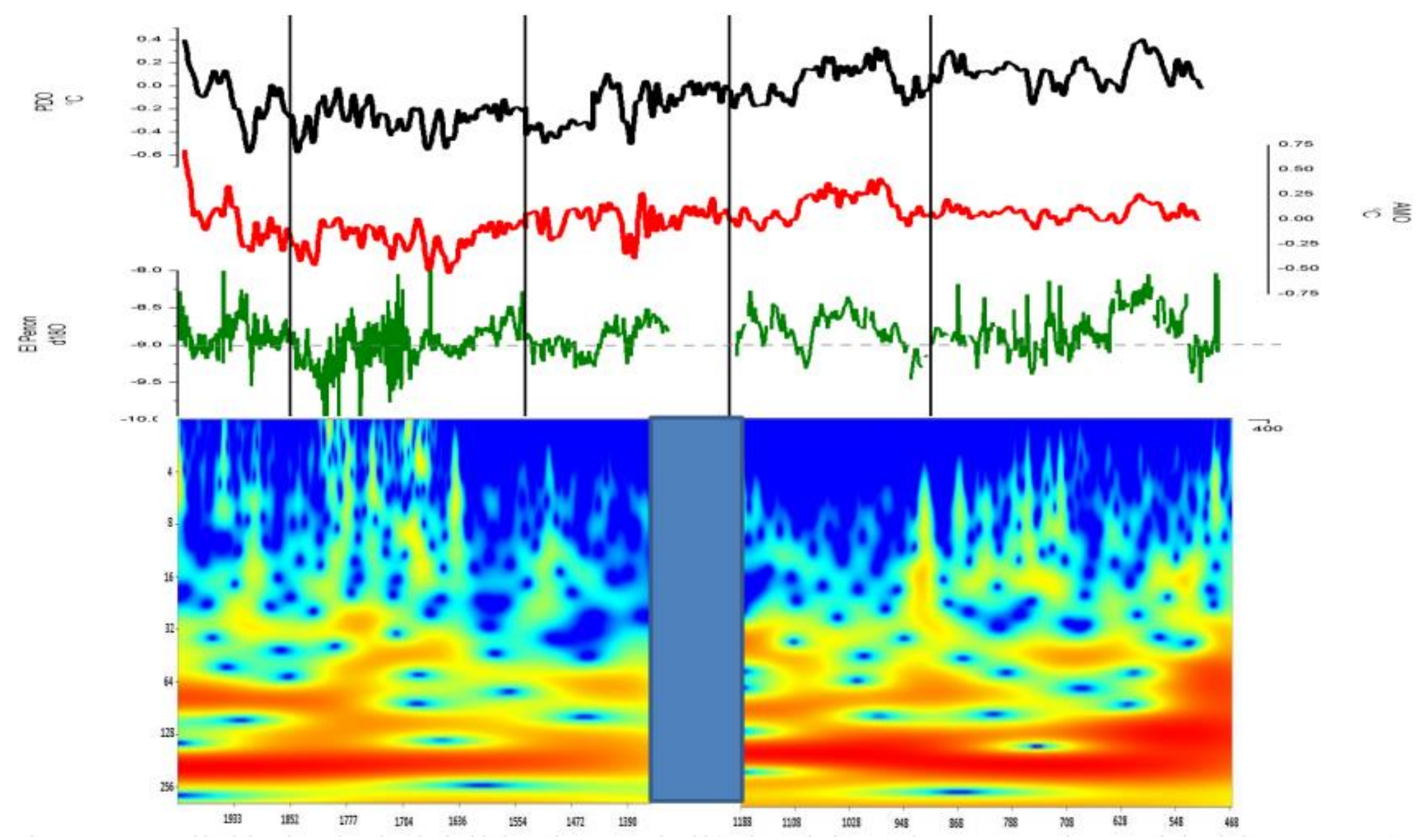

Figura 6.4. Comparação do registro isotópico de El Peñon (Colômbia) com as variações dos modos climáticos multidecadais do Atlântico (AMO) e decadais do Pacífico PDO (Mann et al, 2009), durante os últimos 1500 anos. 
A série de AMO deslocada de 25 anos apresentada na Figura 6.5, diferentemente do observado anteriormente, aponta para fases de aumento de precipitação em El Peñon concomitante com períodos de esfriamento do Atlântico Norte na escala multidecadal. O aumento de chuvas durante as fases de AMO e PDO negativos durante o LIA pode ter relação com o desenvolvimento de condições tipo Niña (Sachs et al, 2009).

Outro aspecto importante que chama a atenção no registro é a forte excursão negativa registrada em 1796 na estalagmite CAR1. O evento é contameporâneo, considerando o erro da datação de 12 anos, a grande erupção do vulcão Laki, ocorrido em na Islândia em 1783, que resultou em queda de até $-3{ }^{\circ} \mathrm{C}$ na temperatura do Hemisfério Norte (Oman, 2006). Nos anos seguintes a erupção do Laki, entre 1783 e 1784, o déficit hídrico causado pela redução das monções africanas resultou em fortes quedas do nível do rio Nilo. Como reflexo das estiagens subsequente causados por esse evento eruptivo, em janeiro de 1785 praticamente 1/6 da população do Egito havia morrido de fome ou emigrado em decorrência das fortes secas do Nilo (Oman, 2006).

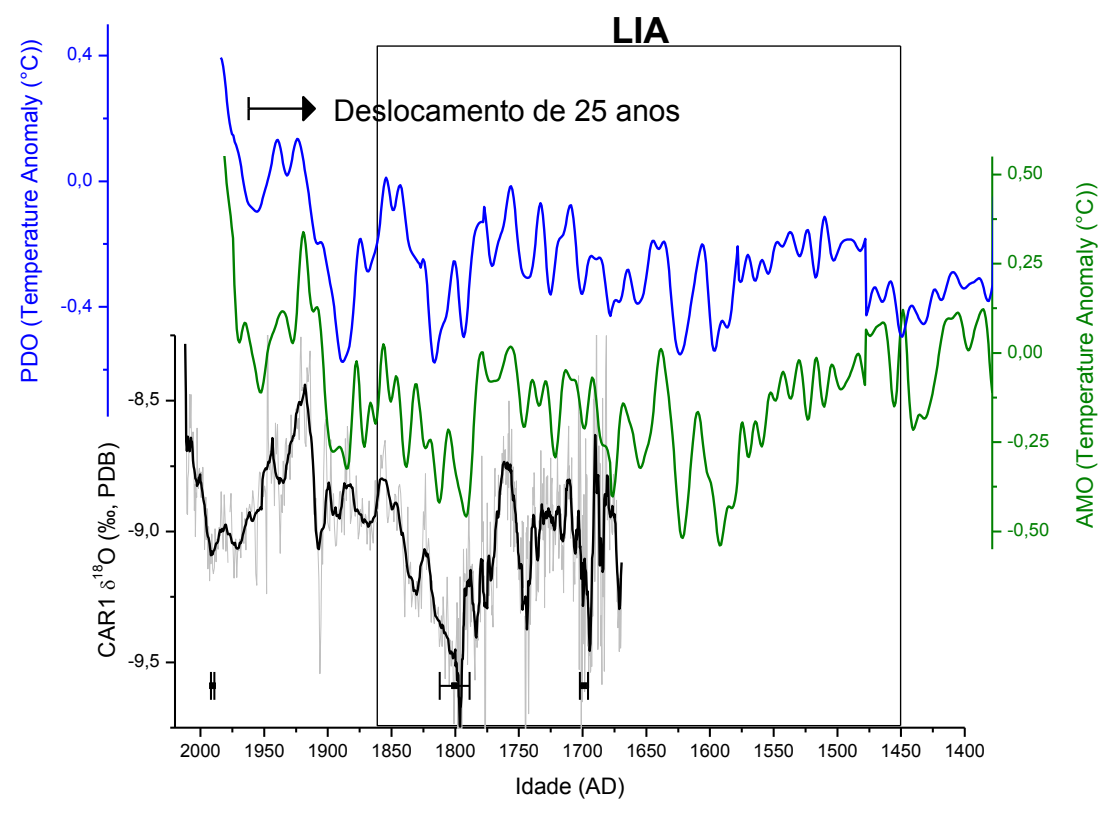

Figura 6.5. Comparação do registro isotópico de El Peñon (Colômbia) com as variações dos modos climáticos multidecadais do Atlântico (AMO e decadais do Pacífico PDO (Mann et al, 2009) durante o LIA. Atentar para o deslocamento temporal da curva de AMO em 25 anos. 
O bom acoplamento entre as precipitações em El Peñon com os ciclos de AMO e PDO seguem mesmo com o final do LIA. Eventos secos como entre 1910 e 1950 bem como uma forte tendência de redução de chuvas a partir de 1992 encontra forte relação com fases de PDO e AMO positivas.

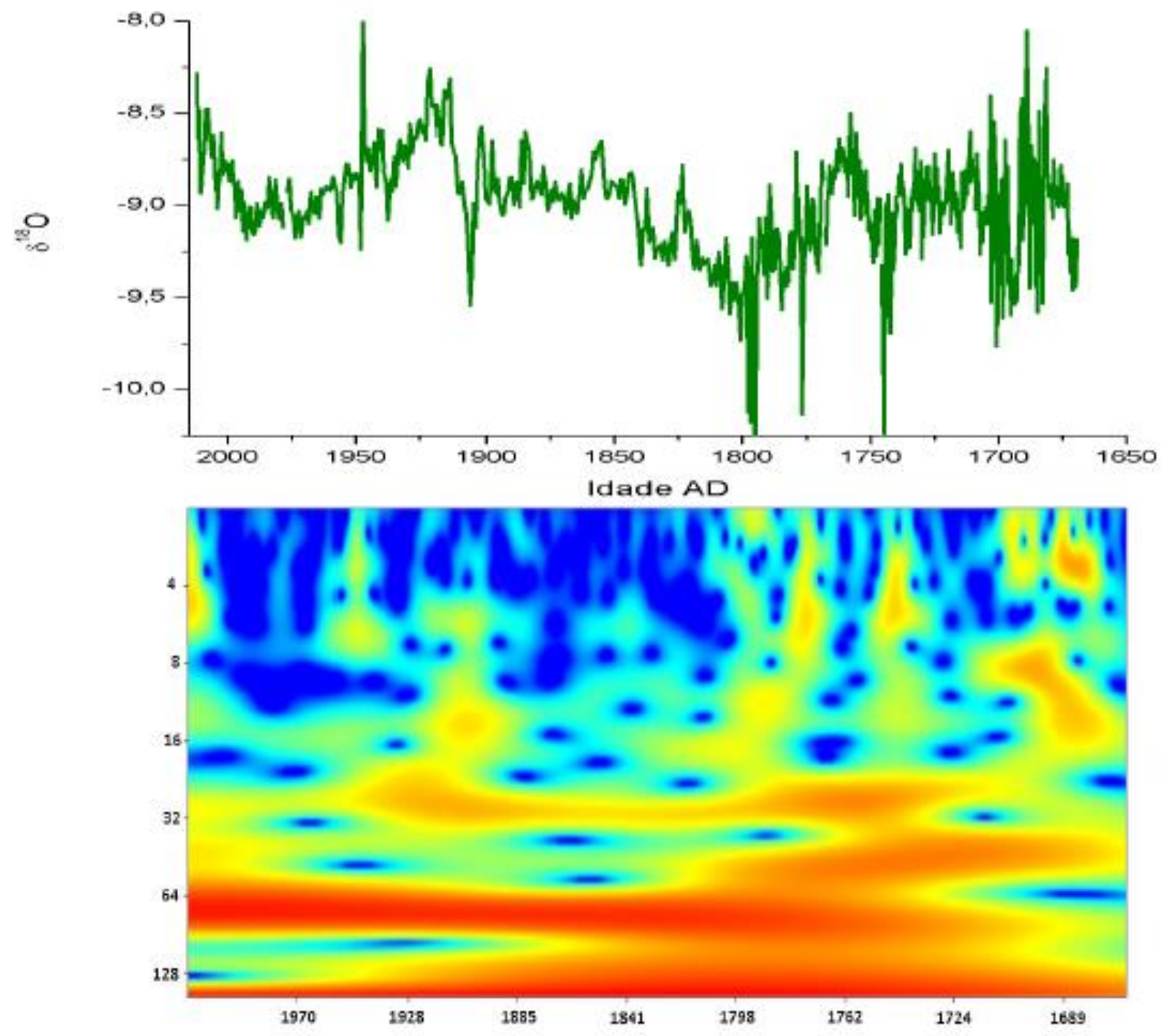

Figura 6.6 Gráfico da análise de wavelet realizado no registro de $\delta^{18} \mathrm{O}$ de El Peñon, Colômbia, do software PAST (Hammer et al., 2001). No eixo x, está a idade em anos abrangendo todo o intervalo temporal do registro, no eixo y estão os valores das periodicidades em escala logarítmica e a o índice de cor é indicativo da intensidade dos eventos periódicos, as cores mais quentes (vermelho) determinam os eventos de maior intensidade e as cores mais frias (azul) os de menores. 
A influência da oscilação da temperatura do Pacífico, devido aos ciclos tipo PDO sobre a área da Colômbia pode ser explicada pela redução do gradiente da TSM entre a Colômbia e o Equador-Peru, no qual minimiza a entrada de umidade do Pacífico para a os Andes colombianos em condições tipo El Niño, como observado na climatologia moderna. Esse fenômeno pode ocorre em conjuntura com variações climáticas no oceano Atlântico e por conseguinte no regime dos ventos alísios. Com a intensificação dos alísios de NE no Atlântico, pode existir um deslocamento da ZCIT para sul que gera períodos secos mais a norte do continente sul-americano, o qual é também favorecido pelo gradiente de TSM do Pacífico, como explica Timmermann (2007). Como acima mencionado, a comparação entre os registros de Cariaco e El Peñon sugerem que esse deslocamento da ZCIT para sul é pequeno, mas o suficiente para deixar o clima na Venezuela mais seco ao passo que a Colômbia estaria mais úmida.

Os valores entre 40 e 60 anos observados no gráfico de wavelet do registro de $\delta^{18} \mathrm{O}$ de El Peñon são persistentes em todo série temporal de $\delta^{18} \mathrm{O}$ (Figura 6.6). Nos períodos onde o registro apresenta mudanças mais fortes observa-se uma relação com ciclos de curta duração entre 4 até 6 anos (Figuras 6.4, 6.5 e 6.6). Também são observadas periodicidades muito significativas entre 150-250 e 64-100 anos (Figura 6.6). Já as oscilações temporais entre 18-22 anos estão presentes em quase todo o registro, principalmente, durante o evento LIA, no entanto sua energia decai entre 950 e 1500 AD (Figura 6.6). Estas oscilações entre 18-22 anos têm sido associadas à PDO positiva, os quais podem intensificar as condições tipo La Niña que causam maior pluviosidade na região (Poveda et al, 2006).A persistência conjunta dos sinais de PDO e AMO em El Peñon sugere influência acoplamento das condições climáticas dos oceanos Pacíficos e Atlântico nas chuvas da região estudada (Figura 6.5).

Comparações realizadas com outros registros paleoclimáticos de alta resolução localizada em áreas tropicais influenciadas diretamente pela ZCIT trazem informações muito relevantes na discussão sobre o impacto dos oceanos Atlântico e Pacífico na pluviosidade da Colômbia.

A comparação dos registros de $\delta^{18} \mathrm{O}$ das estalagmites de El Peñon com os dados de temperatura do Hemisfério Norte permite discutir provável influencia oceânica nas 
variações na posição da ZCIT com origem tanto no Atlântico como no Pacifico, o que ajudar a identificar os fatores que influenciam nas mudanças de pluviosidade na Colômbia, especificamente durante os eventos abruptas como o MCA e LIA. Esse tipo de análise foi realizado em estudos prévios na região Andina e adjacentes como em (Bird, 2011; Conroy et al, 2008; Stansell et al, 2012).

A curva de reconstituição de chuvas da Colômbia apresenta relações importantes com registros de paleoprecipitação da América Central, a exemplo dos dados de $\delta^{18} \mathrm{O}$ de espeleotemas da caverna Chaac Tecoh, localizada na Península de Yucatán, México (Medina Elizalde et al, 2010). Como é possível observar na Fig. 7, ao longo do último milênio tanto o regime de chuvas da Colômbia como da América Central descrevem variações semelhantes em torno da média, com oscilações climáticas abruptas de maior amplitude na escala decadal modulado por importante componente de escala secular. Em ambos os registros, uma importante excursão climática indicativa de condições mais úmidas é registrada ao final do LIA, próximo de 1800 e pode ter relação com erupção do vulcão Laki na Islândia de 1783 (Oman, 2006).

Entre os anos 1683 e 1837 AD os valores do registro de Pumacocha apontam para climas mais secos interrompidos por eventos abruptos de curta duração centrados em 1770AD e 1807 AD (Figura 6.7). Tais eventos pontuais são próximos de importantes eventos eruptivos, com o já cita vulcão Laki, da Islândia e a erupção do Tambora, em 1815.

Tomando o registro paleoclimático de Cariaco (Haug et al., 2003) como referencial do posicionamento latitudinal da ZCIT, seria possível afirmar que, mudanças nas condições de umidade no final da LIA, observadas tanto na Península de Yucatán como na Colômbia,não coincidem com os deslocamentos da ZCIT. Ao passo que o registro de Cariaco aponta para deslocamento para norte da ZCIT os registros Colombianos e da América Central apontam para climas mais secos, ao contrário do que se esperaria (Figura 6.7). Todavia, o bom acoplamento com a PDO, apresentado na Figura 6.5, sugere que variações de componente zonal da circulação atmosférica de altos níveis desempenham um papel importante no controle das chuvas na Colômbia e América central na escala secular.

Os últimos 150 do registro paleoclimático da Colômbia descreve as variações climáticas durante o CWP (da sigla em inglês para atual período quente) que, por sua vez, 
representa as variações climáticas que se sucedem com o final do LIA. Nos registros isotópicos da estalagmite CAR1, o CWP é caracterizado por um forte acoplamento com AMO e PDO, descrevendo duas excursões isotópicas pronunciadas em direção a climas mais secos entre 1905 - 1950 e outra entre 1990 até o presente (Figura 6.5). Comportamento semelhante é observado no registro da Laguna Pumacocha, no Peru (Bird et al., 2011). As variações climáticas observadas durante o CWP também encontram correspondência com o registro de eventos ENSO baseado na granulação de sedimentos do Lago El Junco, nas ilhas Galápagos (Conroy et al., 2009). Como é possível observar na Figura 6.7 as excursões relacionadas a climas mais secos nos períodos supracitados é concordante com estabelecimento de condições Niño no Pacífico leste. 


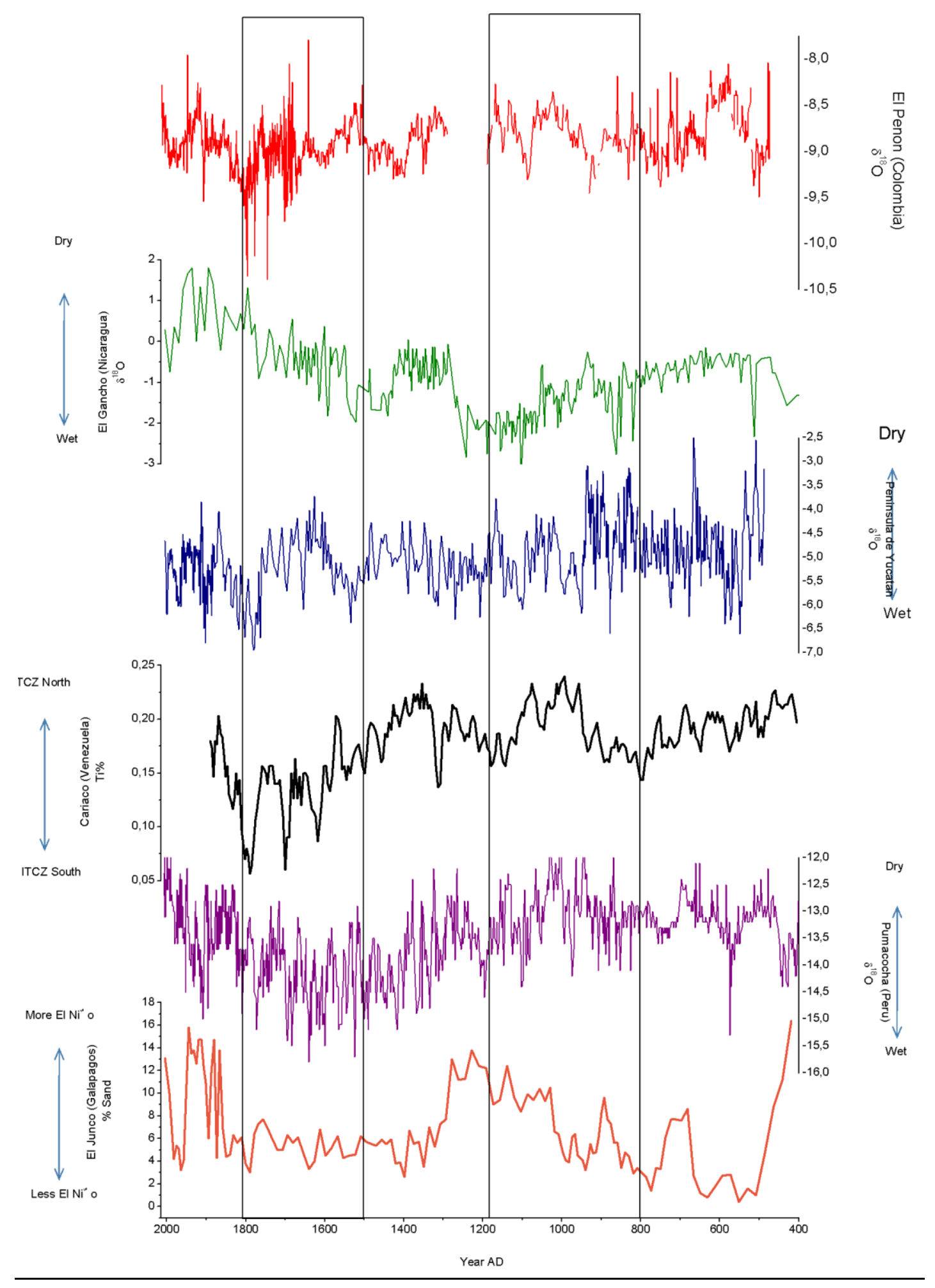

Figura 6.7 Comparações entre os registros de El Peñon (Colômbia), Península de Yucatan (Medina-Elizalde et al, 2010), El Gancho (Stansell et al, 2012), Cariaco (Haug et al, 2001), Pumacocha (Bird et al, 2011) e El Junco (Conroy et al, 2008), para os últimos 1500 anos apresentando as variações acontecidas principalmente durante a ACM e LIA. 


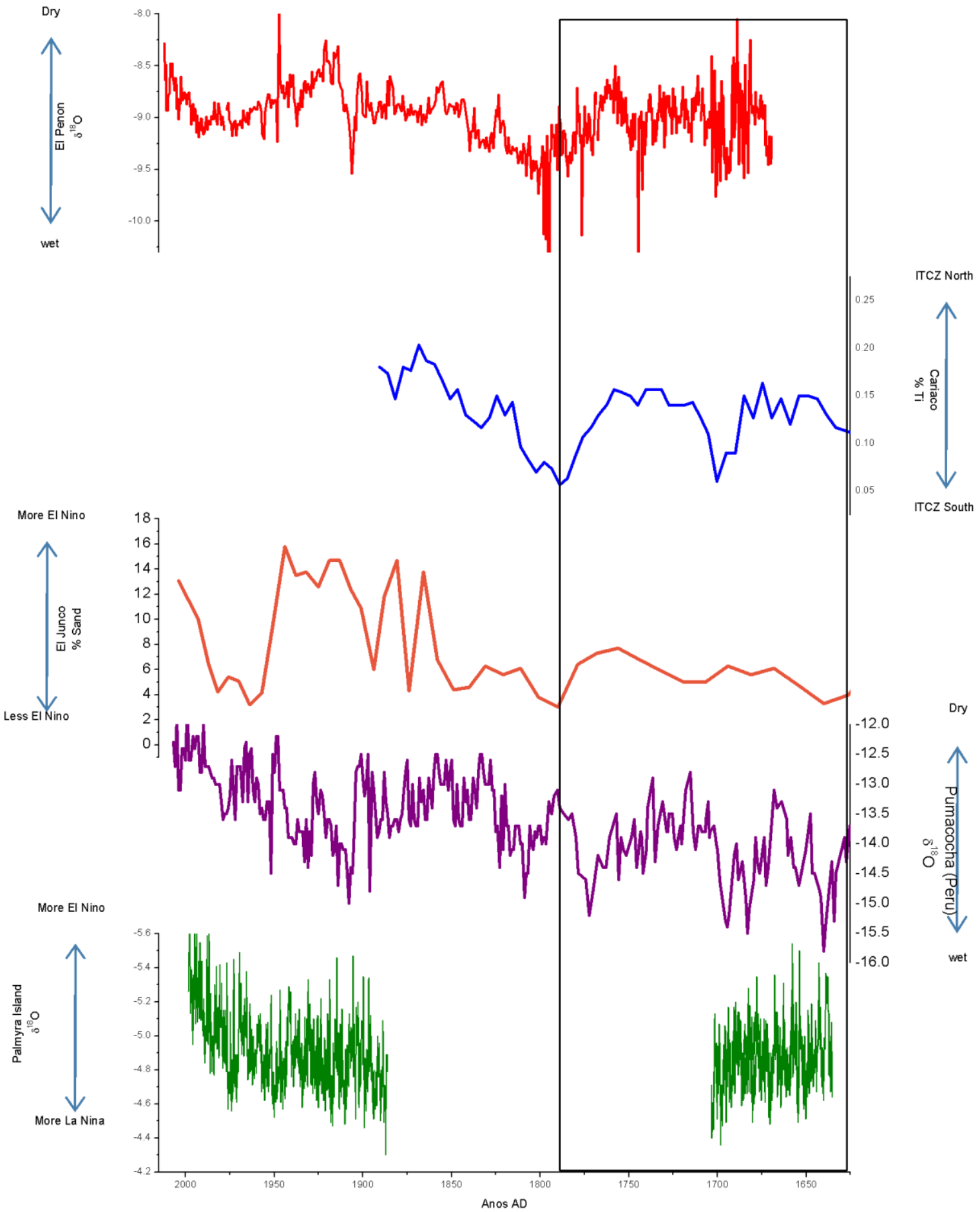

Figura 6.8. Comparación entre los registros de El Peñon (Colombia), Cariaco (Haug et al, 2001), El Junco (Conroy et al, 2008), Pumacocha (Bird et al, 2011) y las islas Palmyra (Cobb et al, 2003), para los últimos 390 años haciendo énfasis principalmente en la variaciones durante el CWP y los eventos ENSO registrados en el Pacifico. 
As variações na posição da ZCIT durante os últimos 1500 anos têm sido associadas com períodos de fortalecimento e enfraquecimento do fenômeno ENOS, assim interpretaram os registros do Centro e Leste do Pacífico, como o Junco (Conroy et al, 2008), Ilha Washington (Sachs et al, 2009) e Palmyra (Cobb et al, 2003); igualmente o registro localizado na área continental do Sul América tem marcado a intensidade deste fenômeno durante o último milênio (Bird et al, 2011).

A comparação feita para o período da ACM mostra no registro Colombiano eventos com tendências a baixa pluviosidade, marcada por dois picos mais semelhantes ao registro da seca semelhante na caverna Chaac Tecoh; no entanto registos de Cariaco em Venezuela mostram tendências para eventos de maior precipitação relacionado com um deslocamento para o norte da ZCIT (Figura 6.4). O registro de El Junco (Conroy et al, 2008) e a Ilha Washington (Sachs et al, 2009) mostram maiores pluviosidades nesta temporalidade devido à localização da ZCIT na área; as condições da alta pluviosidade nestes registros do Pacifico são interpretadas como um indicativo do aumento da frequência dos eventos tipo El Niño para o período da ACM (Figura 6.6).

A interpretação dos períodos de maior influência do El Niño poderia ser um dos determinantes de condições mais secas na área nessa temporalidade, no entanto as análises de ondoletas do registro de El Peñon com resolução anual amostra enfraquecimento dos ciclos com duração entre 4-7 anos os quais são relacionados com os períodos de repetição de El Niño, igualmente os ciclos associados ao PDO entre 20-30 anos também apresentam um enfraquecimento no mesmo tempo no registro Colombiano (Figura 6.6 ).

Durante o período das condições LIA se reflete no aumento da precipitação na região da Colômbia, o registro também mostra amplitudes mais elevadas nos eventos registrados e no aumento dos ciclos de corta duração entre (4 e 7 anos); os registros de Cariaco para este período mostra um deslocamento ao sul da ZCIT. Os registros do Pacífico como El Junco e a Ilha Washington, mostrar menos condições de chuva durante o ACM o que é assumido como um fortalecimento das condições de El Niño na área para este período (Figura 6.7) (Sachs et al, 2009).

As condições durante a LIA mudam para condições tipo La Niña como mostra o registro da Ilha Palmyra, também localizada no Pacifico, onde são registrados um 
fortalecimento dos ciclos de curta duração especialmente fortes durante os anos 1650-1700 AD registrados nas anomalias de chuvas y variações na TSM (figura 6.8). As variações da Ilha de Palmyra tem coincidem com o registro da Colômbia durante a LIA, devido a que os eventos tipo La Niña em nossa área de estudo mostra para o mesmo período aumento na amplitude do registro além de ter eventos de alta pluvisiodade que se apresentam em ciclos de corta duração, principalmente entre os anos 1637 y 180 AD (Figura 6.8). Durante os períodos de fortalecimento dos ciclos curto, que tem relação com eventos tipo La Niña, também se tem um fortalecimento dos ciclos que tem durações entre 18-30 anos, que estão associados com modulações da ODP (Figura 6.6).

A partir dos movimentos ZCIT observa-se influência no aumento/diminuição nos períodos de chuva na área dos Andes Orientais Colombianos, geralmente quando a ZCIT está localizada em uma posição mais ao norte se tem períodos com tendências á menos chuva na área de El Peñon, como observado entre 3500-2500 anos BP e ACM (Figuras 6.1, 6.2 e 6.7). Em eventos de migração para uma posição ao sul da ZCIT o registro de El Peñon mostra aumento da precipitação, ligando os registros obtidos com as variações que apresentam a áreas do Peru no mesmo período (Bird et al, 2011), como o acontecido durante a LIA (Figura 6.7 e 6.8). Estas variações na posição da ZCIT também podem estar influenciando a posição na "língua fria" entre o Pacífico localizado no Equador/Peru e Colômbia, que tem um papel importante na entrada de umidade da área do Pacífico colombiano como explicado em capítulos anteriores, e estar associado com a redução dos ciclos da ODP em El Peñon durante eventos secos, tipo ACM, e um aumento em tempos de maior pluviosidade como durante a LIA (Figura 6.6, 6.7 e 6.8). 


\section{CONSIDERAÇÕES FINAIS}

A reconstituição da paleopluviosidade dos últimos 5500 anos realizada nos Andes Orientais Colombianos, obtido por meio de análises isotópicas de oxigênio em estalagmites da caverna Caracos, representa uma importante contribuição na compreensão do comportamento do sistema climático Sul-americano frente às mudanças climáticas de escala global, devido a sua localização e interação entre os sistemas que vem do oceano Atlântico e Pacifico. A partir do registro isotópico de $\square \mathrm{O}^{18}$ foi possível estimar como os deslocamentos da ZCIT no Atlântico e Pacifico afeta a região leste da Colômbia durante eventos abruptos frios e quentes registrados nas zonas de altas latitudes do Hemisfério norte e que, em última análise, são relacionados a alterações da circulação oceânica. Através das oscilações periódicas encontradas no sinal foi possível relacionar os deslocamentos da ZCIT com as variabilidades oceânicas e atmosféricas ocorridas nos oceanos Pacífico e Atlântico extrapolando para o passado a relativa influência de cada. Da mesma forma que a comparação com índices que reconstroem o comportamento de parâmetros como a TSM no Atlântico e Pacifico aliada a aplicação de ferramentas matemáticas foi possível determinar a correspondente intensidade das chuvas em relação com a ZCIT na área da Colômbia de acordo com o cenário climático mais global.

O registro isotópico da caverna de Caracos na Colômbia revelou que durante os últimos 5500anos a ZCIT apresenta deslocamentos para o Norte/Sul, que influenza a quantidade de chuva na área além de relacionar-se com outros sistemas que tem importância na chuva na Colômbia. Os deslocamentos da ZCIT também se refletem em outros registros nas áreas próximas a Colômbia, como são os registros do Cariaco (Venezuela), Galápagos (Ecuador) e Pumacocha (Peru), mostrando uma influência regional destas mudanças. Para os últimos 5500 anos observam-se eventos no de esfriamento do Atlântico, associados aos eventos

Bond, que se refletem nas chuvas da Colômbia especialmente marcados por associar-se com eventos de menos chuva na área; o evento especifico localizado entre 3500 e 2500 anos BP é concordante com nosso registro e com os outros registros da Colômbia, que mostram uma mudança importante nas chuvas da área para este período; podendo associarse com períodos de deslocamento da ZCIT. 
Durante os últimos 1500 anos o registro mostra umas mudanças forte nos ciclos e amplitude do registro dos isótopos de chuva; os principais períodos de variações no registro de El Peñon acontecem na ACM (800- 1100 AD) e LIA (1500 - 1850 AD), onde se tem variações na quantidade de chuva, sendo a ACM mais seca que a LIA; além se observam mudanças nos ciclos de variações que afetam na área, principalmente nos ciclos de curta duração que estão ausentes no ACM e são fortalecidos na LIA.

Comparações entre a curva isotópica do registro de $\delta \mathrm{O}^{18} \mathrm{em}$ El Penon e mudanças nas taxas de variações que ocorrem no Atlântico e no Pacífico mostram uma forte relação entre os eventos; desta forma observa-se uma relação entre as fases positivas da ODP e AMO com menos chuvas em nossa área de estudo, como mostrado no registo da ACM. As anomalias negativas da ODP e da ACM mostram uma relação aos eventos de maior variabilidade amplitude e precipitação registrado em El Peñon, que influenciam o fortalecimento de ciclos curtos que operam na região, o que é observado no registro da LIA.

O refinamento da amostragem feita para o último 1500 anos permitiu uma resolução de até uma amostra por ano, com o tipo de análises estatísticas foram aplicadas análises de ondoletas para observar ciclicidade de eventos que influenciam El Peno, estas análises mostraram ciclos de desenvolvimento, principalmente entre 65-90 anos, 20-30 anos e tempos de ciclo curtos que estão entre 3-8 anos de idade. Análise estatística da série de $\delta 180$ do registro de El Peñon permitiu a identificação de modo de variabilidade multidecadal ( 65 anos) confirmando sinais identificadas com influência da OMA no registro da área; adicionalmente, modo de variabilidade de 25-30 anos no registro foi identificado principalmente a fases da Oscilação Decadal do Pacífico (ODP) como têm sido documentados para esta área de Sul América em vários trabalhos de climatologia moderna.

O fortalecimento e / ou enfraquecimento dos sinais AMO e ODP na área de estudo também está ligada segundo análise de ondoletas, como surgimento de ciclo de curta duração; de acordo com esta relação observa-se um reforço associado aos ciclos da ODP e ciclos que ocorrem cada 3-8 anos, igualmente observou-se que embora a influência dos ciclos de ODP em El Peñon é reforçada, uma relação inversa com a AMO, que diminui para os mesmos períodos, como mostrado nas temporalidades entre 1536-1724AD 576-779AD e presentes. Os ciclos curtos associados ENSO mostrar um reforço significativo no LIA, especialmente 
no período entre $1637-1800 \mathrm{AD}$, o que é observado no $\log$ em $\delta^{18} \mathrm{O}$ ampla e contínua variação dos valores isotópicos.

A relação dos deslocamentos da ZCIT no Pacifico e Atlântico com os ciclos de corta duração e sua influência na área de estudo, como observa-se nas variações entre os períodos da ACM e LIA, com fortalecimento dos eventos tipo El Niño e/ou La Niña em cada um destes períodos, o qual é apoiado pelas análises de ondoletas feitos com os registros de resolução anual de El Peñon para os últimos 1500 anos.

Por último a compreensão das variações climáticas nos últimos milênios na Sul-América, e especificamente na Colômbia, contribui ao desenvolvimento do trabalho multidisciplinar no campo da arqueologia e compreender o desenvolvimento dos grupos humanos na área em relação ao clima; isso é interessante para a área de estudo, pois as áreas vizinhas, como o Vale do Magdalena identificam-se no registro arqueológico colombiano como a rota natural para entrada e saída do interior ou zona andina para o oceano Atlântico. Estudos arqueológicos conduzidos por Lopez $(1989 ; 1990)$ e Correal (1993) sugere rota ao longo do vale do rio Magdalena tem sido utilizada a mais de 10 mil anos pelas populações andinas; de acordo com Rivet (1964) e Dolmatoff (1986) esta teria servido como uma das principais rotas para acesso e povoamento do continente sul-americano. As relações entre variações climáticas e mudanças populacionais dos grupos pré-hispânicos assentados sobre a zona de vale do rio Magdalena Médio, das quais se tem registros desde 11.000 B.P. (López, 1990).

A relação que se possa estabelecer entre a paleoclimatologia e as mudanças populacionais na área, pode ajudar a entender o processo de assentamento e desenvolvimento dos grupos humanos na região, toda vez que na área se apresentam cavernas com registro arqueológico que ainda não foi estudado. 


\section{BIBLIOGRAFIA}

BATTARBEE, R.W; BINNEY, H.A. 2008. Natural Climate Variability and Global Warming: A Holocene Perspective. Wiley- Blackwell.

BARD, E., RAISBECK, G., YIOU, F. \& JOUZEL, J. 2000. Solar Irradiance During the last 1200 years Based on Cosmogenic Nuclides. Tellus B 52, 985-992.

BARNES, C.J., ALLISON, G.B. 1983. The Distribution of Deuterium and Oxygen-18 in Dry Soils: 1. Theory, J. Hydrol. 60, pp. 141-156

BEDOYA RUEDA, C; NOMESQUI ORTIZ, H. E. 2013. Estratigrafía, Quimio estratigrafía y Petrografía de la Formación Rosablanca: Implicaciones para la Identificación de Eventos Anóxicos Oceánicos en la Cordillera Oriental Colombiana. Trabajo de Grado. Universidad de Caldas. Manizales.

BIRD, B. W; ABBOTTA, M. B; VUILlE, M.; RODBELlC, D. T; STANSELLA, N. D, ROSENMEIERA, M. F. 2011. A 2,300 year - long annually Resolved Record of the South American Summer Monsoon from the Peruvian Andes. PNAS, v 108

BLACK, D.E.; ABAHAZI, M. A; THUNELL, R. C; KAPLAN, A; TAPPA, E. J; PETERSON, L. C. 2007. An 8-century tropical Atlantic SST record from the Cariaco Basin: Baseline Variability, Twentieth-Century Warming, and Atlantic Hurricane Frequency. Paleoceanography, v. 22, PA4204, doi: 10.1029/2007PA001427.

BROCCOLI, A.; DAHL, K. A.; STOUFFER, R. J. Response of the ITCZ to Northern Hemisphere Cooling, Geophysical Reserarch Letters, v. 33, LO1702, doi:10.1029/2005GL024546, 2006. 
BROWN, J. 2004. The Response of Stable Water Isotopes in Precipitation and the Surface Ocean to Tropical Climate Variability. School of Earth Sciences, University of Melbourne.

BERRIO, J.C; BEHLING, H; HOOGHIEMSTRA, H. 2000. Tropical Rain-Forest History From The Colombian Pacific Area: A 4200-year Pollen Record from Laguna Jotaordó. The Holocene, v10, p 749 -756

BERRIO, J.C; HOOGHIEMSTRA, H; BEHLING, H; VAN DER BORG, K. 2002. LateQuaternary Savanna History of the Colombian Llanos Orientales from Lagunas Chenevo and Mozambique: a Transect Synthesis. The Holocene, v 12, p 35 - 48.

BOND, G.; SHOWERS, W.; CHESEBY, M.; LOTTI, R.; ALMASI, P.; DEMENOCAL, P.; PRIORE, P.; CULLEN, H.; HAJDAS, I.; BONANI, G. A. 1997. Pervasive MillennialScale Cycle in North Atlantic Holocene and Glacial Climates. Science, v 278, p 1257 1266.

BOND, G; KROMER, B; BEER, J; MUSCHELER, R; EVANS, M.N; SHOWERS, W; HOFFMANN, S;LOTTI-BOND, R; HAJDAS, I; BONANI, G. 2001. Persistent Solar Influence on North Atlantic Climate during the Holocene. Science, v 294, pp 2130-2136.

CHELliAH, M., BELL, G. D. 2004. Tropical Multi-decadal and Interannual Climate Variations in the NCEP/NCAR Reanalysis. Journal Climate, 17, pp.1777- 1803

CHENG, H; EDWARDS, R. L.; BROECKER, W. S; DENTON, G. H; KONG, X; WANG, Y; ZHANG, R; WANG, X. 2009. Ice Age Terminations. Science, v 326, p 248 - 252.

CLARK, I; FRITZ, P.1997. Environmental Isotopes in Hydrogeology. Nueva York, Lewis Publisher, p 328 
COBB, K. M; CHARLES, C. D; CHENG, H; EDWARDS, R. L. 2003. El Niño/Southern Oscillation and Tropical Pacific Climate During the last Millennium. Nature, v. 424, pp. 271- 276.

CONROY, J.L; OVERPECK, J. T; COLE, J. E; SHANAHAN, T. M; STEINITZKANNAN, M. 2008. Holocene Changes in Eastern Tropical Pacific Climate Inferred from a Galapagos Lake Sediment Record. Quaternary Science Reviews, v. 27, pp. 1166- 1180

CRAIG, H., Isotopic variations in meteoric waters, Science, 133, 1702-1703, 1961.

CRAIG, H., AND L. I. GORDON, Deuterium and oxygen-18 Variations in the Ocean and Marine Atmosphere, in Stable Isotopes in Oceanic Studies and Paleotemperatures, Laboratory of Geological and Nuclear Science, Pisa, Italy, 1965.

CRUZ, F.W; KARMANN, I; VIANA JR. O; BURNS, S. J; FERRARI, J. A; VUILLE, M; SIAL, A. N; MOREIRA, M.Z. 2005. Stable Isotope Study of Cave Percolation Waters in Subtropical Brazil: Implications for Paleoclimate Inferences from Speleothems. Chemical Geology, v 220, p 245-262.

CRUZ, F.W; BURNS, S. J; KARMANN, I; SHARP, W.D; VUILLE, M. 2006 a. Reconstruction of Regional Atmosphere Circulation Features during the Late Pleistocene in Subtropica Brazil from Oxygen Isotope Composition of Speleothems. Earth and Planetary Sciences Letters, v 248, p 494- 506.

CRUZ, F.W; BURNS, S.J; KARMANN, I; SHARP, W.D; VUILLE, M; FERRARI, J.A. 2006b. A Stalagmite Record of Changes in Atmospheric Circulation and Soil Processes in 
the Brazilian Subtropics during the Late Pleistocene. Quaternary Science Reviews, v 25, p 2749- 761.

CRUZ, F.W; BARNS, S; JERCINOVIC, M; KARMANN, I; SHARP, W.D; VUILLE, M. 2007. Evidence of Rainfall Variations in Southern Brazil from Trace Element Ratios $(\mathrm{Mg} / \mathrm{Ca}$ and $\mathrm{Sr} / \mathrm{Ca})$ in a Late Pleistocene Stalagmite. Geochimica et Cosmochimica Acta, v71, p 2250- 2263.

CRUZ, F.W; VUILLE, M; BURNS, S.J; WANG, X; CHENG, H; WERNER, M; EDWARDS, R.L; KARMANN, I; AULER, A.S; NGUYEN, H. 2009. Orbitally Driven East-West Antiphasing of South American Precipitation. Nature Geosciences, v 2, p 1-5.

CRUZ, F.W.; WANG, X.; AULER. A.; VUILLE. M.; BURNS; S.J.; EDWARDS, L.R.; KARMANN, I.; CHENG, H. 2009a. Orbital and Millennial-scale Precipitation Changes in Brazil from Speleothem Records. In Francoise, V. et al. (Eds.). Past Climate Variability in South America and Surrounding Regions. Paris: Springer, 29 - 60

CURTIS, S., HASTENRATH, S., 1995. Forcing of Anomalous Sea Surface Temperature Evolution in the Tropical Atlantic during Pacific Warm Events. J. Geophys. Res. 100 (C8), $15,835-15,847$.

DANSGAARD, W., Stable isotopes in precipitation, Tellus, 16, 436-468, 1964

DIAZ, H. F; AND MARKGRAF, V (Editores). 2000. El Niño and the Southern Oscillation-Multiscale Variability and Global and Regional Impacts, Cambridge Univ. Press, New York.

DORALE, J.A., EDWARDS, R.L., ITO, E., GONZALEZ, L.A., 1998. Climate and Vegetation History of the Midcontinent from 75 to $25 \mathrm{ka}$ : A Speleothem Record from Crevice Cave, Missouri, USA. Science 282, 1871-1874 
DRYSDALE, R. N; ZANCHETTAB, G; HELLSTROMC, J. C; FALLICKD, A. E; ZHAOE, J; ISOLAF, I;BRUSCHIG, G. 2004. Palaeoclimatic Implications of the Growth History and Stable Isotope ( $z^{180}$ and $\left.z^{13 C}\right)$ Geochemistry of a Middle to Late Pleistocene Stalagmite from Central-Western Italy. Earth and Planetary Science Letters, v 227, p 215 229.

DYKOSKI, C; EDWARDS, R; CHENG, H; YUAN, D; CAI, Y; ZHANG, M; LIN, Y. 2005. A high-Resolution, Absolute-Dated Holocene and Deglacial Asian Monsoon Record from Dongge Cave, China. Earth and Planetary Science Letters, v 233, p 71-86.

EDWARDS, R.L.; CHEN, J.H.; WASSERBURH, G.J. 1986. 238U - 234U - 230Th 232Th Systemtics and the Precise Measurement of Time over the Past 500.000 years. Earth Planetary Science Letters, v. 81, p. 175-192.

FAIRCHILD, I.J; SMITH, C.L; BAKER, A; FULLER, L; SPÖTL, C; MATTEY, D; MCDERMOTT, F. 2006. Modification and Preservation of Environmental Signals in Speleothems. Earth- Science Reviews, v 75, p 105-153.

FORD, D; Y WILLIAMS, P. 2007. Karst Hydrogeology and Geomorphology. Inglaterra, Willey, p 562.

GÓMEZ, L. A; LANCHEROS, J. A; LÓPEZ, C; PATIÑO, A; BELTRÁN, A; RENZONI, G; GUERRA, A; QUINTERO, A. 2008. Cartografía Geológica y Muestreo Geoquímico: Escala 1:100.000 De La Plancha 150 - Cimitarra. INGEOMINAS. Bogota.

GAT, J.R., 1996. Oxygen and Hydrogen Isotopes in the Hydrologic Cycle. Annual Rev. Earth Planet. Sc. 24: 225-262 
GARREAUD, R. 2009. The Andes Climate and Weather. Advances in Geosciences, v.7

GOOSSE, H; RENSSEN, H; TIMMERMANN, A; BRADLEY, R. 2005. Internal and Forced Climate Variability during the Last Millennium: A Model-Data Comparison Using Ensemble Simulations. Quaternary Science Reviews, v 24, p 1345-1360.

GRAY, T.S; GRAUMLICH, L.J; BETANCOURT, J.L; PEDERSON, T. 2004. A tree-ring based reconstruction of the Atlantic MultidecadalOscillation since 1567 A.D. Geophysical Research Letters, v. 31, doi: 10.1029/2004GL019932.

GROSSMANN, I., KLOTZBACH, P., 2009. A Review of North Atlantic Modes of Natural Variability and Their Driving Mechanisms. Journal of Geophysical Research-Atmospheres. No. 114

GHIL, M.; ALLEN, M.R.; DETTINGER, M.D.; KONDRASHOV, D.; MANN, M.E.; ROBERTSON, A.W.; SAUNDERS, A.; TIAN, Y.; VARADI, F.; YIOU, P. 2002. Advanced Spectral Methods for Climatic Time Series. American Geophysical Union, v. 40, p. 1-41, doi: 10.1029/2001RG000092.

HAUG, G.H; HUGHEN, K.A; SIGMAN, D.M; PETERSON, L.C; RÖHL, U. 2001. Southward Migration of the Intertropical Convergence Zone throughthe Holocene. Science, v293, p $1304-1308$.

HAMMER, Ø.; HARPER, D. A. T.; RYAN, P. D. 2001. Past: Paleontological Statistics software package for education and data analysis, Paleontological Eletronics, v. 4, p. 1-9.

HURRELL, J.W., KUSHNIR, Y., OTTERSEN, G., VIS- BECK, M. 2003. An Overview of the North Atlantic Oscillation. In Hurrell, J.W. The North Atlantic Oscillation: Climatic 
Significance and Environmental Impact: American Geophysical Union Geophysical Monograph, v 134, pp. 1-35.

LINGE, H. 2001. Stable Isotope Stratigraphy of Holocene Speleothems: Examples from a Cave System, Northern Norway. Palaeogeography, Palaeoclimatology, Palaeoecology, v 167, p 209-224.

LACHNIET, M. 2009. Climatic and Environmental Controls on Speleothem Oxygen Isotope Values. Quaternary Science Reviews, v 28, pp. 412- 432.

LONGINELLI, A. AND EDMOND, J.M. 1983. Isotope geochemistry of the Amazon Basin: A Reconnaissance. Journal of Geophysical Research, 88: doi: 10.1029/JC088iC06p03703

MANN, M.E., ZHANG, Z., RUTHERFORD, S., BRADLEY, R.S., HUGHES, M.K., SHINDELL, D., AMMANN, C., FALUVEGI, G., AND NI, F., 2009, Global signatures and dynamical origins of the Little Ice Age and Medieval Climate Anomaly: Science, v. 326, p. 1256-1260, doi:10.1126/science.1177303.

MANTUA, N. J, HARE, S. R., ZHANG, Y., WALLACE, J. M, FRANCIS, R.C. 1997. A Pacific Interdecadal Climate Oscillation with Impacts on Salmon Production. Bulletin of the American Meteorological Society, v. 78, No. 6, pp 1069-1079.

MARTINEZ, J.I., KEIGWIN, L., BARROWS, T.T., YOKOYAMA, Y., SOUTHONS, J. 2003. La Niña-like Conditions in the Eastern Equatorial Pacific and a Stronger Choco jet in the Northern Andes during the Last Glaciation. Paleoceanography, Vol. 18, No. 2, pp. 1033 
MCDERMOTT, F. 2004. Palaeo-Climate Reconstruction from Stable Isotope Variations in Speleothems: A Review. Quaternary Science Reviews, v 23, p 901-918.

MEDINA-ELIZALDE, M.; BURNS, S.J.; LEA, D.W.; ASMEROM, Y; VON GUNTEN, L.; POLYAK, V.; VUILlE, M.; KARMALKAR, A. 2010. High Resolution Stalagmite Climate Record from the Yucatán Peninsula Spanning the Maya Terminal Classic Period. Earth Planet. Sci. Lett. doi:10.1016/j.eps1.2010.08.016

MEEHL, G.A; TEBALDI, C; WALTON, G.; EASTERLING, D.; MCDANIEL, L. 2009. Relative Increase of Record High Maximum Temperatures Compared to Record Low Minimum Temperatures in the U.S.Geophysical Research Letters, v. 36, doi: 10.1029/2009GL040736.

MENDOZA-PARADA, J.E; MORENO-MURILLO, J.M; RODRÍGUEZ-ORJUELA, G. 2009. Sistema Cárstico de la Formación Rosa Blanca Cretácico Inferior, en la Provincia Santandereana de Vélez, Colombia. Geología Colombiana, v 34, p 35-44.

MERLIVAT, L., AND J. JOUZEL. 1979. Global Climatic Interpretation of the Deuterium Oxygen18 Relationship for Precipitation. Journal of Geophysical Research, 80, pp 54555467.

NEWMAN, M., COMPO, G. P., AND ALEXANDER, M. 2003. ENSO-Forced Variability of the Pacific Decadal Oscillation. Journal of Climate, v. 16, No 23, pp. 3853 - 3857.

PESSENDA, L.C.R; ARAVENA, R.M; MELFI, A.J. 1996. The Use of Carbon Isotopes (C13-C14) in Soil to Evaluate Vegetation Changes during the Holocene in Central Brasil. Radiocarbon, v. 38, pp. 191-201. 
POVEDA, G., MESA, O.J., 1996. The North Atlantic Oscillation and its Influence on the Hydro-Climatology of Colombia (in Spanish). Proc. XVII Latin-American Congress on Hydraulics and Hydrology, Guayaquil, Ecuador, IAHR, vol. 2, pp. 343- 354.

POVEDA, G; GIL, M.M; QUICENO, N. 1998. El Ciclo Anual de la Hidrología de Colombia en Relación con el ENSO y la NAO. Boletin del Instituto Francés de Estudios Andinos, v 27, p 721-731.

POVEDA, G., MESA, O.J. 2000. On the Existence of Lloró (The Rainiest Locality on Earth): Enhanced Ocean-Land- Atmosphere Interactions by a Low Level Jet. Geophysical Research Letters, v 27, No 11. Pág. 1675- 1678.

POVEDA, G; MESA, O.J; CARVAJAL, L.F; HOYOS, C.D; MEJIA, J.F; CUARTAS, A; PULGARÍN, A. 2002. Predicción de Caudales Medios Mensuales en Ríos Colombianos Usando Métodos no Lineales. Meteorología Colombiana, v 6, p 101- 110.

POVEDA, G, WAYLEN, P.R, PULWARTY, R.S. 2006. Annual and Inter-annual Variability of the Present Climate in Northern South America and Southern Mesoamerica. Palaeogeography, Palaeoclimatology, Palaeoecology, v 234, p 3 - 27.

POVEDA, G., JARAMILLO, L., VALLEJO, L. 2014. Seasonal Precipitation Patterns along Pathways of South American Low-Level Jets and Aerial Rivers. Water Resources Research, v. 50, pp. 1-21, doi: 10.1002/2013wr014087

PULWARTY, R., DIAZ, H., 1993. A Study of the Seasonal Cycle and its Perturbation by ENSO Events over the Tropical Americas. Fourth International Conference on Southern Hemisphere Meteorology and Oceanography, March 29-April 2. Hobart, Australia. 
RENSSEN, H.; SEPPÄ, H.; HEIRI, O.; ROCHE, D. M.; GOOSSE, H.; FICHEFET, T. 2009. The Spatial and Temporal Complexity of the Holocene Thermal Maximum, Nature Geoscience, v. 2, p. $411-414$.

RICHARD, D.A.; DORALE, J.A. 2003. Uranium-Series Chronology and Environmental Applications of Speleothem. In: Bourdon, B. et al. (Eds.), Uranium-Series Geochemistry. Reviews in Mineralogy and Geochemistry, V. 52, P. 407-460

ROYERO GUTIÉRREZ, J.M; CLAVIJO, J. 2001. Mapa Geológico Generalizado de Santander. Escala 1:400000. Bogotá. INGEOMINAS.

ROGERS, J.C., 1988. Precipitation variability over the Caribbean and tropical Americas associated with the Southern Oscillation. J. Climate 1, 172- 182.

ROZANSKI, K., L. ARAGU'AS-ARAGU'AS, AND R. GONFIANTINI, Isotopic patterns in model global precipitation, in Climate Change in Continental Isotopic Records, edited by P. K. Swart, K. C. Lohman, J. McKenzie, and S. Savin, Geophysical Monograph No. 78, pp. 1-36, Washington, 1993.

RUDDIMAN, R. 2008. Earth's Climate: Past and Future. Segunda Edición. Nueva York, W. H Freeman and Company, p 465.

SACHS, J. P; SACHSE, D.; SMITTENBERG, R. H; ZHANG, Z.; BATTISTI, D. S; GOLUBIC, S. 2009. Southward Movement of the Pacific Intertropical Convergence Zone AD 1400-1850. Nature Geoscience, v.2, pp. 519- 525.

SPÖTL, C., \& VENNEMANN, T. W. 2003. Continuous-Flow Isotope Ratio Mass Spectrometric Analysis of Carbonate Minerals. Rapid communications in mass spectrometry\#: RCM, v 17, p 1004-6. 
SCHOLZ, D; HOFFMANN, D. 2008. Th/U- Dating of Fossil Corals and Speleothems. Quaternary Science Journal, v 57, p $52-76$.

STRIKIS, N. 2011. Paleopluviosidade no Norte de Minas Gerais Durante o Glacial Tardio e Holoceno com Base em Registros de Espeleotemas. Disertación de Maestría. Universidade de São Paulo.

SAYLOR J. E; MORA, A; HORTON, B.K; NIE, J. 2009. Controls on the Isotopic Composition of Surface Water and Precipitation in the Northern Andes, Colombian Eastern Cordillera. Geochimica et Cosmochimica Acta, v 73, p 6999-7018.

SNOW, J.W. 1976. The climate of Northern South America. Schwerdtfeger, W. (Ed.), Climates of Central and South America. Elsevier, Amsterdam, p 295-403.

TAN, M; BAKER, A; GENTY, D; SMITH, C; ESPER, J; CAI, B. 2006. Applications of Stalagmite Laminae to Paleoclimate Reconstructions: Comparison withDendrochronology/Climatology. Quaternary Science Reviews, v 25, p 2103-2117.

TIMMERMANN, A.; OKUMURA, Y.; AN, S.-I.; CLEMENT, A.; DONG, B.; GUILYARDI, E.; HU, A.; JUNGCLAUS, J.H.; RENOLD, M.; STOCKER, T.F.; STOUFFER, R.J.R. SUTTON, R.; XIE, S.-P.; YIN, J. The Influence of a Weakening of the Atlantic Meridional Overturning Circulation on ENSO. Journal of Climate, v. 20, pp. 48994919, 2007.

TRENBERTH, K. E. ET AL. Observations: Surface and Atmospheric Climate Change. In: Solomon, S. D. et al. (Ed.) Climate Change 2007: The Physical Science Basis. Contribution of Working Group I to the Fourth Assessment Report of the Intergovernmental Panel on 
Climate Change. Cambridge, United Kingdom, New York: Cambridge University Press, 2007.

SWINGEDOUW， D.; FICHEFET, T.; HUYBRECHTS， P.; GOOSSE， H.; DRIESSCHAERT, E.; LOUTRE, M. F. 2008. Antarctic Ice-Sheet Melting Provides Negative Feedbacks on Future Climate Warming. Geophysical Research Letters, v. 35, L17705, Doi: 10.1029/2008g1034410.

VELÁZQUEZ C.A; HOOGHIEMSTRA, H. 2013. Pollen-Based 17-kyr Forest Dynamics and Climate Change from the Western Cordillera of Colombia; No-Analogue Associations and Temporarily Lost Biomes. Review of Palaeobotany and Palynology, v 194, p 38 - 49.

VÉLEZ, M; WILLE, M; HOOGHIEMSTRA, H; METCALFE, S; VANDERBERGHE, J; VAN DER BORG, K. 2001. Late Holocene Environmental History of Southern Choco Region, Pacific Colombia; Sediment, Diatom and Pollen Analysis of Core El Caimito. Palaeogeography, Palaeoclimatology, Palaeoecology, v 173, p 197-214.

VELEZ, M.I; HOOGHIEMSTRA, H; METCALFE, S; MARTINEZ, I; MOMMERSTEEG, H. 2003 Pollen and Diatom Based Environmental History since the Last Glacial Maximum from the Andean Core Fúquene-7, Colombia. Journal of Quaternary Science, v 18, p $17-30$.

VÉLEZ, M.I; WILLE, M; HOOGHIEMSTRA, H; METCALFE, S. 2005. Integrated Diatom-Pollen Based Reconstruction of Environmental Change from Laguna Las Margaritas in The Western Colombian Savanna Area. The Holocene, v 15, p 1184-1198.

VELEZ, M.I; HOOGHIEMSTRA, H; METCALFE, S; WILLE, M; BERRIO, J.C. 2006. Late Glacial and Holocene Environmental and Climatic Changes from a Limnological 
Transect Through Colombia, Northern South America. Palaeogeography, Palaeoclimatology, Palaeoecology, v 234, p 81- 96.

VUILLE, M.; BRADLEY, R. S.; WERNER, M.; HEALY, R.; KEIMIG, F. 2003. Modeling $\delta 180$ in Precipitation over the Tropical Americas: Interannual Variability and Climatic Controls. Journal of Geophysical Research, v.108, p. 4174.

WALTER, K., GRAF, H., 2002. On the Stability of Regional Connection between North Atlantic Oscillation and Sea Surface Temperature. J. Geophys. Res. 107

WANG, X; AULER, A.S; EDWARDS, R. L; HAI, C; ITO, E; MANIKO, S. 2006. Interhemispheric Antiphasing of Rainfall during the Last Glacial Period. Quaternary Science Reviews, v 25, p 3391- 3403.

WANG, X; AULER, A.S; EDWARDS, R.L; CHENG, H; ITO, E; WANG, Y.J; KONG, X.G; SOLHEID, M. 2007a. Millennial-Scale Precipitation Changes in Southern Brazil Over the Past 90,000 years. Geophysics Research Letters, v 241, p 699-706.

WANG, X; EDWARDS, R. L; AULER, A. S; CHENG, H; ITO, E. 2007b. MillennialScale Interhemispheric Asymmetry of Low-Latitude Precipitation: Speleothem Evidence and Possible High Latitude Forcing. Geophysical Research Letters, v 34.

WANG, Y; CHENG, H; EDWARDS, R.L; KONG, X; SHAO, X; CHEN, S; WU, J; JIANG, X; WANG, X; AN, Z. 2008. Millennial and Orbital-Scale Changes in the East Asian Monsoon over the Past 224,000 Years. Nature, v 452, p 1090-1093. 
ZAMARREÑO, D. J., 1963. Estudio Petrográfico de las Calizas de la Formación Rosablanca de la Región de la Mesa de los Santos. Boletín de Geología, Universidad Industrial de Santander. pp. 5-34

ZHANG, R; DELWORTH, T.L. 2005. Simulated Tropical Response to a Substantial Weakening of the Atlantic Thermohaline Circulation. Journal of Climate, v 18, p 18531860. 
ANEXO I

(Datações Th230) 
${ }^{230} \mathrm{Th}$ dating results. The error is $2 \sigma$ error.

\begin{tabular}{|c|c|c|c|c|c|c|c|c|c|c|c|c|c|c|c|c|c|c|}
\hline Sample & \multicolumn{2}{|c|}{${ }^{238} \mathrm{U}$} & \multicolumn{2}{|c|}{${ }^{232} \mathrm{Th}$} & \multicolumn{2}{|c|}{${ }^{230} \mathrm{Th} /{ }^{232} \mathrm{Th}$} & \multicolumn{2}{|c|}{$\delta^{234} U^{\star}$} & \multicolumn{2}{|c|}{${ }^{230} \mathrm{Th} /{ }^{238} \mathrm{U}$} & \multicolumn{2}{|c|}{${ }^{230} \mathrm{Th}$ Age (yr) } & \multicolumn{2}{|c|}{${ }^{230} \mathrm{Th}$ Age (yr) } & \multicolumn{2}{|c|}{$\delta^{234} U_{\text {Initial }^{\star \star}}$} & \multicolumn{2}{|c|}{$\begin{array}{c}{ }^{230} \mathrm{Th} \text { Age (yr } \\
\mathrm{BP})^{* * *}\end{array}$} \\
\hline Number & $(p p$ & & & & (atomic & $\left.\times 10^{-6}\right)$ & (meas & red) & (acti & ivity) & (uncor & ted) & (corre & ed) & (corre & & (corre & d) \\
\hline CAR1-7 & 3515,8 & $\pm 25,7$ & 194 & \pm 5 & 64 & \pm 4 & 243,0 & $\pm 4,1$ & 0,0002 & $\pm 0,0000$ & 19 & \pm 1 & 18 & \pm 1 & 243 & \pm 4 & -40 & \pm 1 \\
\hline CAR1-44 & 4089 & \pm 5 & 2436 & \pm 49 & 68,3 & $\pm 2,2$ & 191,1 & $\pm 2,0$ & 0,0025 & $\pm 0,0001$ & 226 & \pm 6 & 212 & \pm 12 & 191 & \pm 2 & 150 & \pm 12 \\
\hline CAR1-88 & 4164,2 & $\pm 28,3$ & 39 & \pm 1 & 6016 & \pm 225 & 215,0 & $\pm 3,7$ & 0,0034 & $\pm 0,0000$ & 309 & \pm 3 & 309 & \pm 3 & 215 & \pm 4 & 251 & \pm 3 \\
\hline CAR1-123 & 2737 & \pm 16 & 442 & \pm 10 & 1162 & \pm 26 & 249,6 & $\pm 3,5$ & 0,0114 & $\pm 0,0001$ & 998 & \pm 9 & 994 & \pm 9 & 250 & \pm 4 & 936 & \pm 9 \\
\hline CAR1-138 & 4409,8 & $\pm 4,6$ & 337 & \pm 9 & 2694 & \pm 77 & 233,3 & $\pm 1,6$ & 0,0125 & $\pm 0,0001$ & 1111 & \pm 10 & 1109 & \pm 10 & 234 & \pm 2 & 1047 & \pm 10 \\
\hline CAR1-150 & 4684,2 & $\pm 5,4$ & 162 & \pm 8 & 6502 & \pm 329 & 258,1 & $\pm 1,8$ & 0,0136 & $\pm 0,0001$ & 1187 & \pm 10 & 1186 & \pm 10 & 259 & \pm 2 & 1124 & \pm 10 \\
\hline CAR1-180 & 4241,5 & $\pm 4,6$ & 224 & \pm 9 & 4677 & \pm 185 & 250,8 & $\pm 1,7$ & 0,0150 & $\pm 0,0001$ & 1313 & \pm 12 & 1312 & \pm 12 & 252 & \pm 2 & 1250 & \pm 12 \\
\hline CAR1-196 & 5158 & \pm 6 & 187 & \pm 8 & 6867,9 & $\pm 308,3$ & 222,3 & $\pm 1,6$ & 0,0151 & $\pm 0,0001$ & 1356 & \pm 10 & 1355 & \pm 10 & 223 & \pm 2 & 1293 & \pm 10 \\
\hline CAR1-227 & 4717 & \pm 5 & 217 & \pm 9 & 5781,5 & $\pm 238,3$ & 189,0 & $\pm 1,7$ & 0,0161 & $\pm 0,0001$ & 1490 & \pm 12 & 1489 & \pm 12 & 190 & \pm 2 & 1427 & \pm 12 \\
\hline CAR1-244 & 3761,3 & $\pm 30,7$ & 227 & \pm 5 & 4583 & \pm 111 & 185,6 & $\pm 4,3$ & 0,0168 & $\pm 0,0002$ & 1551 & \pm 18 & 1550 & \pm 18 & 186 & \pm 4 & 1492 & \pm 18 \\
\hline
\end{tabular}




\begin{tabular}{|c|c|c|c|c|c|c|c|c|c|c|c|c|c|c|c|c|c|c|}
\hline \multirow{3}{*}{$\begin{array}{l}\text { Sample } \\
\text { Number } \\
\text { CAR2-8 }\end{array}$} & \multicolumn{2}{|c|}{${ }^{238} \mathrm{U}$} & \multicolumn{2}{|c|}{${ }^{232} \mathrm{Th}$} & \multicolumn{2}{|c|}{${ }^{230} \mathrm{Th} /{ }^{232} \mathrm{Th}$} & \multicolumn{2}{|c|}{$\delta^{234} U^{\star}$} & \multirow{2}{*}{\multicolumn{2}{|c|}{${ }^{230} \mathrm{Th} /{ }^{238} \mathrm{U}$}} & \multirow{2}{*}{\multicolumn{2}{|c|}{${ }^{230}$ Th Age (yr) }} & \multirow{2}{*}{\multicolumn{2}{|c|}{$\begin{array}{c}{ }^{230} \text { Th Age } \\
\text { (yr) }\end{array}$}} & \multicolumn{2}{|c|}{$\delta^{234} U_{\text {Initial }}{ }^{* *}$} & \multicolumn{2}{|c|}{$\begin{array}{c}{ }^{230} \text { Th Age (yr } \\
\text { BP)*** }\end{array}$} \\
\hline & (pp & & (pp & & (atomi & c x10- & (meası & red) & & & & & & & (correc & ed) & (corre & ed ) \\
\hline & 3179,3 & $\pm 22,1$ & 565 & \pm 12 & 314 & \pm 8 & 200,6 & $\pm 4,1$ & 0,0034 & $\pm 0,0000$ & 308 & \pm 4 & 304 & \pm 5 & 201 & \pm 4 & 246 & \pm 5 \\
\hline $\begin{array}{l}\text { CAR2- } \\
20\end{array}$ & 3215,8 & $\pm 4,4$ & 91 & \pm 2 & 2264 & \pm 68 & 201,7 & $\pm 1,8$ & 0,0039 & $\pm 0,0001$ & 351 & \pm 5 & 351 & \pm 5 & 202 & \pm 2 & 289 & \pm 5 \\
\hline $\begin{array}{l}\text { CAR2- } \\
27\end{array}$ & 3270 & \pm 4 & 70 & \pm 2 & 3241,8 & $\pm 105,1$ & 208,9 & $\pm 1,8$ & 0,0042 & $\pm 0,0001$ & 378 & \pm 5 & 378 & \pm 5 & 209 & \pm 2 & 316 & \pm 5 \\
\hline $\begin{array}{l}\text { CAR2- } \\
49\end{array}$ & 3013,2 & $\pm 4,3$ & 195 & \pm 4 & 1411 & \pm 35 & 208,3 & $\pm 2,0$ & 0,0055 & $\pm 0,0001$ & 501 & \pm 6 & 500 & \pm 6 & 209 & \pm 2 & 438 & \pm 6 \\
\hline $\begin{array}{l}\text { CAR2- } \\
71\end{array}$ & 2041,6 & $\pm 3,5$ & 237 & \pm 8 & 969,0 & $\pm 42,9$ & 214,5 & $\pm 2,1$ & 0,0068328 & $\pm 0,00020$ & 615 & \pm 18 & 612 & \pm 18 & 214,9 & $\pm 2,1$ & 550 & \pm 18 \\
\hline $\begin{array}{l}\text { CAR2- } \\
71\end{array}$ & 2638,5 & $\pm 3,3$ & 174 & \pm 4 & 1689 & \pm 48 & 216,3 & $\pm 1,8$ & 0,0067 & $\pm 0,0001$ & 606 & \pm 9 & 605 & \pm 9 & 217 & \pm 2 & 543 & \pm 9 \\
\hline $\begin{array}{l}\text { CAR2- } \\
82\end{array}$ & 2885,4 & $\pm 5,2$ & 55 & \pm 2 & 6365 & \pm 261 & 211,3 & $\pm 2,3$ & 0,0074 & $\pm 0,0001$ & 665 & \pm 13 & 664 & \pm 13 & 212 & \pm 2 & 602 & \pm 13 \\
\hline $\begin{array}{l}\text { CAR2- } \\
92\end{array}$ & 2710,7 & \pm 14 & 304 & \pm 7 & 1190 & \pm 27 & 213,6 & $\pm 3,1$ & 0,0081 & $\pm 0,0001$ & 728 & \pm 6 & 726 & \pm 6 & 214 & \pm 3 & 668 & \pm 6 \\
\hline
\end{tabular}

\begin{tabular}{|c|c|c|c|c|c|c|c|c|c|c|c|c|c|c|c|c|c|c|}
\hline CAR3-2 & 308,9 & \pm 1 & 1721 & \pm 35 & 43 & \pm 1 & 104,3 & $\pm 2,4$ & 0,0144 & $\pm 0,0002$ & 1432 & \pm 22 & 1.285 & \pm 106 & 105 & \pm 2 & 1227 & \pm 106 \\
\hline $\begin{array}{l}\text { CAR3- } \\
63\end{array}$ & 521 & \pm 0 & 2526 & \pm 51 & 132,6 & $\pm 3,2$ & 114,5 & $\pm 1,6$ & 0,0390 & $\pm 0,0005$ & 3880 & \pm 51 & & & 116 & \pm 2 & 3692 & \pm 103 \\
\hline $\begin{array}{l}\text { CAR3- } \\
84\end{array}$ & 1061,7 & \pm 4 & 292 & \pm 6 & 2209 & \pm 50 & 106,5 & $\pm 2,7$ & 0,0368 & $\pm 0,0002$ & 3686 & \pm 22 & 3.679 & \pm 23 & 108 & \pm 3 & 3621 & \pm 23 \\
\hline $\begin{array}{l}\text { CAR3- } \\
95\end{array}$ & 1035 & \pm 1 & 119 & \pm 4 & 5357,5 & $\pm 204,3$ & 103,1 & $\pm 1,9$ & 0,0375 & $\pm 0,0003$ & 3767 & \pm 31 & 3764 & \pm 31 & 104 & \pm 2 & 3702 & \pm 31 \\
\hline $\begin{array}{l}\text { CAR3- } \\
183\end{array}$ & 331,7 & \pm 1 & 194 & \pm 4 & 1715 & \pm 40 & 279,1 & $\pm 3,0$ & 0,0610 & $\pm 0,0004$ & 5316 & \pm 35 & 5.302 & \pm 36 & 283 & \pm 3 & 5244 & \pm 36 \\
\hline
\end{tabular}


